\title{
Live imaging of cleavage variability and vesicle flow dynamics in dextral and sinistral spiralian embryos
}

\author{
Erica K. O. Namigai ${ }^{1}$ and Sebastian M. Shimeld ${ }^{2}$ \\ Department of Zoology \\ University of Oxford \\ South Parks Road \\ Oxford \\ OX1 3PS \\ ${ }^{1}$ current address: EPFL Innovation Park, Lausanne, Switzerland \\ ${ }^{2}$ correspondence to: sebastian.shimeld@zoo.ox.ac.uk
}

\begin{abstract}
Spiral cleavage is a mode of embryonic cell division found in species from several Phyla including molluscs, annelids and flatworms. It reflects a tilting in the direction of spindle orientation and cell division at the 4 to 8-cell stage, which may be dextral or sinistral, and propagates into later organismal asymmetry. Genetic analysis in a small number of gastropod molluscs shows the direction of spiral cleavage is determined by maternal genotype, though whether this is also the case more generally for spiralians, and whether spiral cleavage at the 4-8 cell stage is preceded by earlier internal chirality in any spiarian species, is unknown. Here we study the early cleavage stages of two equal-cleaving spiralians, the dextral annelid Spirobranchus lamarcki and the sinistral mollusc Biomphalaria glabarata, using light sheet microscopy to image subcellular vesicles in live embryos and asking if chirality of movement is identifiable. We observe variability in the early cleavage of S. lamarcki, including a viable 3-cell stage. Image data are analysed by both particle tracking and particle image velocimetry. Neither finds evidence for chiral movement in 1, 2, 3 or 4 cell embryos, nor do we detect consistent differences between the embryos of the dextral and sinistral species. The methodological and evolutionary implications of this are discussed.
\end{abstract}

Keywords: spiralian; embryo; cleavage; time lapse; light sheet microscopy 


\section{Introduction}

Animals whose embryos exhibit spiral cleavage belong to the Lophotrochozoa, one of the three major lineages of bilaterally-symmetrical animals. The Lophotrochozoa encompass a wide diversity of animals including annelids, platyhelminthes, nemerteans, and molluscs (Costello and Henley, 1976; Aguinaldo and Lake, 1998). Together with the Ecdysozoa (including arthropods and nematodes), Deuterostomia (including vertebrates and echinoderms), and some flatworm lineages (Ruiz-Trillo et al., 1999), these constitute the living Bilateria. Early cell divisions of the animal embryo can be remarkably conserved both within and between phyla. Spiral cleavage is a key example of this, and since many members of the Lophotrochozoa display this character, Lophotrochozoa is sometimes used as synonymous with Spiralia (for example (Giribet, 2008)). This however is somewhat controversial, as it is unclear whether spiral cleavage is a synapomorphic character for this group (Paps et al., 2009; Hejnol, 2010; Edgecombe et al., 2011). Here we use the term Lophotrochozoa to define the whole lineage, reserving spiralian to indicate those animals showing spiral cleavage.

Spiral cleavage is characterized by a distinctive spiral arrangement of blastomeres. The first two planes of cleavage typically align along the Animal-Vegetal (AV) axis, with spiralling initiating at the third cleavage. This cell division separates animal from vegetal cells, with the animal tier of cells usually smaller than the vegetal cells and hence known as micromeres. The angle of this third cleavage is predictably tilted relative to the AV axis, such that the micromeres are produced with a spiral offset (Figure 1). Subsequent divisions alternate this tilted cleavage to generate a spiral arrangement of blastomeres. This, 'textbook' description of spiral development is, however, a generalised simplification of the more diverse patterns of cleavage encountered across the various spiralian taxa. Rather than one stereotypical mode of spiral cleavage it may be better considered as three sub-types: equal cleavage, unequal cleavage, and polar lobe development (Whitman, 1878; Wilson, 1892; Lillie, 1895; 
Conklin, 1898; Wilson, 1898; Child, 1899; Costello and Henley, 1976; Boyer and Jonathan, 1998). Unequal cleavage indicates a very early difference in blastomere specification, and in unequal and polar lobe development there is usually (though not always, for example (Martindale and Henry, 1995; Henry et al., 2006)) a clear size difference between blastomeres during the first few cleavages. Experimental embryology shows the DorsalVentral (DV) axis is already specified at the 4-cell stage in unequal-cleaving spiralians, indicating blastomeres may have set identities by this point in development (Henry and Martindale, 1999). However, there is variation between species, especially in the ability to develop normally in cell ablation and isolation experiments, making it difficult to pinpoint exactly when developmental fates are first specified. Blastomeres of equal-cleaving spiralians are thought to be equipotent at the 2-cell and 4-cell stages (Morrill et al., 1973; Arnolds et al., 1983; Martindale et al., 1985; Martindale and Henry, 1995), with the DV axis specified through cell-cell interactions considerably later in development, at the 24-cell stage when the third micromere quartet forms (Martindale et al., 1985). At cleavage stages prior to third quartet formation equal-cleaving spiralians develop remarkably normally following ablation of blastomeres, with remaining cells recapitulating normal cleavage patterns (Morrill et al., 1973). Several studies implicate MAPK signalling in the first inductive interactions, though its precise timing may vary between species (Lambert and Nagy, 2001; Lambert and Nagy, 2003; Koop et al., 2007). An early role for Bmp signalling has also been identified in the mollusc Ilyanassa (Lambert et al., 2016; Lanza and Seaver, 2018). This mechanistic variation highlights the need for increased taxon sampling in developmental studies of spiralians, especially equal-cleaving spiralians, if we are to understand both the mechanisms involved and their evolutionary history.

In addition to differences in blastomere size and blastomere fate, spiralians may also differ in the orientation of spiral cleavage (Figure 1). Most spiralians are dextral, with the first micromere quartet shifted clockwise when viewed from the animal pole. However, some 
species are sinistral, showing an anticlockwise shift at the 4-8 cell stage. In molluscs this predicts inverted body handedness in adults (Shibazaki et al., 2004), but it is unclear whether this relationship is more widespread amongst spiralians; few studies have attempted to correlate embryo cleavage patterns with adult morphology, and one that has, comparing dextral and sinistral cleaving Hydroides spcs. serpulid annelids, suggested this did not affect the handedness of an adult asymmetry as assessed by the handedness of the operculum (Arenas-Mena and Li, 2015). Little is also known about the molecular basis of sinistral versus dextral cleavage, though the involvement of an actin interacting protein in this process in the gastropods Lymnaea stagnalis and Lymnaea peregra implicates the actin cytoskeleton in these species (Davison et al., 2016; Kuroda et al., 2016). Furthermore, while the 4-8 cell stage is the first readily-visible sign of spiralling, it is not necessarily the first event determining dextrality or sinistrality. It is likely that some aspect of sidedness and/or chirality is present earlier in development, as originally predicted by Brown and Wolpert (Brown and Wolpert, 1990), and more recently explored by various authors, with possibilities including the actin and/or tubulin cytoskeletons and the centrioles (Vandenberg and Levin, 2013; Namigai et al., 2014).

Recently, there has been a resurgence of interest in the dynamics of early cleavage in animal development, in the organisation and re-organisation of cell structures that accompanies cleavage, and in their relationship to mechanisms of symmetry breaking (Ajduk et al., 2014; Naganathan et al., 2014; Schonegg et al., 2014). Most studies have used model organisms, primarily the nematode Caenorhabditis elegans where the anterior-posterior (AP) and dorsal-ventral (DV) axes are established by the 4-cell stage through a combination of spatial constraints and spindle orientation (Pohl and Bao, 2010; Pohl, 2011; Schonegg et al., 2014). Most informatively, early cleavage planes and the handedness of the $C$. elegans embryo and adult respectively are determined by the chirality of the actin cytoskeleton in the egg (Schonegg et al. 2014). Other studies have followed cytoplasmic flow correlated with AP 
axis formation in mouse (Yi et al., 2011), and flow-like communication in the cytoplasm in the frog (Ishihara et al., 2014), though clear links to later axis specification have not been established. Cell culture studies have also provided evidence that individual cells can spontaneously generate chiral cytoskeletal structures and cortical cytoplasmic flow (Wan et al., 2011; Naganathan et al., 2014). Critical to all such studies has been the development of reagents that allow imaging of cytoskeletons, and of technologies for monitoring live embryos such that cleavage dynamics can be followed at the subcellular level in real time. While such studies have been highly informative, the focus on model species means it is not clear how generalizable such findings are outside of the few organisms studied, especially given the diversity of early cell cleavage methods deployed by animals. For example, while C. elegans shows a degree of spiral arrangement of its early blastomeres (Wood, 1991; Bergmann et al., 2003), it is not clear how, or even if, this basic aspect of early development is mechanistically related to spiral organisation in spiralian embryos.

Here we study the early cleavage stages of two equal-cleaving spiralians, the dextrally spiralling annelid Spirobranchus lamarcki and the sinistral mollusc Biomphalaria glabrata. Time lapse imaging of live embryos coupled with confocal imaging of cytoskeletal structures in fixed specimens provides a foundational description of early cleavage. We find diversity in the early cleavage of $S$. lamarcki, including a viable 3-cell stage that some embryos of this species pass through. We also used light sheet microscopy in both species to visualise and track vesicle movement as a proxy for cytoplasmic movement, finding that this does not appear different between dextral and sinistral embryos.

\section{Materials and Methods}

Adult and embryo acquisition and culture

S. lamarcki adults were collected from the coast of Tinside, Plymouth, UK and maintained in recirculating sea water at approximately $12^{\circ} \mathrm{C}$. S. lamarcki spawn upon being broken out of 
their tubes. Animals were spawned as previously described (McDougall et al., 2006) by breaking the end of the calcareous tube with tongs and breaking open a hole from the posterior end using a blunt probe. The animal was then pushed backwards out of this hole by pushing against the operculum at the anterior end using a blunt probe. Adults were then placed individually in filtered sea water (FSW) and allowed to exude eggs or sperm for 20 mins. The eggs were fertilized with a drop of a mixture of sperm from multiple males.

B. glabrata adults (strain BB02) were obtained from David Rollinson (Natural History Museum, London, UK) and maintained in shallow containers of standing bottled water at $26^{\circ} \mathrm{C}$. Natural breeding was allowed and egg masses were collected at approximately hourly intervals in order to capture necessary developmental stages. Egg masses were developed in the same conditions as the adults. Egg masses were dissected under a dissecting microscope, using fine forceps to break open individual egg capsules. Eggs were gently sucked out of the broken egg capsule using a glass capillary (custom-made by pulling over a Bunsen burner and breaking until opening was larger than $200 \mu \mathrm{m}$ ).

$\underline{\text { Time lapse recordings of live embryos and confocal imaging of fixed embryos }}$

For time lapse imaging, live S. lamarcki and B. glabrata embryos were imaged in sea water or bottled water respectively under an inverted microscope using a Nikon, Digital Sight DSL1 time lapse recorder. For confocal imaging embryos were fixed in 4\% paraformaldehyde (PFA) and stored in methanol $(\mathrm{MeOH})$ at $-20^{\circ} \mathrm{C}$. Embryos were rehydrated into Phosphate Buffered Saline (PBS) with 0.1\% Tween 20 (PBT), washed three times in PBT at room temperature (RT), and incubated in block (2\% BSA dissolved in PBT) at $4^{\circ} \mathrm{C}$ overnight. Block was replaced with primary antibody at a 1:1000 dilution of anti-acetylated mono-betatubulin (Sigma T0198: Antibody Registry $\left.\mathrm{AB} \_477556\right)$ in block at $4^{\circ} \mathrm{C}$ overnight. The primary antibody was washed off with four 20 -minute washes in block at $4^{\circ} \mathrm{C}$, and replaced with secondary antibody (Alexa Fluor 596, Molecular Probes) at a dilution of $1: 800$ in block at $4^{\circ} \mathrm{C}$ overnight. The secondary antibody was washed off with four 20-minute washes in block at 
$4^{\circ} \mathrm{C}$ and embryos were permeabilized in PBT at RT for one hour. Embryos were incubated in a 1:40 dilution of Oregon Green Phalloidin 488 (Molecular Probes) in PBT at RT for one hour. Embryos were washed three times in PBS at RT for 15 mins, immersed in $60 \%$ glycerol/PBS and mounted in Vectashield with DAPI (1:1000 dilution in Vectashield). Primary antibody, phalloidin, and DAPI were omitted for respective negative controls. Confocal images were taken at a magnification of 400x using the Olympus FV1000 Fluoview confocal microscope at RT.

\section{Light sheet microscopy}

Embryos (from 2 hours post fertilization) were stained with 0.001mM Lysotracker (Red DND99, Molecular Probes) for 5 mins at RT and diluted into low melting point agarose (Promega, V2111). Embryos were embedded in 1\% low melting point agarose in sea water or bottled water for S. lamarcki and B. glabrata respectively, and drawn up a thin capillary. For imaging, a small portion of the agarose embedded with the embryos was gently extruded from the end of the capillary at RT (for S. lamarcki) or at $26^{\circ} \mathrm{C}$ (for B. glabrata) and submersed in sea water or bottled water respectively in the mounting chamber. Data were collected on the Z.1 Light sheet microscope (Zeiss) using a 20x detection objective and 10x illumination objective. For a schematic of the experimental set up see Figure 3A.

\section{$\underline{\text { Image data processing and analysis }}$}

Images were compiled using maximum intensity projection to flatten the z-axis (ZEN software- Zeiss) into a time lapse video and saved as an AVI (Audio Video Interleave) file. Videos were too large to be imported directly into FIJI (Schindelin et al., 2012). The plug-in BIOFORMATS (Linkert et al., 2010) was therefore used, and videos were imported in 200 frame increments. Upon import, videos were oriented and cropped to a single Region Of Interest (ROI). For each we noted the position of the polar bodies as an indication of the animal-vegetal axis, helping orientate the images during later analysis. 
Vesicles were tracked in each ROI using MOSAIC Particle Tracker 2D/3D (Helmuth et al., 2010; Shivanandan et al., 2013) in 200 frame increments (Note: the terms "vesicle" and the more general term "particle" are used from here on, with the former in reference to staining and the latter in reference to analysis methods). For particle tracking, each blastomere was divided into four spatial quadrants, each quadrant corresponding to one ROI. For S. lamarcki parameters were set at a zoom of 2.5 , maximum particle radius ( $r$ ) at 13 pixels as lysosomes are at a range of $0.1-1.2 \mu \mathrm{m}$ (or $0.9257-12.093$ pixels), minimum radius (c) at 0.5 pixels to account for smaller vesicles at farther depths, percentile (p) at 1 where particles in the upper first percentile of the image intensity distribution are accepted as a segmented particle, number of frames (L) used to link optimal trajectories at 2 (this sets how many frames can overlap yet still maintain distinct particle identities), and maximum pixel displacement (D) between frames at 75 . For $B$. glabrata parameters were set at a zoom of 2.0 with the above settings at $r=11, c=0.5, p=1, L=2, D=75$, and for zoom 2.5 all were maintained the same except for $r=14$.

Particle tracking data were transferred to Excel and used to calculate the bearing of each vesicle using the following formula: $90-\arctan 2(y 2-y 1) / x 2-x 1)$, with the results saved as a .CSV file. This formula calculates bearing (arctan2) relative to the normal ("90-"). An R (Team, 2008) script was written to generate polar plots for all bearings in each ROI using the Rcpp (Eddelbuettel, 2013), plyr (Wickham, 2011), plotrix (Lemon, 2006), and ggplot2 (Wickham, 2009) packages and compiled to one PDF file using the multiplot function in R.

Particle image velocimetry (PIV) analyses were done separately using the PIV plugin (Tseng et al., 2012). PIV measures the velocity of labelled particles, termed optic flow, in subregions of an image. This is done for pairs of images and the data are cross-correlated. During this process, interrogation window sizes (the subregions of the image) are gradually decreased, 
which allows for a better PIV resolution. For S. lamarcki, two passes of PIV were done, whereas for B. glabrata, three passes of PIV were done, both with decreasing window sizes using the basic cross-correlation method.

\section{Results}

\section{$\underline{\text { S. lamarcki embryos show variation in early cleavage patterns }}$}

S. lamarcki embryos are approximately $60 \mu \mathrm{m}$ in diameter and undergo equal cleavage ((Segrove, 1941):Figure 2A, B). Spiralian embryogenesis is generally considered to be strictly controlled and deterministic, however in the time lapse recordings we noted that some S. lamarcki embryos appeared to cleave asynchronously at the 2-4 cell stage, with a transition through a 3-cell stage rather than the expected synchronous cleavage from 2 to 4 cells (Figure 2C, Supplementary movie 1). Not all embryos showed this 3-cell stage, but embryos that transitioned through a 3-cell stage typically stayed this way for about 30 minutes before the undivided blastomere also cleaved, yielding a 4-cell stage embryo.

We considered whether the 3-cell stage might be an imaging artefact of the time lapse microscopy, for example whether it was the result of awkwardly-shaped or orientated blastomeres, with or without real cell boundaries, such that what appeared to be three blastomeres was in fact four. Closely staged batches of embryos were fixed, stained for DNA, actin and tubulin, and studied by confocal microscopy to visualize embryos in 3 dimensions. Some embryos clearly had only 3-cells, with intact cell membranes between all three blastomeres and clear separate nuclei (Figure 2C), indicating that there were indeed three bona fide blastomeres. As the 3-cell stage transitioned to a 4-cell stage it appeared as if one blastomere had simply been delayed in completing cleavage with no obvious differences between embryos once they reached the 4-cell stage. At the 4-cell stage, embryos entering metaphase exhibited angled spindles associated with spiral cleavage 
(Figure 2Biv). At the 8-cell stage, the oblique orientation of the blastomeres can best be seen in embryos that are in the midst of cleaving, where it becomes clear that the blastomeres are not aligned linearly. We did not observe asynchrony at any stage after the 2-4 cell division by either time lapse or confocal imaging.

We considered whether the embryos transiting through a 3-cell stage might be compromised in some way, such that cleavage asynchrony was a manifestation of abnormal development. To quantify this we distributed single embryos derived from normal fertilisations and which had not been subjected to any experimental manipulation to the wells of a 96-well plate, recording which ones passed through a distinct 3-cell stage and which ones transited direct from 2- to 4-cells, and related this to their development into normal trochophore larvae (exhibiting typical spiral swimming and associated behaviours). We found survival was lower in embryos transiting via a 3-cell stage (33\% survival versus $55 \%$ survival) but that this was not a statistically significant difference (Table $1 ; p>0.1, n=96)$.

\section{B. glabrata shows synchronous cleavage}

B. glabrata embryos are approximately $120 \mu \mathrm{m}$ in diameter and like S. lamarcki undergo equal cleavage. They are however sinistral, with spiral cleavage initiating in an anticlockwise direction (Say 1818). Time lapse and confocal imaging of $B$. glabrata embryos showed no evidence of transition through a 3-cell stage (Figure 2E, F), or of any other cleavage asynchrony.

\section{Tracking movement in S. lamarcki and B. glabrata blastomeres.}

To track movement within blastomere cytoplasm we labelled lysosomes using a fluorescent dye that can be applied to live embryos and which can penetrate the maternal envelope that surrounds the eggs of these species (Supplementary movie 2, movie 3). Lysosomes might be moved passively by the movement of the cytoplasm, or actively along cytoskeletal 
elements (Collot et al., 1984; Matteoni and Kreis, 1987); either could illustrate underlying directionality in the organisation of subcellular components during early development. Labelled embryos were mounted in low melting point agarose and imaged using light sheet microscopy (Figure 3A, B). Images were taken at set intervals and labelled vesicles followed through successive images, allowing their direction of movement to be determined. We analysed recordings in two ways: particle tracking, where each blastomere was subdivided to gain insight into movement variation within each cell, and PIV, where the entire blastomere was analysed as one unit but data are plotted by scattered vector arrows, giving a visual impression of overall direction and speed of movement.

\section{Particle tracking of S. lamarcki and B. glabrata}

For particle tracking each blastomere was subdivided into four spatial quadrants. Each quadrant was analysed separately, with the movement of each particle quantified as a bearing. These were then plotted in bins on a $360^{\circ}$ plot, with the number of particles falling into each bin of bearings reflected in the length of the spokes on the plot (an example is shown in Figure 3C, D). In total we analysed thirteen S. lamarcki embryos and seven $B$. glabrata embryos (Table 2), with some embryos traversing multiple cleavage stages (Figure 4). Data quality varied so not all blastomeres in all embryos could be analysed, however in total this amounted to 88 individual blastomere measurements (Figure 4: data deriving from 20 different embryos, graphical representations of each analysis for each embryo in Supplementary file 1, full tabulated data in Supplementary file 2, summary of blastomere classifications in Supplementary file 3). The main bearing for each plot was considered by taking the largest bearing for each plot (for example as shown by the bold arrow on the example in Figure 3D, and in Supplementary file 1). The second largest bearing is also indicated (non-bold arrows on Figure 3D Supplementary file 1) to illustrate the approximate degree of error in using only the largest bearing in this interpretation (for example, if the largest and second largest bearings are very different). Finally, we categorised each 
blastomere into one of five different general categories of movement. Pictorial representations of these categories are shown in Figure 3F. A summary of the classification of each embryo is shown in Table 2 and a breakdown of each blastomere categorization is shown in Figure 4. Briefly, consistent directional movement in blastomere quadrants was classified as 'Horizontal' or Animal-Vegetal' depending on its direction (e.g. SL7 Supplementary file 1 page 21, SL4 Supplementary file 1 page 6, respectively). Some blastomeres showed movement classified as 'Towards the Cell Centre' or 'Circular' with the latter reflecting a consistent change in the major bearing when examining quadrants in a circular fashion (e.g. SL9 Supplementary file 1 page 23, SL1 Supplementary file 1 page 3 respectively). A caveat is that embryos were not imaged from exactly the same orientation since this depended to some extent on how they settled in the agarose. This means interpretation of categories could be affected: for example for the 'Horizontal' category may in fact by Circular, 'Animal-Vegetal' movement would not be visible in embryos viewed directly form the animal pole, and the strength of 'Horizontal' movement in embryos viewed laterally would depend on which side was viewed. Considering this we recognise there is an arbitrary aspect to this classification. To maintain a conservative approach we classified overall movement as "Mixed" (e.g SL5 Supplementary file 1 page 7) in cases where we considered bearings too scattered or inconsistent between quadrants to be include in the above.

The majority of S. lamarcki blastomeres showed the pattern of movement we categorised as 'mixed': that is we detected no consistent directionality. In general, all the blastomeres in an embryo exhibited the same category, thought this was not universal: for example embryo SL7 at the two cell stage showed distinctly different movements in one cell compared to the other (Supplementary file 1, page 9). When considering the embryos we followed through successive stages, some similarity was noted, for example with embryos SL6 and SL7 showing horizontal, or mixed + horizontal movement, at the two cell stage, and horizontal 
movement at the four cell stage (Figure 4; Supplementary file 1, pages 8 and 20, 9 and 21). Again this was not universal, with embryo SL1 showing circular movement at the two cell stage, horizontal movement at the three cell stage, and mixed movement at the 4 cell stage (Figure 4; Supplementary file 1, pages 3, 13 and 16 ). The majority of $B$. glabrata blastomeres exhibited horizontal or mixed movement, though we also categorised one blastomere in BG6 at the two cell stage as AV (Figure 4; Supplementary file 1, page 31).

\section{PIV of S. lamarcki and B. glabrata}

For PIV each blastomere was analysed separately but was not further subdivided into spatial quadrants. This is because PIV captures velocity across the cell in the form of vectors depicted as arrows, with directionality shown from the direction of the arrow and speed from its relative size (an example is shown in Figure 3E). Full tabulated data can be found in Supplementary file 2, with graphical representations of each analysis for each embryo in Supplementary file 1 . The picture that emerges from these analyses is one of high variability. Most embryos showed local movements in a variety of directions, and in many instances there were clear differences in direction and speed between blastomeres within and embryo, or between successive analysis windows in the same embryo; for example S. lamarcki embryo SL2 at the two cell stage shows a distinct difference in scale between the first six windows of analysis and the last two (Supplementary file 1 page 4). Given the high variability, it was not possible to reliably estimate general cytoplasmic flow in each blastomere from these analyses.

\section{Discussion}

\section{A 3-cell stage embryo in the spiralian S. lamarcki}

Time lapse and confocal imaging showed that some S. lamarcki embryos pass through a 3cell stage. Following the development of such embryos showed that their survival to form an apparently-normal trochophore larva was not significantly different from embryos 
progressing directly to a 4-cell stage. Asynchrony in spiralian embryo cleavage has been previously documented, though almost always in unequally cleaving embryos where the first cell division yields one blastomere that is substantial larger than the other. In such situations it is the larger blastomere that divides first at the second cleavage, and this phenomenon has been noted in species from multiple lineages including the mollusc Unio (Lillie, 1895), the oligochaete Tubifex (Shimizu, 1993) and the rotifer Asplanchna (Tannreuther, 1920).

Reports of asynchronous cleavage in the early cell divisions of equally-cleaving spiralians are much rarer. Two reports indicate asynchrony in timing of cleavage in the annelid Pomatoceros triqueter, which is very closely related to S. lamarcki (Dorresteijn and Fischer, 1988; Dorresteijn and Luetjens, 1994). Asynchrony was reported at the 2-4 cell stage, though the transition from 2-cell to 3-cell to 4-cell was said to be less than one minute, much more rapid than we observed in S. lamarcki. Asynchrony was also amplified at later developmental stages, and the cause was thought to be correlated with slight size differences between blastomeres. We did not observe either property in S. lamarcki, with synchronous cleavage in all embryos after the 4-cell stage. Possible asynchrony in cleavage has also been reported in equally-cleaving entoproct and phoronid embryos, (Merkel et al., 2012; Pennerstorfer and Scholtz, 2012), and in a polyclad flatworm (Girstmair et al., 2016), though has not been studied in detail in either case and it is unclear if this is either common or a facet of normal development or an abnormality.

Our confirmation that 3-cell S. lamarcki embryos are common and viable raises a number of issues. First, we note that variable cleavage mechanisms, both within S. lamarcki and between species as closely related as $S$. lamarcki and $P$. triqueter, can result in similar fates, as previously noted for molluscs (Martindale et al., 1985). Such variation and subsequent regulation to produce normal development, particularly within a batch of eggs from a single mother as we have observed in S. lamarcki, may provide an underlying basis for the 
evolution of more drastic spiralian cleavage variants, like unequal cleavage or polar lobe formation. Second, it is possible that this variation is not stochastic, for example the precocious blastomere may have, or adopt, a specific fate. We were not able to follow blastomeres late enough in development to test this, but given the subcellular and asymmetric localisation of maternal transcripts between blastomeres in molluscs it remains a possibility (Lambert and Nagy, 2002; Kingsley et al., 2007; Henry et al., 2010; Lambert, 2010; Rabinowitz and Lambert, 2010). Third, it is possible that such asynchronies are found in more equal-cleaving spiralians than currently appreciated. This is because occasional 3cell spiralian embryos may be assumed to be abnormal and ignored. Live imaging of more species will be needed to address this.

Tracking subcellular movement in spiralian embryo blastomeres by light sheet microscopy To date there have been few reports of the application of light sheet imaging to non-model invertebrates; recent studies include those of Lyons et al and Girstmair et al (Lyons et al., 2015; Girstmair et al., 2016). In particular, Lyons et al successfully combined fluorescent labelling of live embryos and light sheet imaging to study early development of the mollusc Crepidula fornicata (Lyons et al., 2015). This study used injection of mRNAs encoding fluorescent fusion proteins that marked microtubules, microfilaments and other subcellular components. A limitation with this approach is that the mRNA must be translated prior to visualisation, making very early developmental stages difficult to visualise. Alternate strategies could include transgenic lines in which the oocyte is marked by maternallysupplied fluorescent protein, or the use of dyes which can be applied to live embryos without cytotoxic effect. We chose the latter, as the transgenic tools necessary for the former have yet to be developed. Several such dyes marking different organelles are commercially available; we employed a lysosome marker as these organelles are present in large number in spiralian oocytes, allowing visualisation of movement throughout the cell from before the first cleavage and through the 2, 3 and 4 cell stages. 
There are a number of ways that movement in 3D can be effectively captured quantitatively. One option is to do a 3D reconstruction of the embryo for each recorded frame, then perform tracking analyses in all three dimensions. While providing high resolution this is prohibitively computationally expensive when considering many embryos and risks missing variation between specimens. Instead, we opted to perform a less fine-grained quantitative estimate of directional flow, reasoning this would be sufficient to detect gross and consistent particle movement and allowing us to analyse multiple specimens and stages for each species. Images were flattened into 2 dimensions (2D) and analysed using particle tracking and PIV analysis. Two methods were used in order to capture both small individual movements (particle tracking) and more generalised local movement (PIV), with the former subsequently plotted to allow broader generalisation and comparison between cells and embryos.

In S. lamarcki there was no evidence for gross or consistent directional movement common to all embryos. Multiple patterns were observed, which we have classified into 5 types as per Table 2 and Figure 3F. In most cases movement within S. lamarcki cells was variable (i.e. mixed category) over the periods analysed. This strongly suggests that lysosome movements within the blastomeres of this species are not consistently directional during early cleavage stages. We did, however, observe instances where movement could be categorised into a specific type. Typically (though not uniformly) each blastomere within an embryo displayed the same movement category. As our analysis captures short windows of movement, this may reflect embryos passing through distinct phases as they progress between successive cell divisions (considered further below).

B. glabrata embryos showed more consistency at the 2-cell stage, with cells categorised as either horizontal or AV movement. This may indicate more consistent organisation of movement in this species. B. glabrata embryos are relatively large and yolky compared to 
those of S. lamarcki, making following analysis through later development stages particularly challenging: hence, with only two 4-cell embryos successfully captured, we cannot reliably determine if this character persists.

While we did not find evidence of uniform directional movement in either spiralian species, in both species we observed cells and/or stages where directionality was clear. We suspect movement categorised as towards the cell centre (observed in two S. lamarcki embryos) to be related the onset of cell division. However we were unable to confirm this as our analysis time windows (visible on the images in Supplementary file 1) did not capture cell divisions. AV movement was also observed in a small number of embryos. Circular movement is chiral, but was only observed in one embryo at one stage (embryo SL1 at the 2 cell stage: Figure 4 and Supplementary file 1, page 3) so we cannot generalise from this. Horizontal movement was more frequent and could be chiral around the AV axis, but might also reflect non-chiral lateral movement (for example laterally away from the cell centre).

\section{Cell chirality and the evolution of asymmetry in lophotrochozoans}

Long-standing theory suggests that organismal left-right asymmetry may be traced to some form of molecular asymmetry or chirality (Brown and Wolpert, 1990; Vandenberg and Levin, 2013). Direct evidence in support of this theory has, however, been more difficult to acquire. Asymmetric expression of nodal and Pitx is important in some species, including deuterostomes (Namigai et al., 2014) and some molluscs (Grande and Patel, 2009; Kuroda et al., 2009), though how symmetry is originally broken to yield asymmetric gene expression in these lineages, and in species that do not use nodal and Pitx, is much less well understood. Recent advances in this area include the identification of a chiral actin cytoskeleton in the nematode C. elegans (Schonegg et al., 2014), and the implication of cilia in regulating the left-right axis of some vertebrate embryos may also fall into this category; 
cilia are inherently chiral and this property seems to be important for their function in asymmetry (reviewed by (Shinohara and Hamada, 2017)).

The breaking of symmetry in lophotrochozoans has been little studied, with the exception of a small number of mollusc species; primarily fresh water gastropods where in which symmetry reversal mutations have been identified. The key findings from these studies are that organismal asymmetry is determined by the direction of tilt of blastomeres during cleavage at the 4 to 8 cell stage, and that genetic mapping of the locus responsible for symmetry reversal shows the mutated gene to encode a protein that interacts with actin (Davison et al., 2016; Kuroda et al., 2016). These findings point to the cytoskeleton of blastomeres at the 1, 2 and 4 cell stages as likely sources of an internal asymmetric or chiral 'signal' that can be turned into directionally-tilted cleavage at the 4-8 cell stage. Direct evidence of either, however is lacking. The evolutionary dynamics of left-right asymmetry have also been studied in molluscs (for example (Schilthuizen and Davison, 2005; Utsuno et al., 2011)). The evolutionary and ecological implications of these studies are complex, but one clear aspect is that sinistral and dextral forms are not encountered with equal frequency; dextral forms dominate across gastropod phylogeny, with a scattering of sinistral species. This shows sinistrality has evolved independently many times, but also implies that dextrality and sinistrality are not equally viable alternatives. It is unclear how much of this applies across other lophotrochozoan taxa. If we add to this the observation that sinistral and dextral cleavage may not be connected to adult asymmetry in Hydroides polychaetes (Arenas-Mena and Li, 2015), and that at the molecular level at the 4 to 8 cell stage dextral and sinistral mollusc strains may not be mirror images of each other as implied by the mirror imaging of their adult shells (Shibazaki et al., 2004), this indicates any relationships between molecular/cellular chirality, cell division and organismal asymmetry are likely to be complex and may vary between lineages. 
In our study we have attempted to image subcellular organisation in early cleavage using light sheet imaging. While movement was detected, and was sometimes organised, we did not find evidence of movement that could reflect an underlying molecular asymmetry or chirality that could be read into organismal asymmetry. There are several possible explanations for this. It also possible no underlying chirality exists, though we consider this unlikely given what is known about early embryo cytoskeletons in other species. From a technical perspective, collapsing data from 3D to 2D loses resolution and this, plus variable embryo orientation may have led us to miss localised directional movements in some cases but not others. Furthermore, directional movements may be restricted to brief windows that have been missed in analysis of most specimens; we consider this quite likely as the observation windows we captured reflect only part of the time between each cell division.

A further alternative is that some subcellular movement is consistently chiral, but is not seen with lysosome tracking. Cortical movement may fall into this category. Cortical movement has been correlated with a polar cortical cytoskeleton in C. elegans (Schonegg et al., 2014). In this species AP axis formation by cortical flow is connected to DV axis formation by the positioning of the midbody, which is essential for asymmetric spindle positioning via actin and astral microtubules (Singh and Pohl, 2014). This may be similar to the mouse, where there is evidence for the involvement of cortical actin in spindle migration, mediated by the actin nucleators Arp2/3 and Fmn2 (Yi et al., 2013; Chaigne et al., 2015). Evidence for cortical flow in spiralian embryos is less well established, though several studies have reported cytoplasmic movements in early embryos as detected by conventional light microscopy. The annelid Platynereis dumerilii demonstrates cortical flow along the zygote AP axis (Dondua et al., 1997; Fischer and Dorresteijn, 2004). Versions of cortical flow have been reported in other spiralians with various patterns of movement, including in leech (Weisblat and Huang, 2001), chiton (Huebner and Anderson, 1976), Tubifex (Shimizu, 1986) and zebra mussel (Luetjens and Dorresteijn, 1998). While none of these studies specifically 
documented chiral flow, folding of the cell surface in some mollusc eggs has suggested underlying chiral organisation (Dohmen and Vandermey, 1977), and perhaps most notably chiral movement has also been documented in the dextral snails Lymnea stagnalis and Lymnea palustris and the sinistral snails Physa acuta and Physa fontinalis (Meshcheryakov and Beloussov, 1975). These authors demonstrated movement correlated with the chirality of spiral cleavage later in development. Readings however were based on binding small particles to blastomere cell membranes, so what happened inside the cells, and what regulated the direction of movement, remained unidentified. Unravelling this will require similar experiments to those we have performed, but including a fluorescent marker of the cortex and/or actin cytoskeleton along with markers like that used here for lysosomes. This may become feasible with the further development of reliable multigenerational transgenesis in spiralian species.

\section{Acknowledgements}

We thank Professor D. Rollinson (Natural History Museum, London, UK) for supplying the $B$. glabrata adults, and Dr E. Wegel and Dr I. Dobbie (Micron Oxford, Advanced Bioimaging Unit, Oxford, UK) for training on the Light sheet microscope.

\section{Competing interests}

The authors declare that they have no competing interests

\section{Author contributions}

EN: Designed experiments, conducted experiments, analysed data, drafted manuscript.

SMS: Designed experiments, analysed data, drafted manuscript.

\section{References}

Aguinaldo AMA, Lake JA (1998) Evolution of the Multicellular Animals. Amer Zool 38: 878-887 
Ajduk A, Biswas Shivhare S, Zernicka-Goetz M (2014) The basal position of nuclei is one pre-requisite for asymmetric cell divisions in the early mouse embryo. Dev Biol 392: 133-140

Arenas-Mena C, Li A (2015) Development of a feeding trochophore in the polychaete Hydroides elegans. Int J Dev Biol 58: 575-583

Arnolds WJA, Biggelaar JAM, Verdonk NH (1983) Spatial aspects of cell interactions involved in the determination of dorsoventral polarity in equally cleaving gastropods and regulative abilities of their embryos, as studied by micromere deletions in Lymnaea and Patella. Wilhelm Roux's Archives of Developmental Biology 192: 75-85

Bergmann DC, Lee M, Robertson B, Tsou TF, Rose LS, Wood WB (2003) Embryonic handedness choice in C. elegans involves the G protein GPA-16. Development 130: 5731-5740

Boyer BC, Jonathan QH (1998) Evolutionary Modifications of the Spiralian Developmental Program. Amer Zool 38: 621-633

Brown NA, Wolpert L (1990) The development of handedness in left/right asymmetry. Development 109: 1-9

Chaigne A, Campillo C, Gov NS, Voituriez R, Sykes C, Verlhac MH, Terret ME (2015) A narrow window of cortical tension guides asymmetric spindle positioning in the mouse oocyte. Nature Comms 6: 6027

Child C (1899) The Significance of the Spiral Type of Cleavage and its Relation to the Process of Differentiation Biological Lectures delivered at the Marine Biological Laboratory.

Collot M, Louvard D, Singer SJ (1984) Lysosomes are associated with microtubules and not with intermediate filaments in cultured fibroblasts. Proc Natl Acad Sci USA 81: 788-792

Conklin EG (1898) Cleavage and Differentiation. Biological Lectures delivered at the Marine Biological Laboratory Biological Lectures delivered at the Marine Biological Laboratory.

Costello DP, Henley C (1976) Spiralian Development: A Perspective. Amer Zool 16: 277-291

Davison A, McDowell Gary S, Holden Jennifer M, Johnson Harriet F, Koutsovoulos Georgios D, Liu MM, Hulpiau P, Van Roy F, Wade Christopher M, Banerjee R et al. (2016) Formin Is Associated with Left-Right Asymmetry in the Pond Snail and the Frog. Curr Biol 26: 654-660

Dohmen MR, Vandermey JCA (1977) Local Surface Differentiations at Vegetal Pole of Eggs of Nassarius-Reticulatus, Buccinum-Undatum, and Crepidula-Fornicata (Gastropoda, Prosobranchia). Dev Biol 61: 104-113

Dondua AK, Kostyuchenko RP, Fedorova ZE (1997) Effects of some cytoskeleton inhibitors on ooplasmic segregation in the Nereis virens egg. Int J Dev Biol 41: 853-858

Dorresteijn A, Fischer A (1988) The process of early development. in W. Westheide and C. O. Hermans (eds.) The Ultrastructure of Polychaeta.

Dorresteijn A, Luetjens CM (1994) Morphometric analysis of cellular specification in Platynereis and Pomatoceros embryogenesis (Annelida, Polychaeta). in J. C. Dauvin L. Laubier and D. Reish (eds.) Actes de la 4ième Conférence internationale des Polychètes. Mém. Mus. Natn. Hist. Nat., Paris.

Eddelbuettel D (2013) Extending Rcpp Seamless $R$ and $C++$ Integration with Rcpp: Springer New York.

Edgecombe GD, Giribet G, Dunn CW, Hejnol A, Kristensen RM, Neves RC, Rouse GW, Worsaae K, Sørensen MV (2011) Higher-level metazoan relationships: recent progress and remaining questions. Org Divers Evol 11: 151-172

Fischer A, Dorresteijn A (2004) The polychaete Platynereis dumerilii (Annelida): a laboratory animal with spiralian cleavage, lifelong segment proliferation and a mixed benthic/pelagic life cycle. BioEssays 26: 314-325

Freeman G, Lundelius JW (1992) Evolutionary implications of the mode of D quadrant specification in coelomates with spiral cleavage. J Evol Biol 5: 205-247

Giribet G (2008) Assembling the lophotrochozoan (=spiralian) tree of life. Philos Trans R Soc Lond B Biol Sci 363: 1513-1522 
Girstmair J, Zakrzewski A, Lapraz F, Handberg-Thorsager M, Tomancak P, Pitrone PG, Simpson F, Telford MJ (2016) Light-sheet microscopy for everyone? Experience of building an OpenSPIM to study flatworm development. BMC Dev Bio 16: 22

Grande C, Patel NH (2009) Nodal signalling is involved in left-right asymmetry in snails. Nature 457 : 1007-1011

Hejnol A (2010) A Twist in Time--The Evolution of Spiral Cleavage in the Light of Animal Phylogeny. Integr Comp Biol 50: 695-706

Helmuth JA, Paul G, Sbalzarini IF (2010) Beyond co-localization: inferring spatial interactions between sub-cellular structures from microscopy images. BMC Bioinformatics 11: 372

Henry JJ, Martindale MQ (1999) Conservation and innovation in spiralian development Reproductive Strategies and Developmental Patterns in Annelids: Springer Netherlands.

Henry JJ, Perry KJ, Fukui L, Alvi N (2010) Differential Localization of mRNAs During Early Development in the Mollusc, Crepidula fornicata. Integr Comp Biol 50: 720-733

Henry JQ, Perry KJ, Martindale MQ (2006) Cell specification and the role of the polar lobe in the gastropod mollusc Crepidula fornicata. Dev Biol 297: 295-307

Huebner E, Anderson E (1976) Comparative Spiralian Oogenesis-Structural Aspects: An Overview. Amer Zool 16: 315-343

Ishihara K, Nguyen PA, Wuhr M, Groen AC, Field CM, Mitchison TJ (2014) Organization of early frog embryos by chemical waves emanating from centrosomes. Philos Trans R Soc Lond B Biol Sci 369: 20130454-20130454

Kingsley EP, Chan XY, Duan Y, Lambert JD (2007) Widespread RNA segregation in a spiralian embryo. Evol Dev 9: 527-539

Koop D, Richards GS, Wanninger A, Gunter HM, Degnan BM (2007) The role of MAPK signaling in patterning and establishing axial symmetry in the gastropod Haliotis asinina. Dev Biol 311: 200212

Kuroda R, Endo B, Abe M, Shimizu M (2009) Chiral blastomere arrangement dictates zygotic left-right asymmetry pathway in snails. Nature 462: 790-794

Kuroda R, Fujikura K, Abe M, Hosoiri Y, Asakawa S, Shimizu M, Umeda S, Ichikawa F, Takahashi H (2016) Diaphanous gene mutation affects spiral cleavage and chirality in snails. Scientific Reports 6:

Lambert JD (2010) Developmental Patterns in Spiralian Embryos. Curr Biol 20: R72-R77

Lambert JD, Johnson AB, Hudson CN, Chan A (2016) Dpp/BMP2-4 Mediates Signaling from the DQuadrant Organizer in a Spiralian Embryo. Curr Biol 26: 2003-2010

Lambert JD, Nagy LM (2001) MAPK signaling by the D quadrant embryonic organizer of the mollusc Ilyanassa obsoleta. Development 128: 45-56

Lambert JD, Nagy LM (2002) Asymmetric inheritance of centrosomally localized mRNAs during embryonic cleavages. Nature 420: 682-686

Lambert JD, Nagy LM (2003) The MAPK cascade in equally cleaving spiralian embryos. Dev Biol 263: 231-241

Lanza AR, Seaver EC (2018) An organizing role for the TGF-beta signaling pathway in axes formation of the annelid Capitella teleta. Dev Biol 435: 26-40

Lemon J (2006) Plotrix: a package in the red light district of R. R-News 6: 8-12

Lillie FR (1895) The embryology of the Unionidae. A study in cell-lineage. J Morphol 10: 1-100

Linkert M, Rueden CT, Allan C, Burel J-M, Moore W, Patterson A, Loranger B, Moore J, Neves C, MacDonald D et al. (2010) Metadata matters: access to image data in the real world. J Cell Biol 189: 777-782

Luetjens CM, Dorresteijn AWC (1998) The site of fertilisation determines dorsoventral polarity but not chirality in the zebra mussel embryo. Zygote 6: 125-135

Lyons DC, Perry KJ, Henry JQ (2015) Spiralian gastrulation: germ layer formation, morphogenesis, and fate of the blastopore in the slipper snail Crepidula fornicata. EvoDevo 6: 24 
Martindale MQ, Doe CQ, Morrill JB (1985) The role of animal-vegetal interaction with respect to the determination of dorsoventral polarity in the equal-cleaving spiralian,Lymnaea palustris. Wilhelm Rouxs Archives of Developmental Biology 194: 281-295

Martindale MQ, Henry JQ (1995) Modifications of cell fate specification in equal-cleaving nemertean embryos: alternate patterns of spiralian development. Development 121: 3175-3185

Matteoni R, Kreis T (1987) Translocation and clustering of endosomes and lysosomes depends on microtubules. J Cell Biol 105: 1253-1265

McDougall C, Chen W-C, Shimeld SM, Ferrier DEK (2006) The development of the larval nervous system, musculature and ciliary bands of Pomatoceros lamarckii (Annelida): heterochrony in polychaetes. Front Zool 3: 16

Merkel J, Wollesen T, Lieb B, Wanninger A (2012) Spiral cleavage and early embryology of a loxosomatid entoproct and the usefulness of spiralian apical cross patterns for phylogenetic inferences. BMC Dev Biol 12: 11

Meshcheryakov VN, Beloussov LV (1975) Asymmetrical rotations of blastomeres in early cleavage of gastropoda. Wilhelm Roux's Archives of Developmental Biology 177: 193-203

Morrill JB, Blair CA, Larsen WJ (1973) Regulative development in the pulmonate gastropod,Lymnaea palustris, as determined by blastomere deletion experiments. J Exp Zool 183: 47-55

Naganathan SR, Fürthauer S, Nishikawa M, Jülicher F, Grill SW (2014) Active torque generation by the actomyosin cell cortex drives left-right symmetry breaking. eLife 3: e04165

Namigai EK, Kenny NJ, Shimeld SM (2014) Right across the tree of life: the evolution of left-right asymmetry in the Bilateria. Genesis 52: 458-470

Paps J, Baguna J, Riutort M (2009) Lophotrochozoa internal phylogeny: new insights from an up-todate analysis of nuclear ribosomal genes. Proc R Soc Lond [Biol] 276: 1245-1254

Pennerstorfer M, Scholtz G (2012) Early cleavage in Phoronis muelleri (Phoronida) displays spiral features. Evol Dev 14: 484-500

Pohl C (2011) Left-right patterning in the C. elegans embryo: Unique mechanisms and common principles. Commun Integr Biol 4: 34-40

Pohl C, Bao Z (2010) Chiral Forces Organize Left-Right Patterning in C. elegans by Uncoupling Midline and Anteroposterior Axis. Dev Cell 19: 402-412

Rabinowitz JS, Lambert JD (2010) Spiralian quartet developmental potential is regulated by specific localization elements that mediate asymmetric RNA segregation. Development 137: 4039-4049

Ruiz-Trillo I, Riutort M, Littlewood DTJ, Herniou EA, Baguna J (1999) Acoel flatworms: Earliest extant bilaterian metazoans, not members of Platyhelminthes. Science 283: 1919-1923

Say T (1818) Account of two new genera, and several new species, of fresh water and land shells. J Acad Nat Sci Phila 2: 276-284

Schilthuizen M, Davison A (2005) The convoluted evolution of snail chirality. Naturwissenschaften 92: 504-515

Schindelin J, Arganda-Carreras I, Frise E, Kaynig V, Longair M, Pietzsch T, Preibisch S, Rueden C, Saalfeld S, Schmid B et al. (2012) Fiji: an open-source platform for biological-image analysis. Nature Methods 9: 676-682

Schonegg S, Hyman AA, Wood WB (2014) Timing and mechanism of the initial cue establishing handed left-right asymmetry in Caenorhabditis elegans embryos. Genesis 52: 572-580

Segrove F (1941) The Development of the Serpulid Pomatoceros triqueter (L.). Q J Microsc Sci 82: 476-540

Shibazaki Y, Shimizu M, Kuroda R (2004) Body handedness is directed by genetically determined cytoskeletal dynamics in the early embryo. Curr Biol 14: 1462-1467

Shimizu T (1986) Bipolar Segregation of Mitochondria, Actin Network, and Surface in the Tubifex Egg - Role of Cortical Polarity. Developmental Biology 116: 241-251

Shimizu T (1993) Cleavage asynchrony in the Tubifex embryo: involvement of cytoplasmic and nucleus-associated factors. Dev Biol 157: 191-204 
Shinohara K, Hamada H (2017) Cilia in Left-Right Symmetry Breaking. Csh Perspect Biol 9: 1-9

Shivanandan A, Radenovic A, Sbalzarini IF (2013) MosaiclA: an ImageJ/Fiji plugin for spatial pattern and interaction analysis. BMC Bioinformatics 14: 349

Singh D, Pohl C (2014) Coupling of Rotational Cortical Flow, Asymmetric Midbody Positioning, and Spindle Rotation Mediates Dorsoventral Axis Formation in C. elegans. Dev Cell 28: 253-267

Tannreuther GW (1920) The development of Asplanchna ebbesbornii (Rotifer). J Morph 33: 389-437

Team R (2008) R: A language and environment for statistical computing.: R Foundation for Statistical Computing.

Tseng Q, Duchemin-Pelletier E, Deshiere A, Balland M, Guillou H, Filhol O, Thery M (2012) Spatial organization of the extracellular matrix regulates cell-cell junction positioning. Proc Natl Acad Sci USA 109: 1506-1511

Utsuno H, Asami T, Van Dooren TJM, Gittenberger E (2011) Internal Selection against the Evolution of Left-Right Reversal. Evolution 65: 2399-2411

Vandenberg LN, Levin M (2013) A unified model for left-right asymmetry? Comparison and synthesis of molecular models of embryonic laterality. Dev Biol 379: 1-15

Wan LQ, Ronaldson K, Park M, Taylor G, Zhang Y, Gimble JM, Vunjak-Novakovic G (2011) Micropatterned mammalian cells exhibit phenotype-specific left-right asymmetry. Proc Natl Acad Sci USA 108: 12295-12300

Weisblat DA, Huang FZ (2001) An overview of glossiphoniid leech development. Can J Zool 79: 218232

Whitman C (1878) The embryology of Clepsine. Q J Microsc Sci 71: 215-315

Wickham H (2009) ggplot2: elegant graphics for data analysis.: Springer.

Wickham H (2011) The Split-Apply-Combine Strategy for Data Analysis. J Stat Softw 40: 1-26

Wilson EB (1892) The cell-lineage of Nereis. A contribution to the cytogeny of the annelid body. J Morphol 6: 361-480

Wilson EB (1898) CONSIDERATIONS ON CELL-LINEAGE AND ANCESTRAL REMINISCENCE: BASED ON: A Re-Examination ofSome Points in the Early Development of Annelids and Polyclades. Ann N . Acad Sci 11: 1-27

Wood WB (1991) Evidence from reversal of handedness in C. elegans embryos for early cell interactions determining cell fates. Nature 349: 536-538

Yi K, Rubinstein B, Li R (2013) Symmetry breaking and polarity establishment during mouse oocyte maturation. Philos Trans R Soc Lond B Biol Sci 368: 20130002

Yi K, Unruh JR, Deng M, Slaughter BD, Rubinstein B, Li R (2011) Dynamic maintenance of asymmetric meiotic spindle position through Arp2/3-complex-driven cytoplasmic streaming in mouse oocytes. Nat Cell Biol 13: 1252-1258 


\section{$\underline{\text { Table legends }}$}

Table 1. Quantification of S. lamarcki embryo survival to the trochophore stage. Pearson's chi-square test indicates no significant difference $(p>0.1)$ between survival of embryos that transitioned through a 3-cell stage and those that cleaved synchronously from 2-cell to 4cell.

Table 2. Summary of quantification of blastomere vesicle flow phenotypes for S. lamarcki and B. glabrata.

\section{Figure legends}

\section{Figure 1.}

Zygote, 4-cell, and 8-cell stages of unequal and equal cleaving spiral embryos (adapted from (Freeman and Lundelius, 1992)). The directions of spiral cleavage are indicated at the 4- to 8-cell stage. pb, polar bodies.

\section{Figure 2.}

(A-D) S. lamarcki early cleavage stages visualized by DIC and confocal imaging. (A) 2-cell to 4-cell stage transition with timing of division extracted from time lapse videos. Time at the bottom left of each panel is in minutes:seconds. (B) S. lamarcki 2-cell stage (i) and three time points of 4-cell stage (ii-iv) visualized by confocal imaging, labelled for DNA (blue), actin (green) and beta-tubulin (red). (C) S. lamarcki early cleavage stages visualized by DIC microscopy extracted from time lapse video, showing an embryo passing through a three cell stages. Time at the bottom left is minutes:seconds for the first two images, and hours:minutes:seconds for the second two. (D) 3-cell stage visualized by confocal imaging, labelled for DNA (blue), actin (green), beta-tubulin (red). (E, F) B. glabrata early cleavage stages visualized by DIC microscopy and confocal imaging. (E) 2-4 cell stage transition with timing of division extracted from time lapse videos. Time at the bottom left is in minutes:seconds or hours:minutes:seconds. (F) 2-cell stage (i) and 4-cell stage (ii) visualized by confocal imaging labelled for DNA (blue) and beta-tubulin (red). All scale bars are $20 \mu \mathrm{m}$. For broader descriptions of the development of these two species the reader is referred to the following sources: (Say, 1818; Segrove, 1941; McDougall et al., 2006).

\section{Figure 3.}

S. lamarcki and B. glabrata light sheet imaging and analysis. (A) Light sheet mounting set-up with 2-cell embryo. (B) Mounted 2-cell stage S. lamarcki and B. glabrata 2-cell stage embryos labelled with the fluorescent lysosome tracker. (C) Schematic showing subdivision 
of one blastomere of a two cell embryo divided into 4 quadrants for particle tracking analysis. (D) An example chart (see Supplementary file 1 for all data) of binned bearing plots of vesicle movement within each spatial quadrant, plotted on a $360^{\circ}$ axis (bar length represents number of particles according to 'count' on the $x$ axis). Red arrows indicate the direction of the two largest count bearing bins. (E) PIV analysis of the entire 2-cell stage blastomere over time with each PIV image being 200 frames at 5 frames/sec, or 40 seconds of recording per PIV image. The direction of arrow indicates direction of vesicle movement, colour and size of arrow indicate magnitude of movement with large red arrows being at the higher end of the scale. (F) Categories of vesicle movement phenotypes observed through analysis of particle tracking and PIV data.

\section{Figure 4.}

Summary of movements inferred from particle tracking data for S. lamarcki (SL) and B. glabrata (BG) embryos through the 2, 3 and 4 cell stages. Categories of movement are as in Figure 3: AV, Animal-Vegetal. CL, Circular. CC, Towards Cell Centre. H, Horizontal. M, Mixed. Dashes reflect that not all blastomeres were imaged at all stages. 
Unequal cleavage

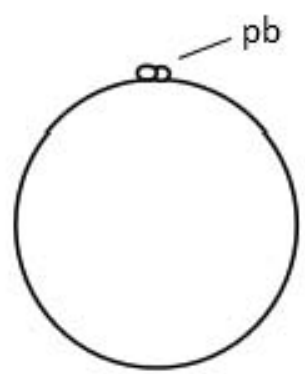

$\downarrow$

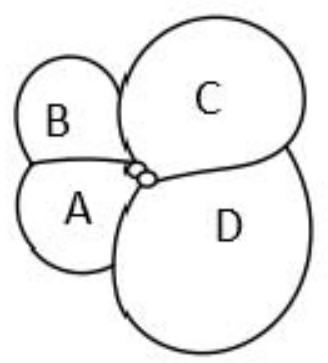

$\downarrow$

Dextral or Sinistral

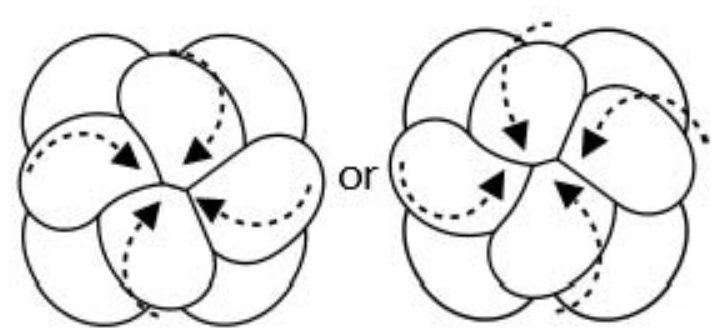

Equal cleavage

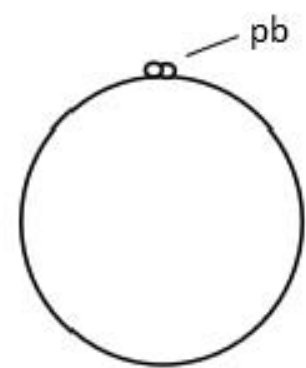

$\downarrow$

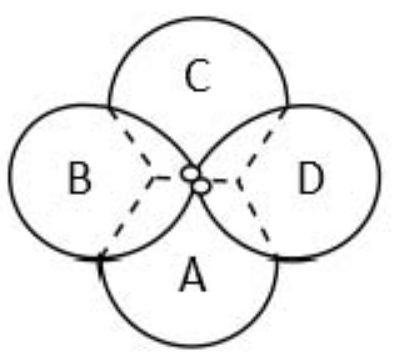

$\downarrow$

Dextral or Sinistral

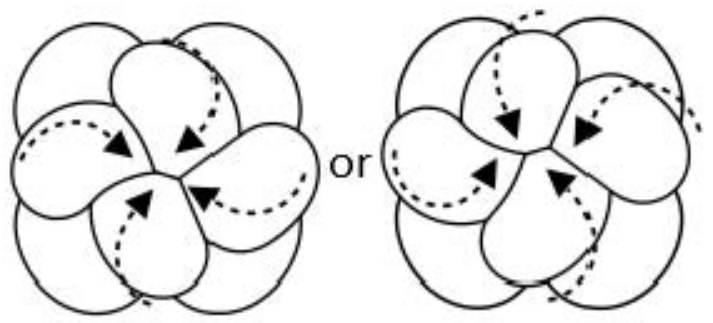

Figure 1. 


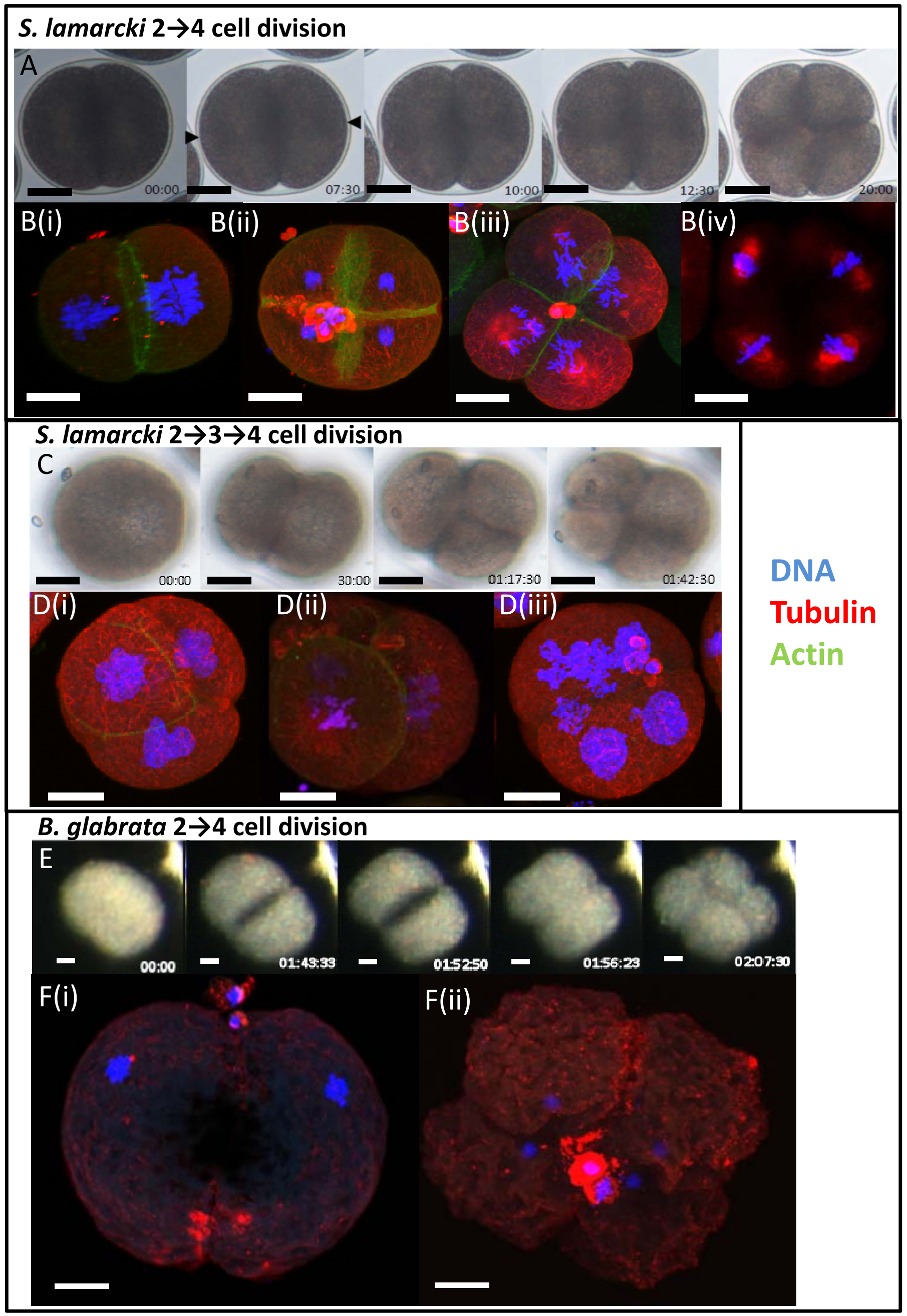

Figure 2. 


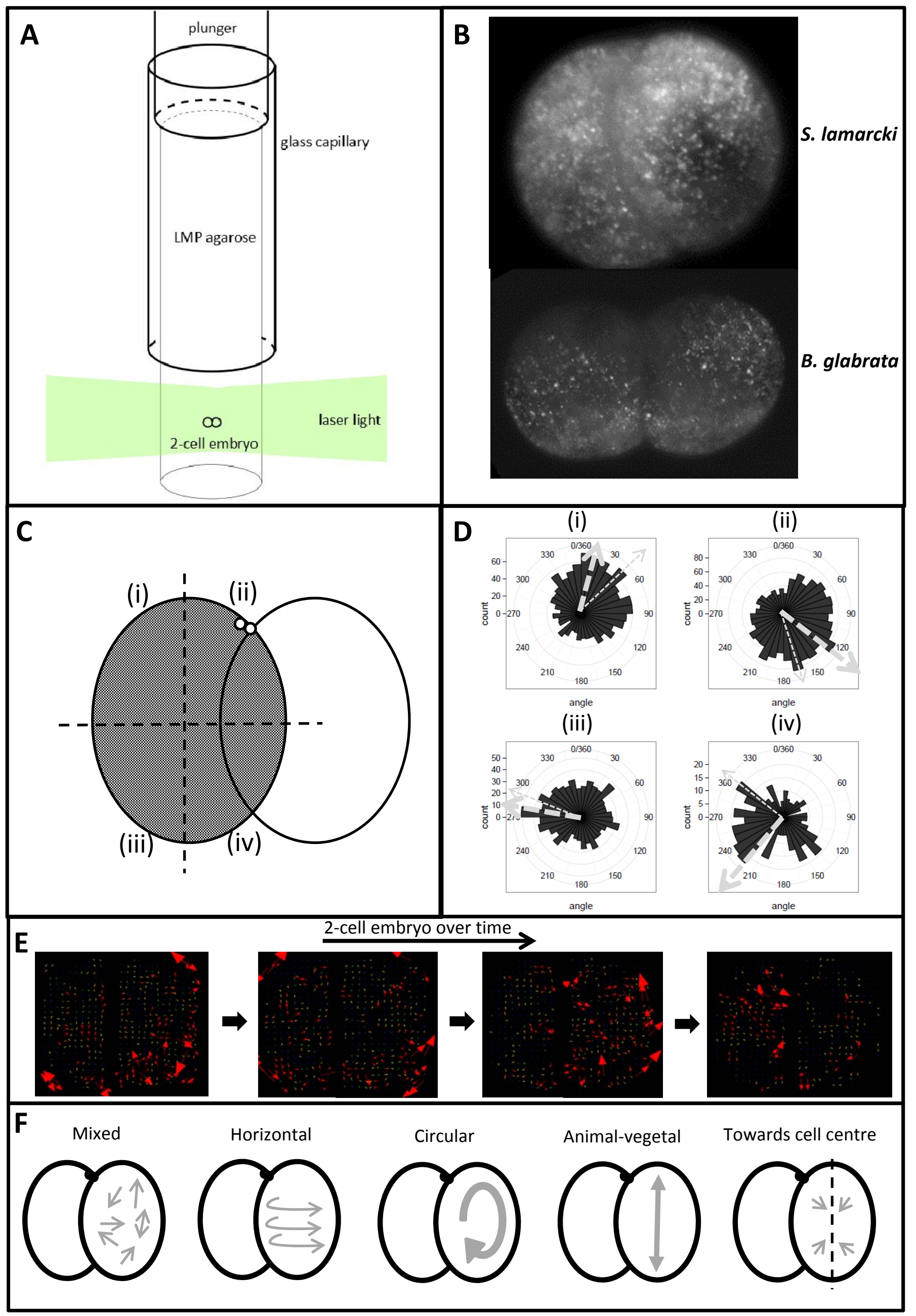

Figure 3. 


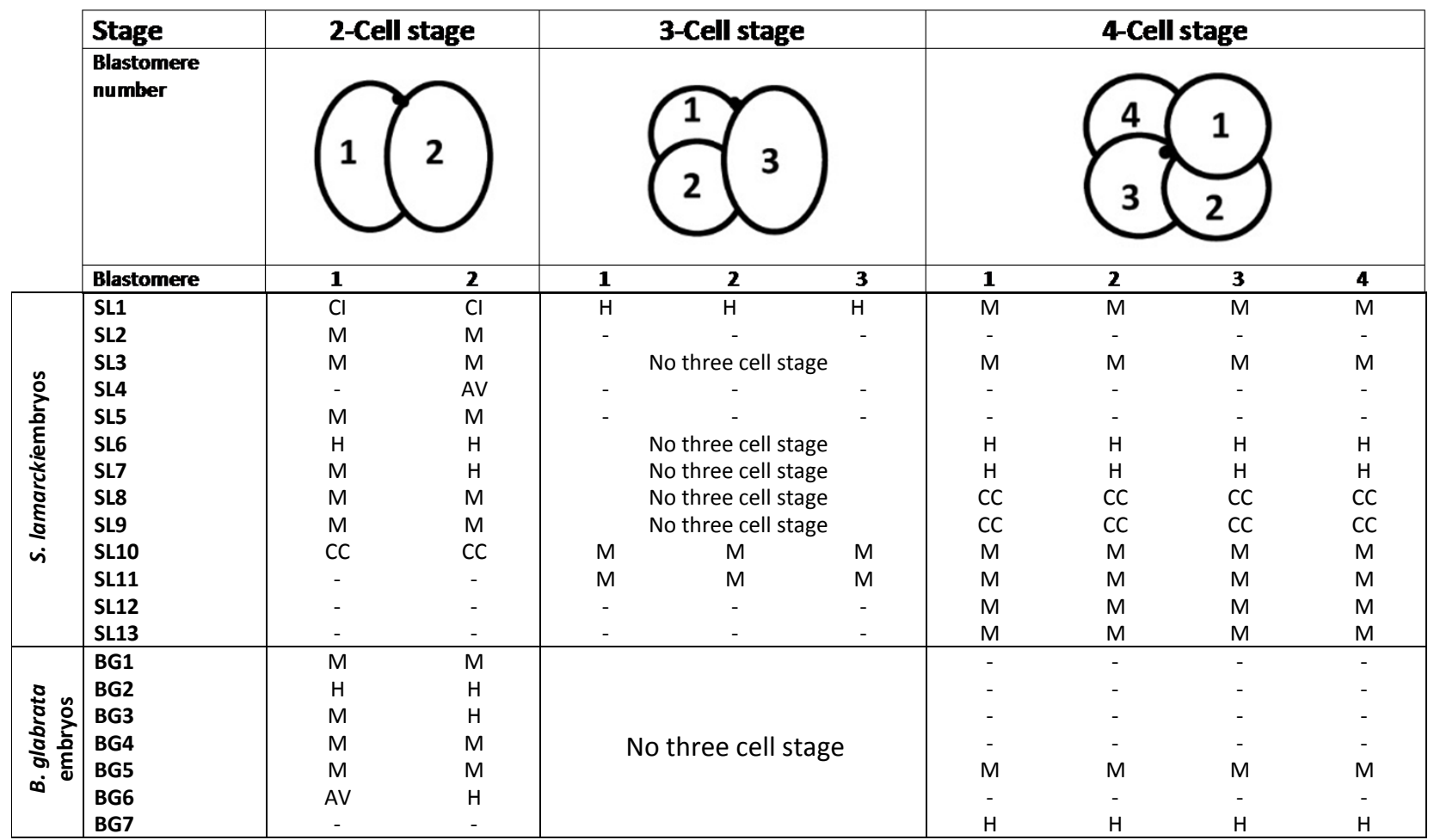


Table 2. Summary of quantification of blastomere vesicle flow phenotypes for $S$. lamarcki and B. glabrata.

\begin{tabular}{|c|c|c|c|c|c|c|}
\hline Species & stage & $\begin{array}{c}\text { Mixed } \\
\text { (M) }\end{array}$ & $\begin{array}{c}\text { Horizontal } \\
\text { (H) }\end{array}$ & $\begin{array}{c}\text { Circular } \\
\text { (CL) }\end{array}$ & $\begin{array}{c}\text { animal- } \\
\text { vegetal } \\
\text { (AV) }\end{array}$ & $\begin{array}{l}\text { Towards } \\
\text { cell centre } \\
\text { (CC) }\end{array}$ \\
\hline \multirow{3}{*}{ S. lamarcki } & $\begin{array}{r}2 \text {-cell } \\
(n=10)\end{array}$ & 7 & 1 & 1 & 0 & 1 \\
\hline & $\begin{array}{l}\text { 3-cell } \\
(n=3)\end{array}$ & 2 & 1 & 0 & 0 & 0 \\
\hline & $\begin{array}{r}4 \text {-cell } \\
(n=10)\end{array}$ & 6 & 2 & 0 & 0 & 2 \\
\hline \multirow[t]{2}{*}{ B. glabrata } & $\begin{array}{l}2 \text {-cell } \\
(n=6)\end{array}$ & 4 & 2 & 0 & 0 & 0 \\
\hline & $\begin{array}{l}\text { 4-cell } \\
(n=2)\end{array}$ & 1 & 1 & 0 & 0 & 0 \\
\hline Total & $(n=31)$ & 20 & 6 & 1 & 1 & 3 \\
\hline
\end{tabular}


Table 1. Quantification of S. lamarcki embryo survival to the trochophore stage. Pearson's chi-square test indicates no significant difference $(p>0.1)$ between survival of embryos that transitioned through a 3-cell stage and those that cleaved synchronously from 2-cell to 4-cell.

\begin{tabular}{lrrrr}
\hline & alive & dead & Total & \% survival \\
\hline Passing via 3-cell & 16 & 31 & 49 & $33 \%$ \\
\hline Direct 2-cell to 4-cell & 26 & 23 & 49 & $53 \%$ \\
\hline Total & 42 & 54 & 96 & $44 \%$ \\
\hline
\end{tabular}


Supplementary file 1

Namigai \& Shimeld

Contents

Page

Introduction to supplementary file 1

Spirobranchus lamarcki 2-Cell embryos

Embryo SL1.

Embryo SL2

Embryo SL3

Embryo SL4

Embryo SL5

Embryo SL6

Embryo SL7

Embryo SL8

Embryo SL9

Embryo SL10.

Spirobranchus lamarcki 3-Cell embryos

Embryo SL1

Embryo SL11

Embryo SL10

Spirobranchus lamarcki 4-Cell embryos

Embryo SL1

Embryo SL3

Embryo SL12

Embryo SL13.

Embryo SL6

Embryo SL7.

Embryo SL8

Embryo SL9

Embryo SL11

Embryo SL10

Biomphalaria glabrata 2-Cell embryos

Embryo BG1

Embryo BG2

Embryo BG3

Embryo BG4

Embryo BG5

Embryo BG6

Biomphalaria glabrata 4-Cell embryos

Embryo BG5

Embryo BG7 


\section{Introduction to supplementary file 1}

This file contains summary diagrams for PIV and particle tracking analysis for each embryo imaged by light sheet microscopy. Note each embryo has a unique identifier (SL1, SL2, BG1 etc.) where the letters indicate Genus and species. The same embryo may appear more than once if it was analysed over successive stages.

Each page gives summary data for one embryo at one stage, with stage and orientation indicated by the schematic embryos at the top of each page. For each a single image form the recording is shown, plus a diagram with polar body position indicated to allow orientation. Diagrams in the first panel are PIV analyses. The number of diagrams varies between embryos depending on the length of the time window we were able to analyse. In some instances two series of PIV diagrams are presented, labelled 1 and 2 . These are temporally sequential, with 1 occurring before 2 , and are separated as analysis was interrupted by a period during which data quality dropped below the threshold needed for PIV analysis. In some cases were not able to extract data for all blastomeres present; in such instances the missing blastomere is represented by a white $\mathrm{X}$.

Below this are the summaries of the particle tracking analyses. Schematic embryos above indicate by hatched lines the blastomere analysed in the diagrams below. Each blastomere has been divided into four quadrants as indicated by the dashed lines, and the summary diagrams below reflect analysis in each quadrant, laid out in the same way. For some embryos one or more quadrants failed to yield analysable data, most likely due to weak fluorescence in that area and/or the angle at which the embryo lay. In such cases the respective diagram is missing and replaced by a black X.

At the bottom of each page is our categorisation of the inferred type of movement, as further discussed and presented in the main paper. The types of movement identified are:

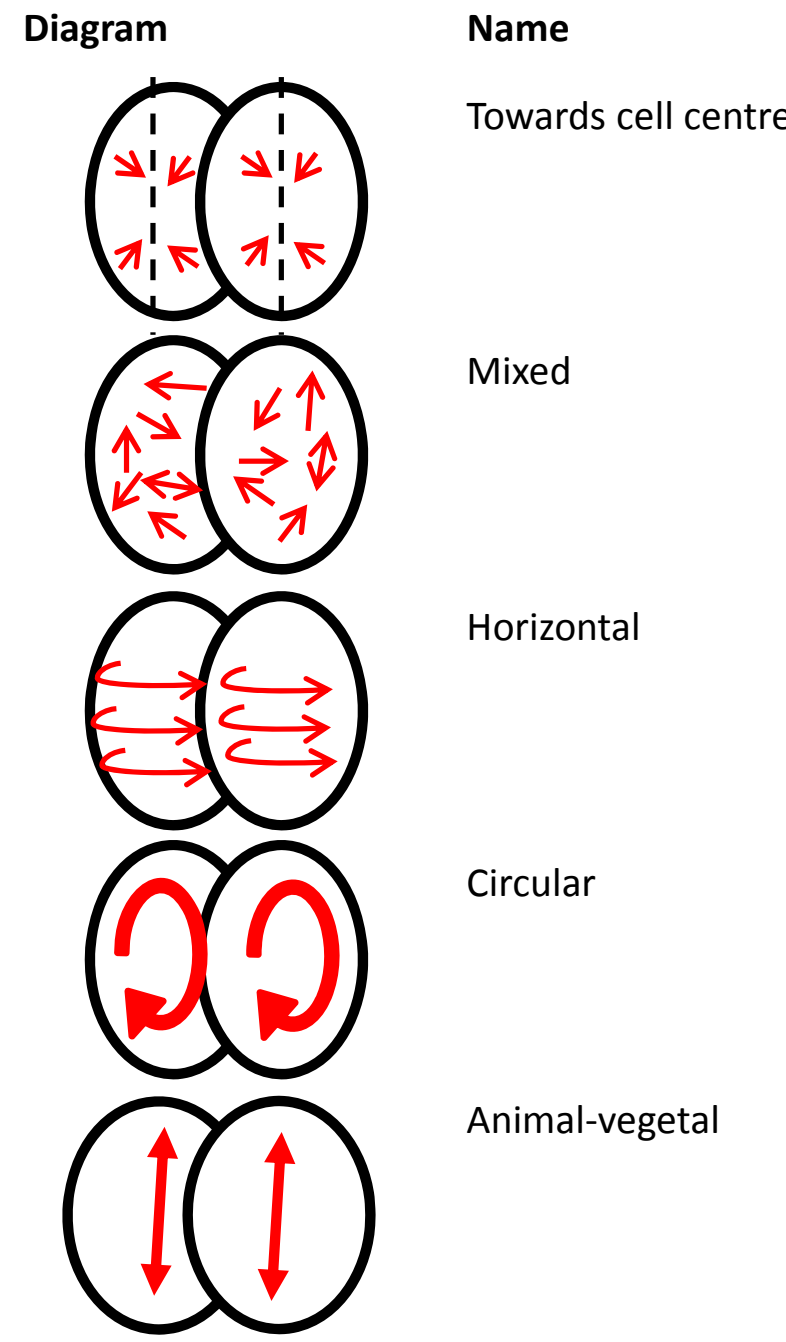

\section{Description}

Movement primarily directed towards the centre of the blastomere.

No obvious generalisation of movement possible. directions

Movement circular around animal vegetal axis. May be chiral.

Movement primarily 'vertical' (ie along animal-vegetal axis) in one or both directions 

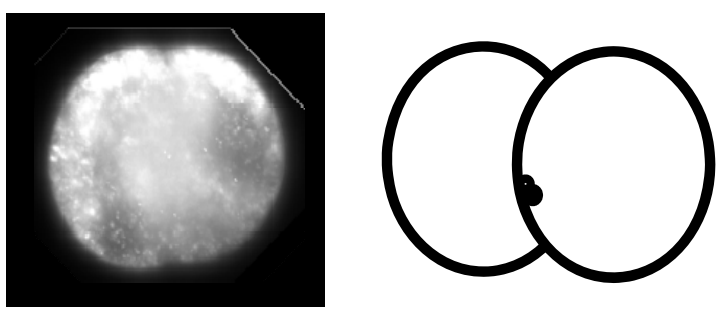

Spirobranchus 2-cell

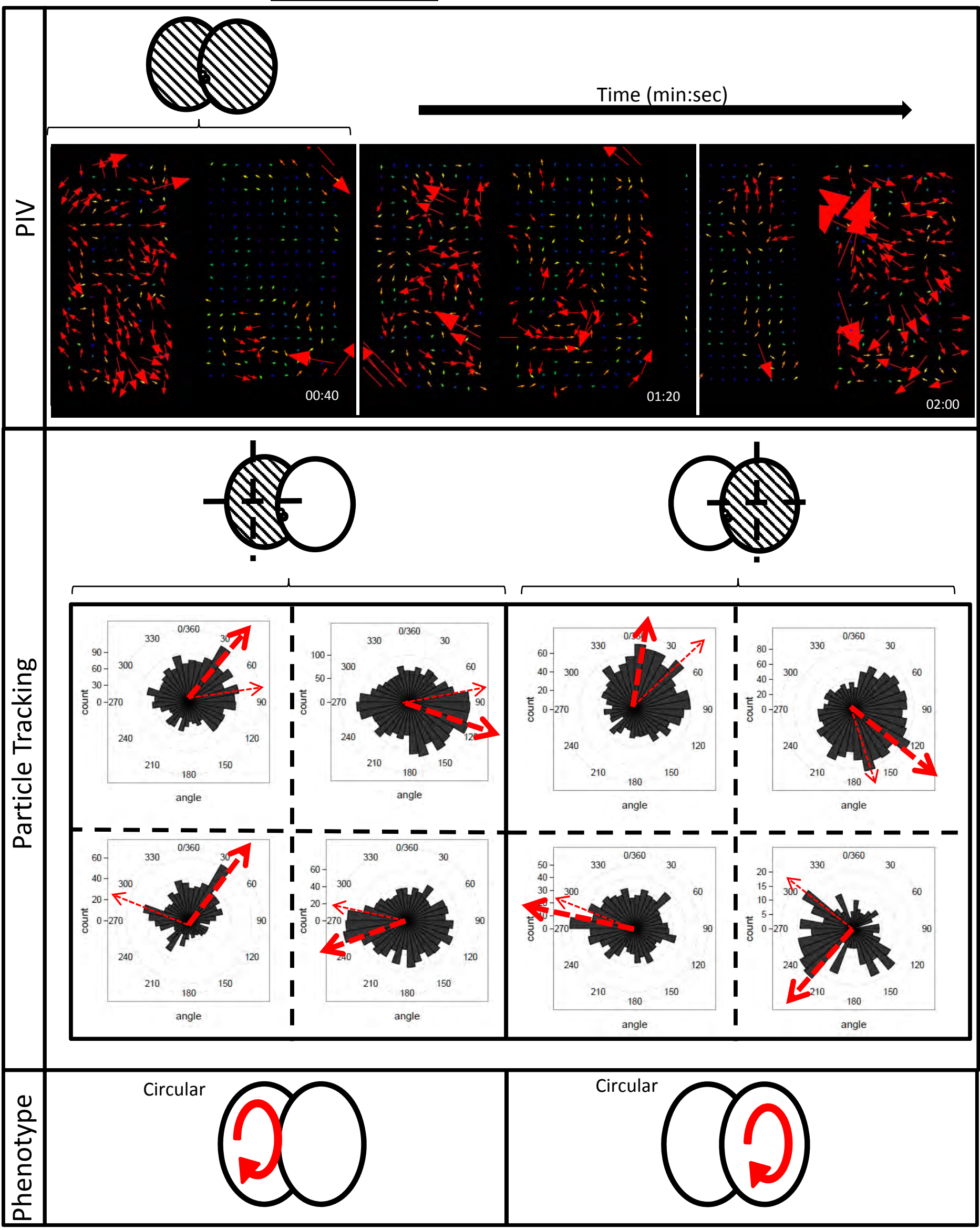



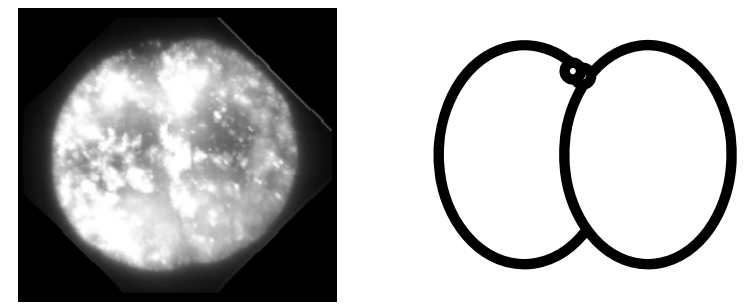

Spirobranchus 2-cell

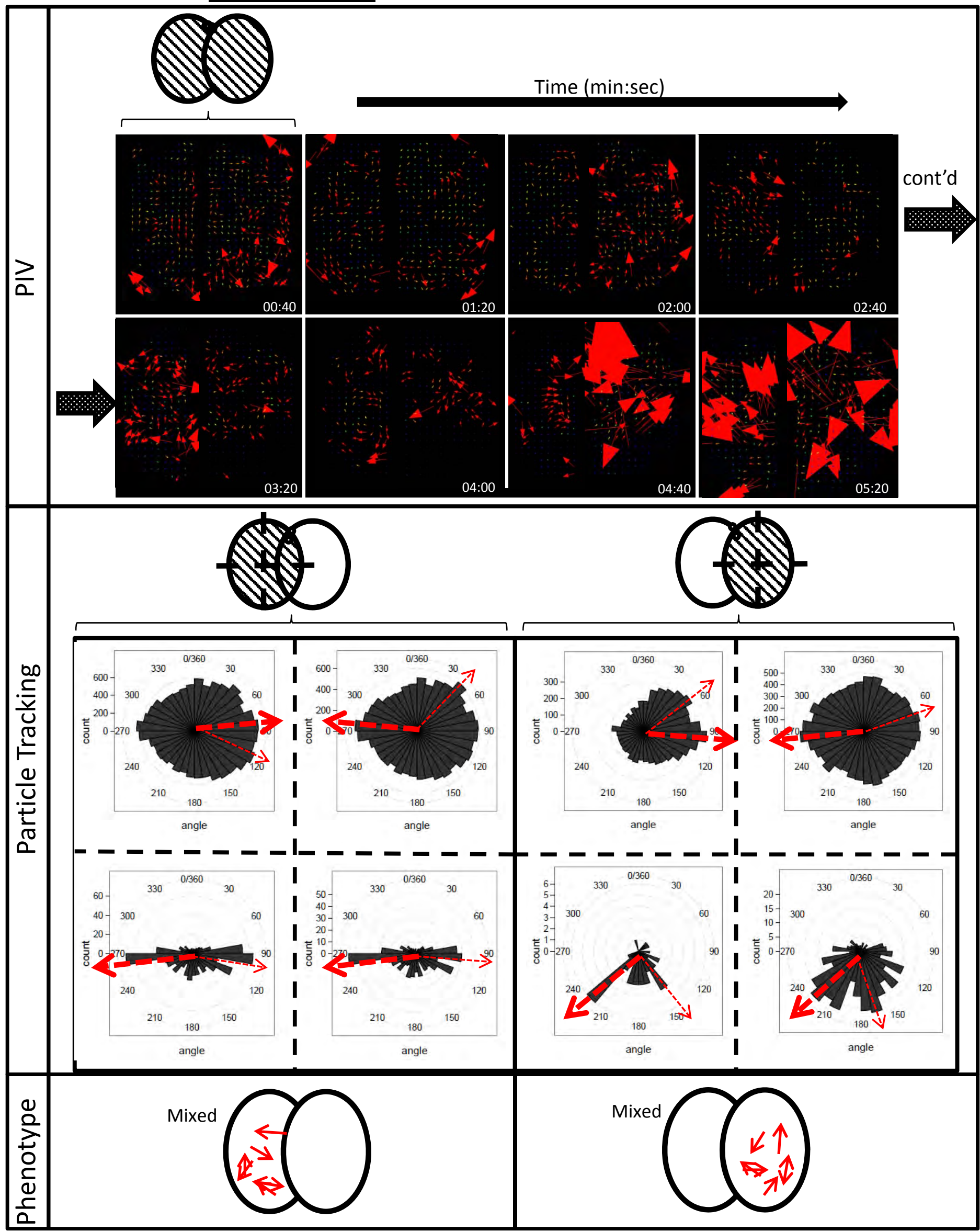



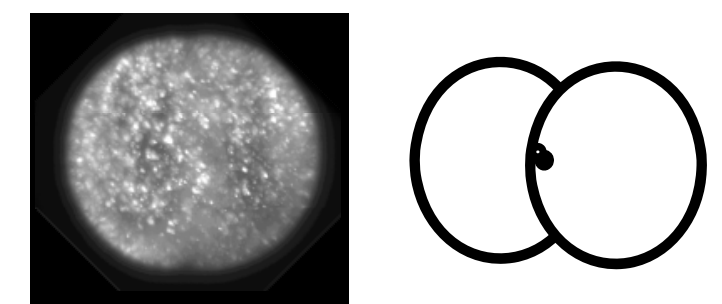

Spirobranchus 2-cell

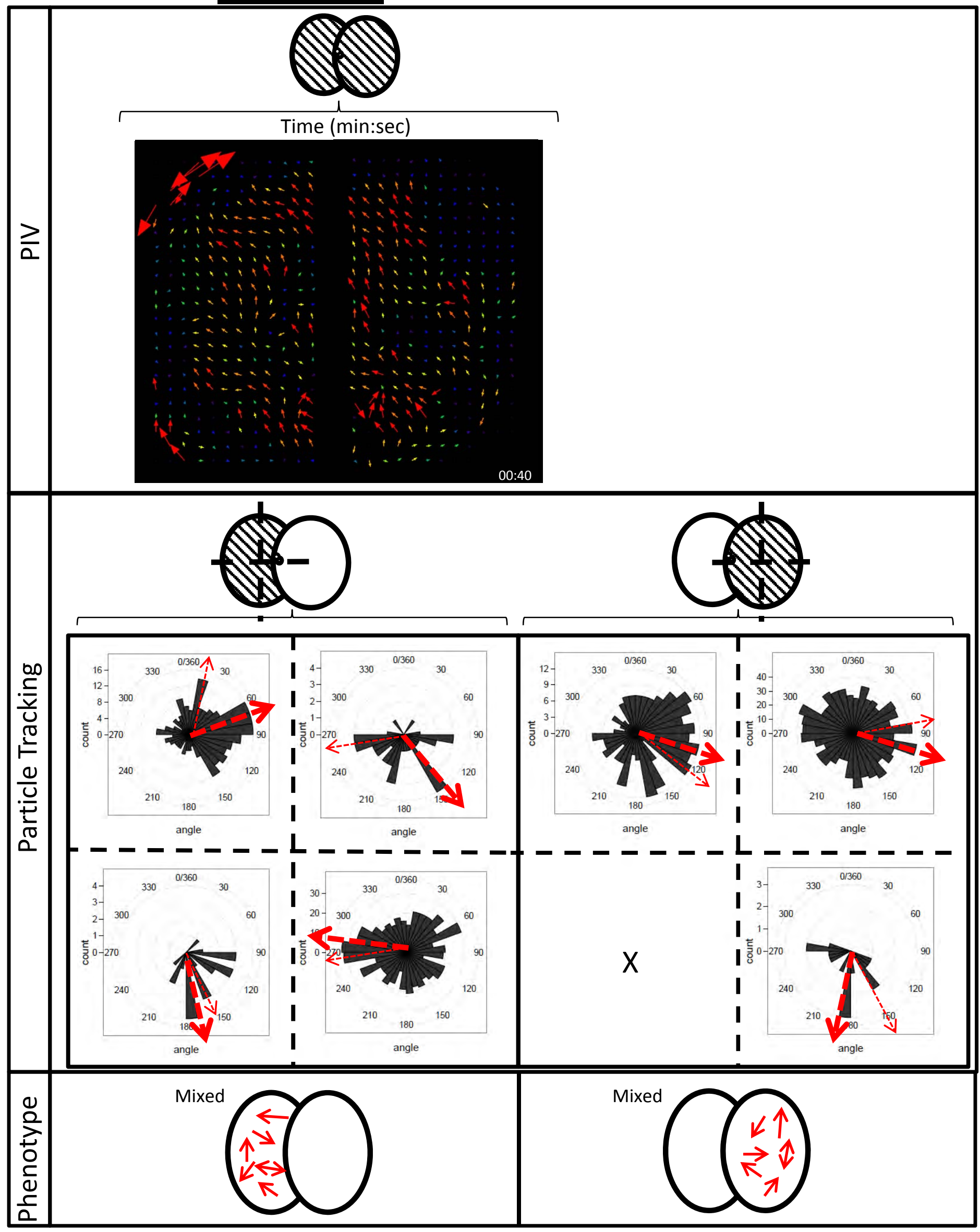



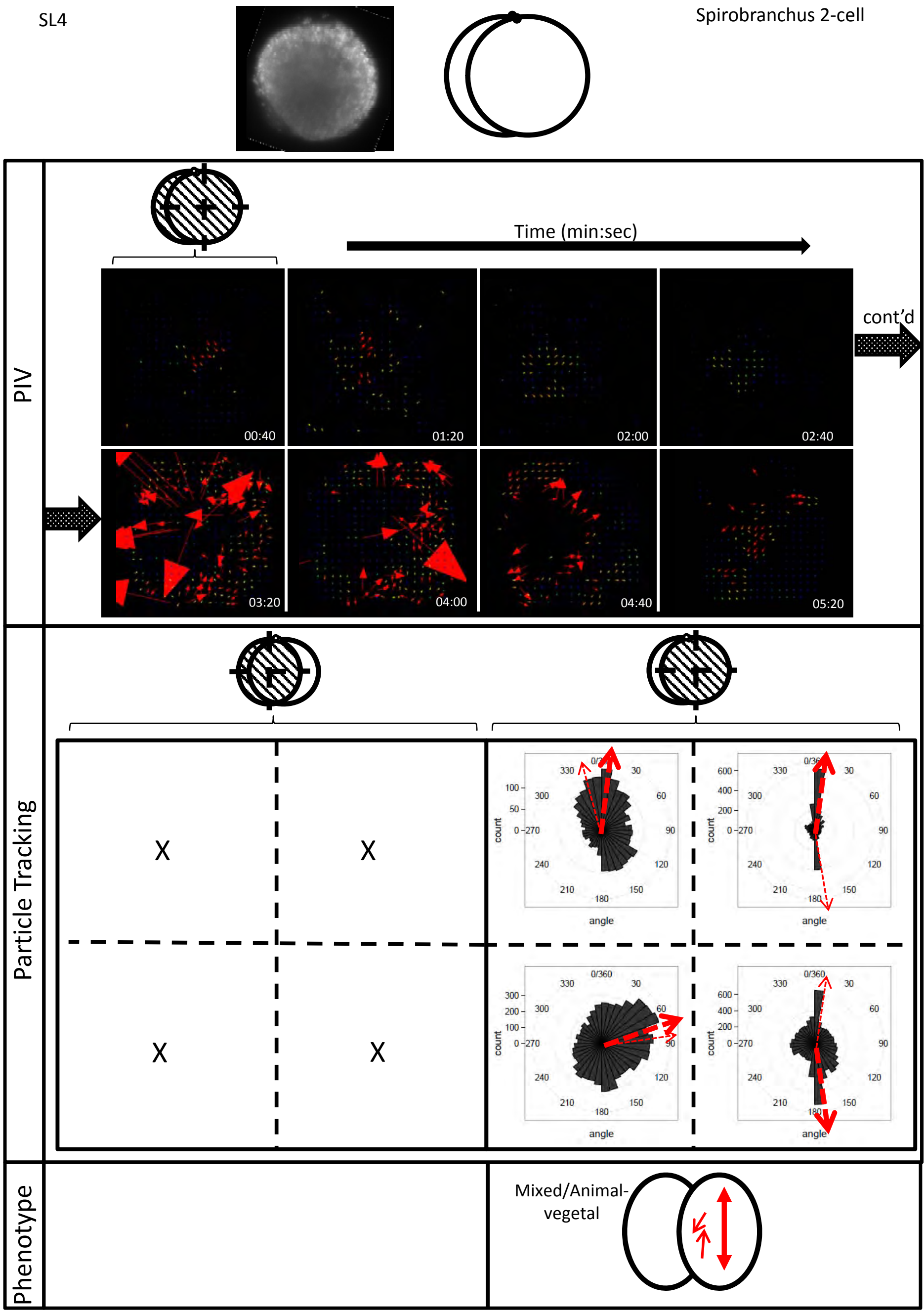


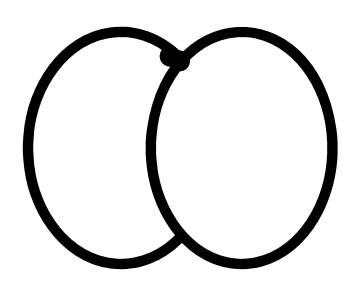

Spirobranchus 2-cell

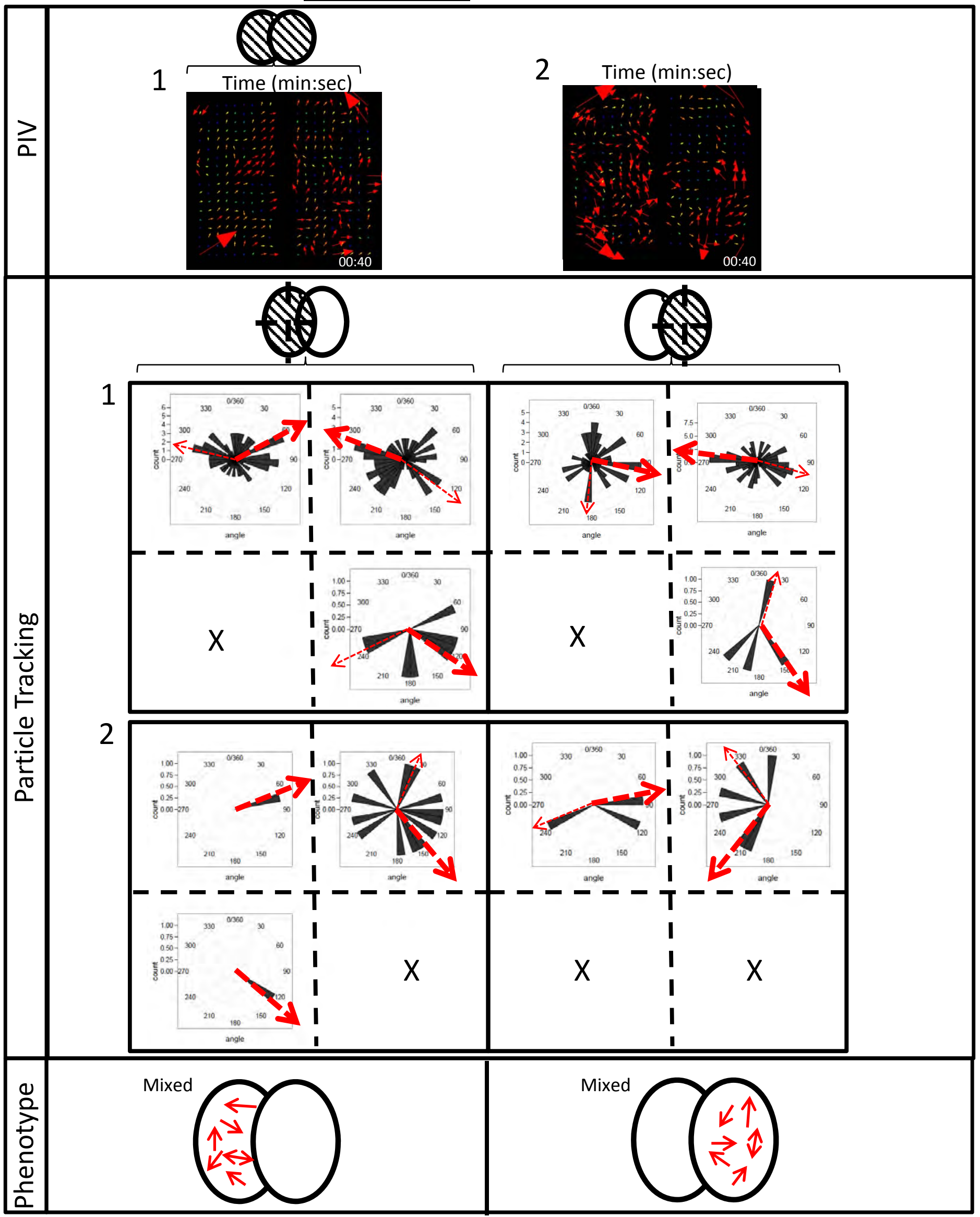




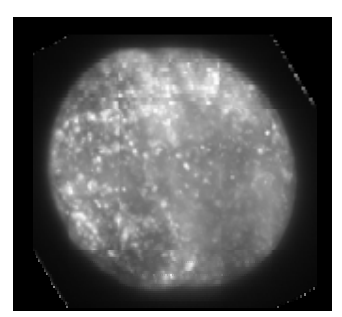

Spirobranchus 2-cell
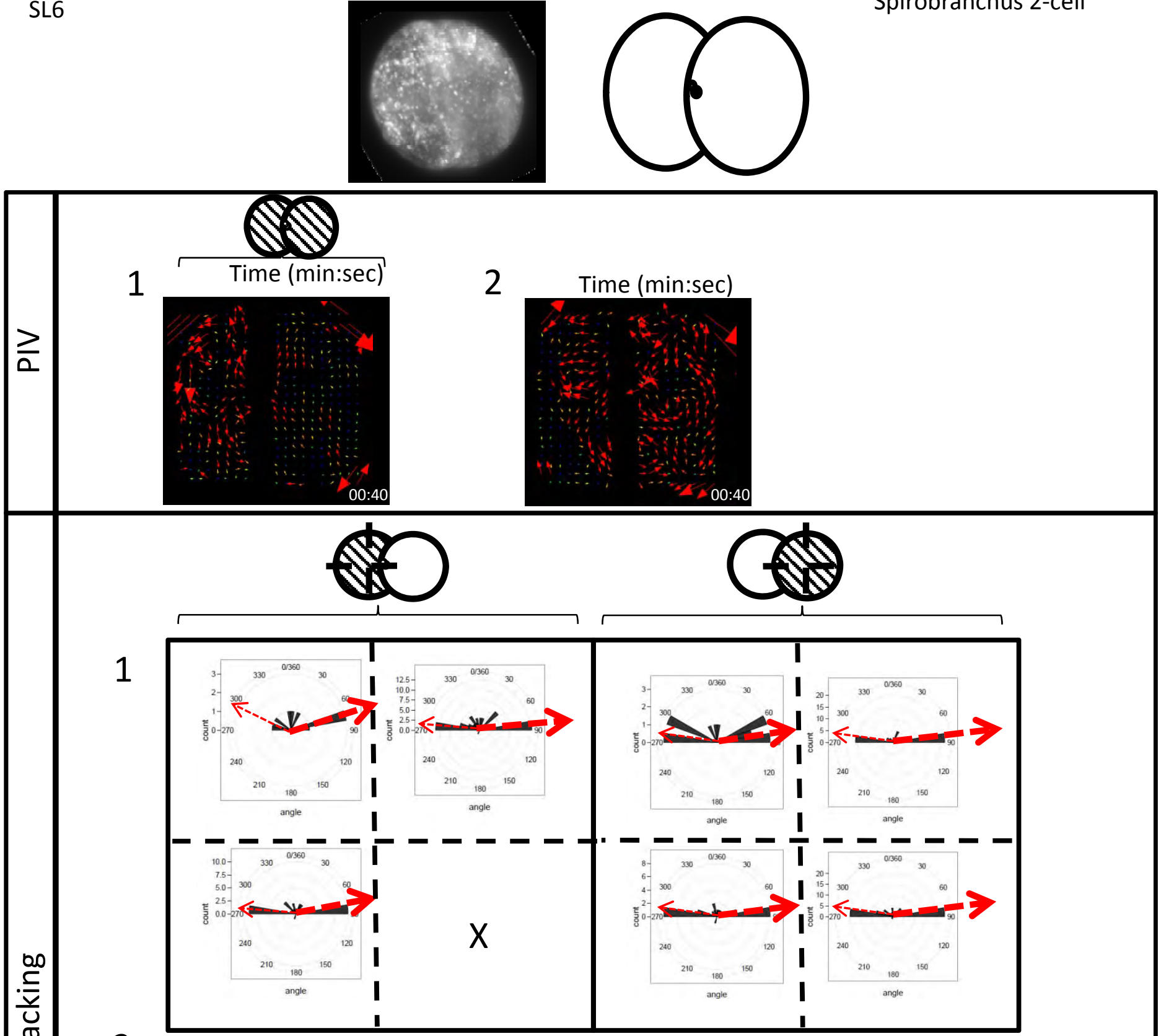

2

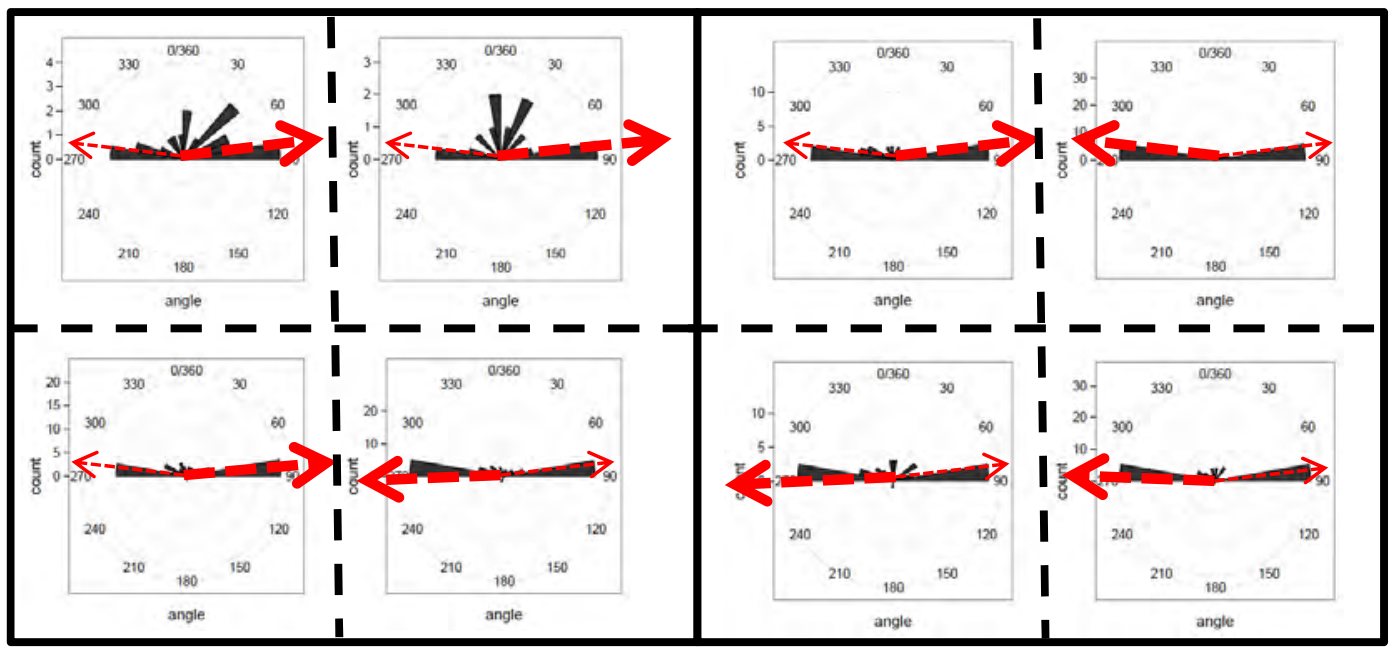

\begin{tabular}{c}
0 \\
$\frac{0}{2}$ \\
$\frac{0}{0}$ \\
$\frac{0}{0}$ \\
$\frac{1}{\alpha}$ \\
\hline
\end{tabular}

Horizontal

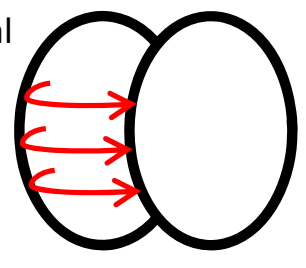

Horizontal

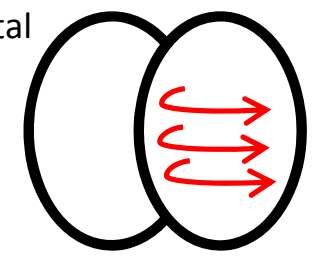



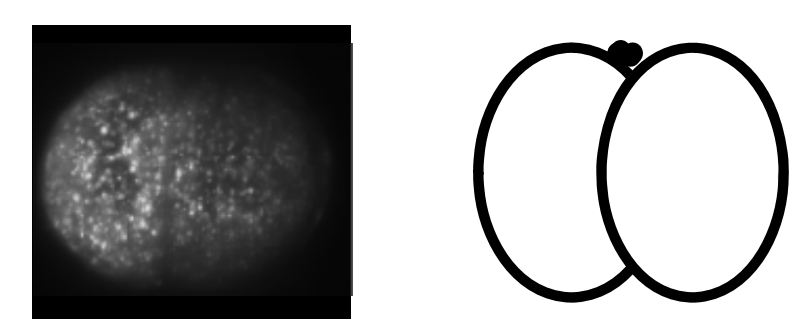

Spirobranchus 2-cell

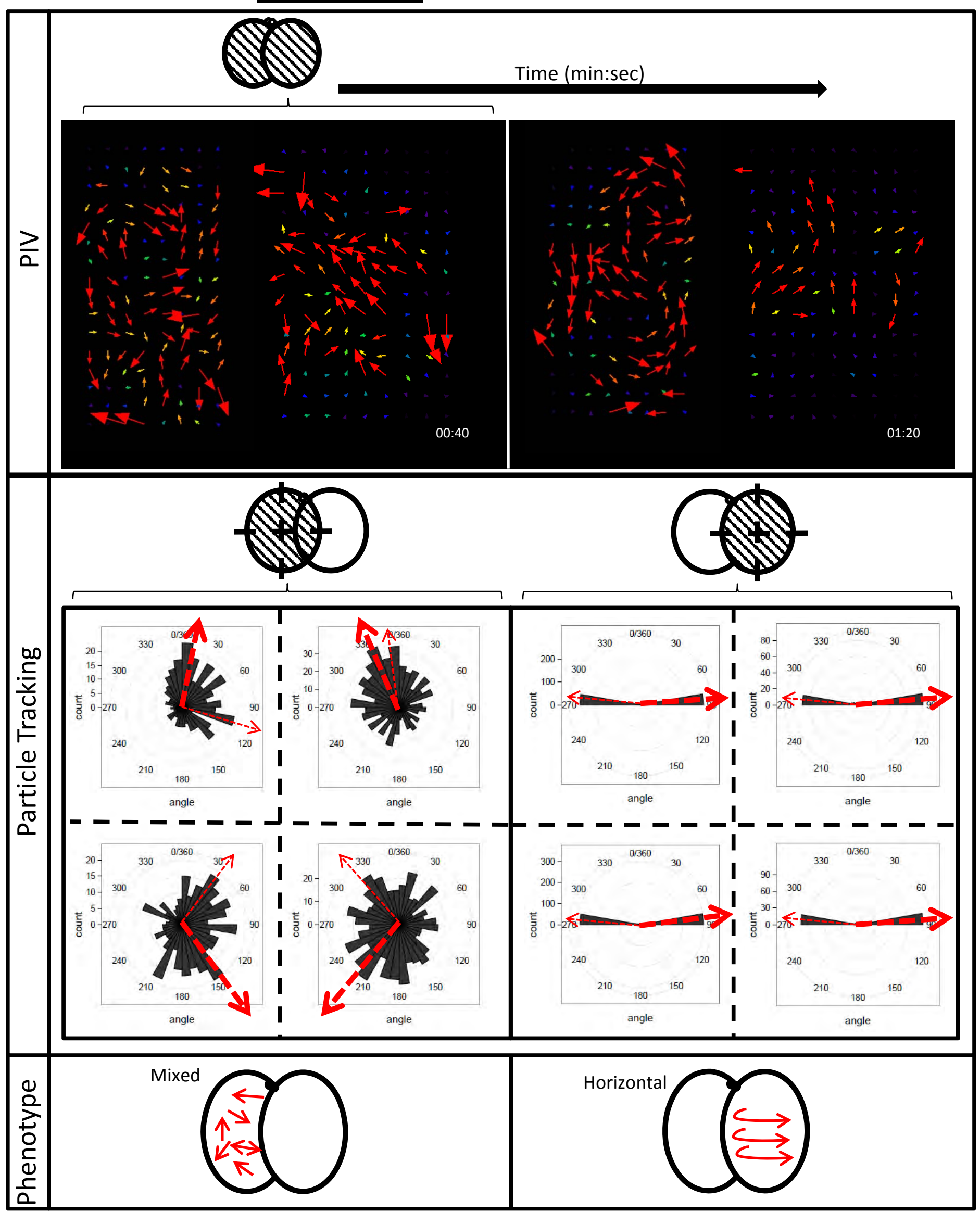



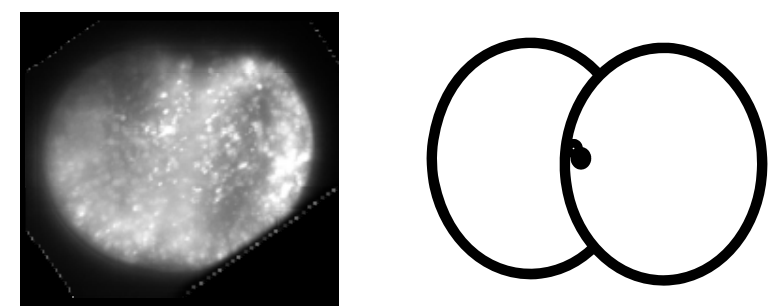

Spirobranchus 2-cell

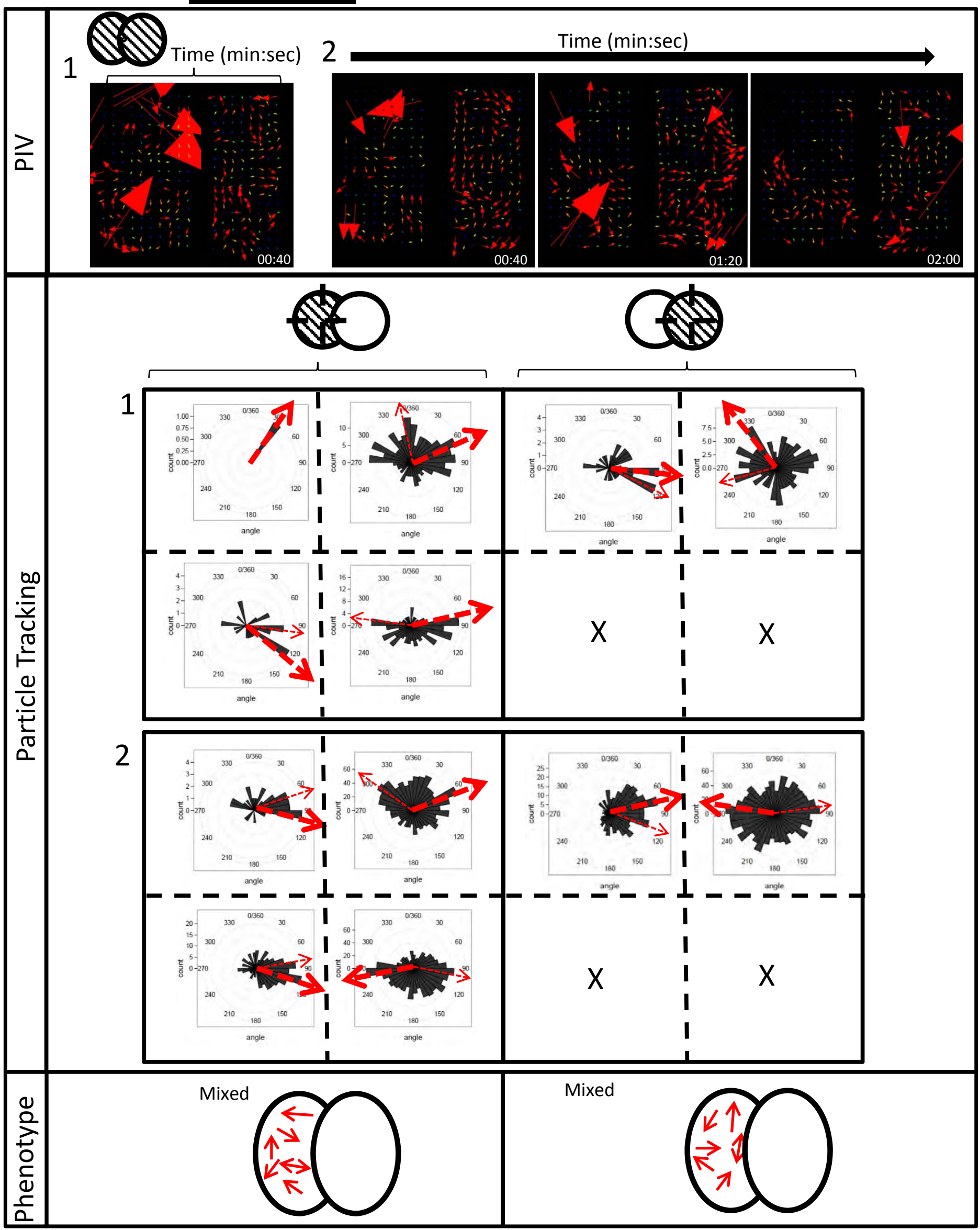



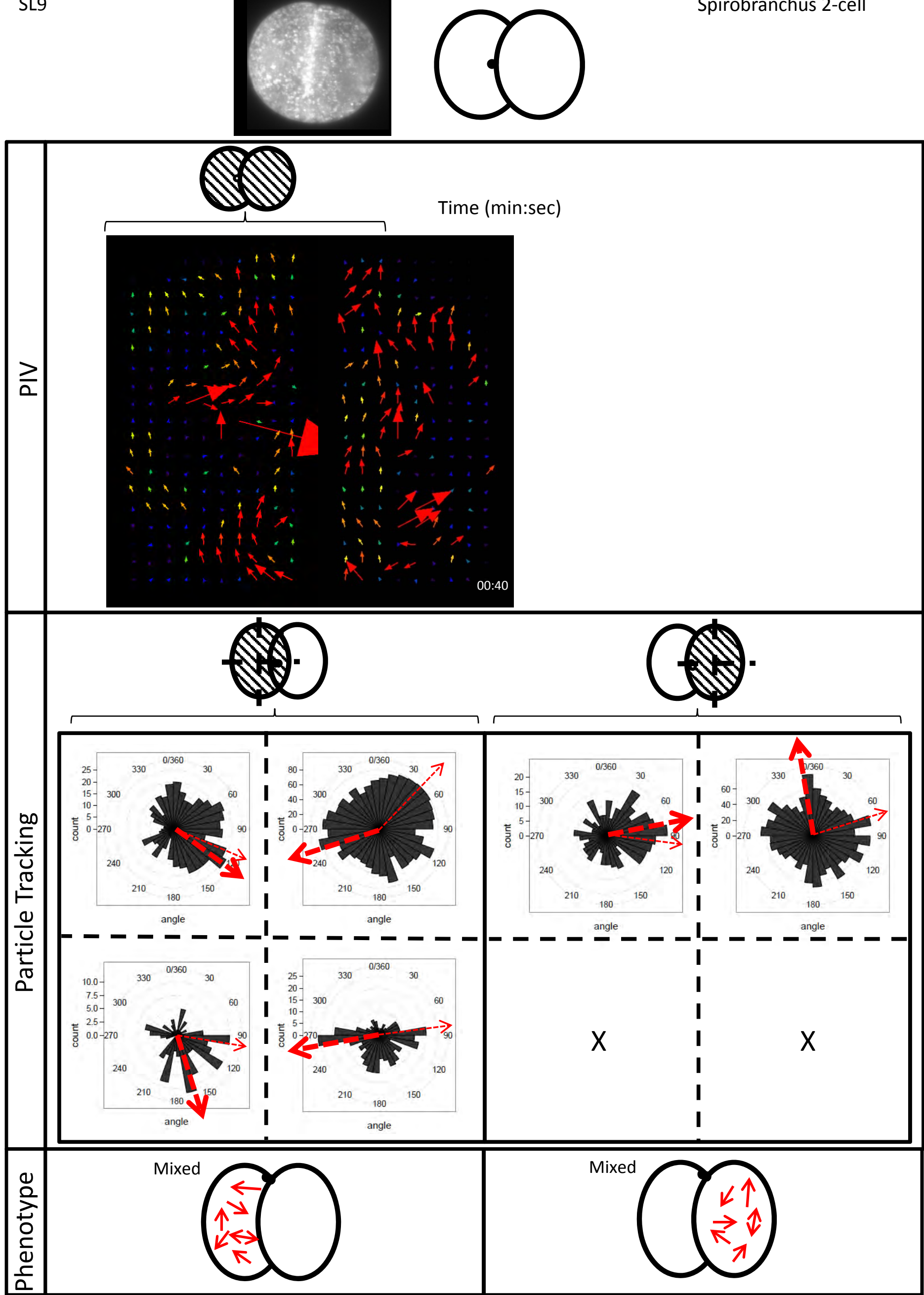

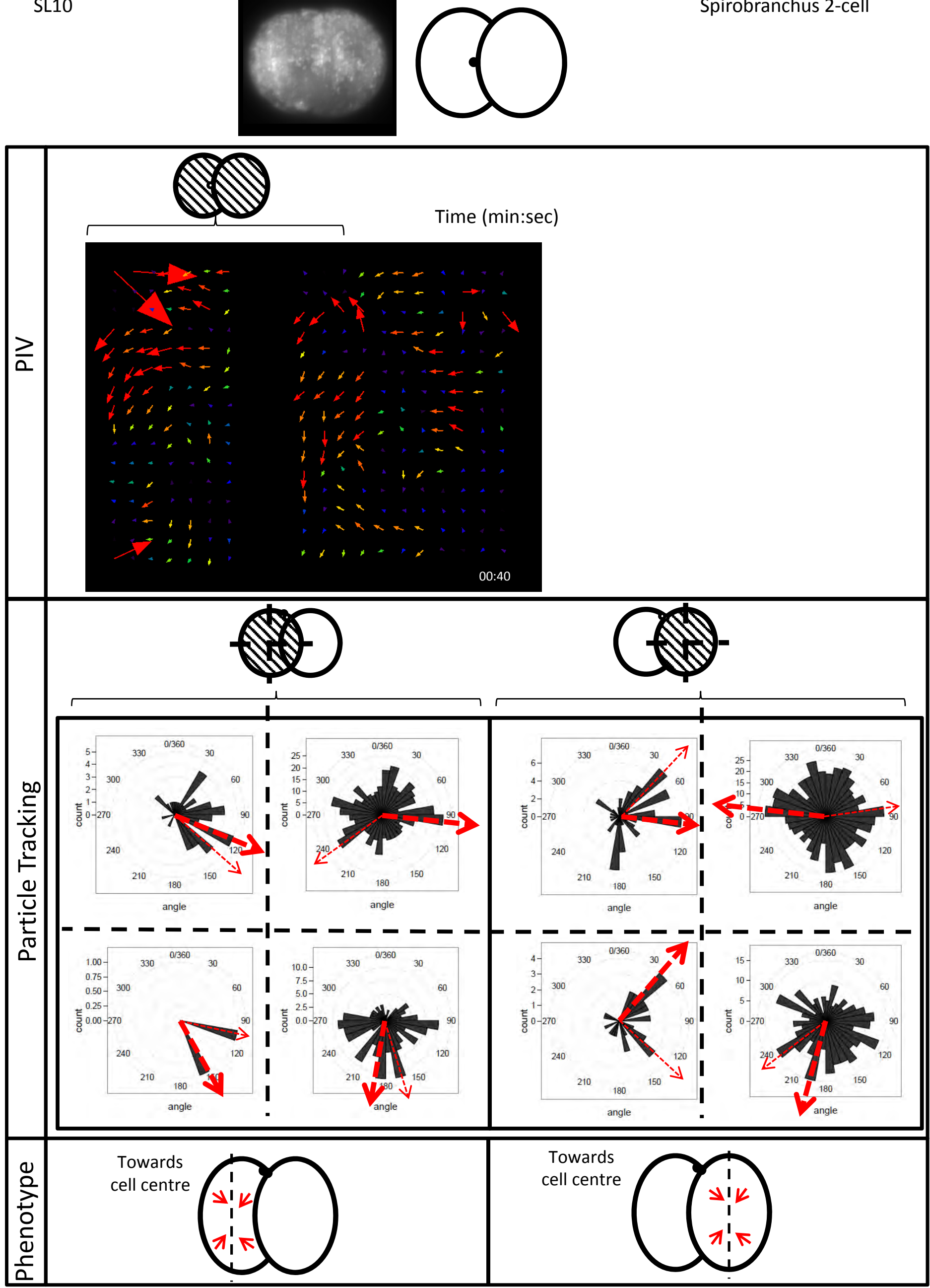

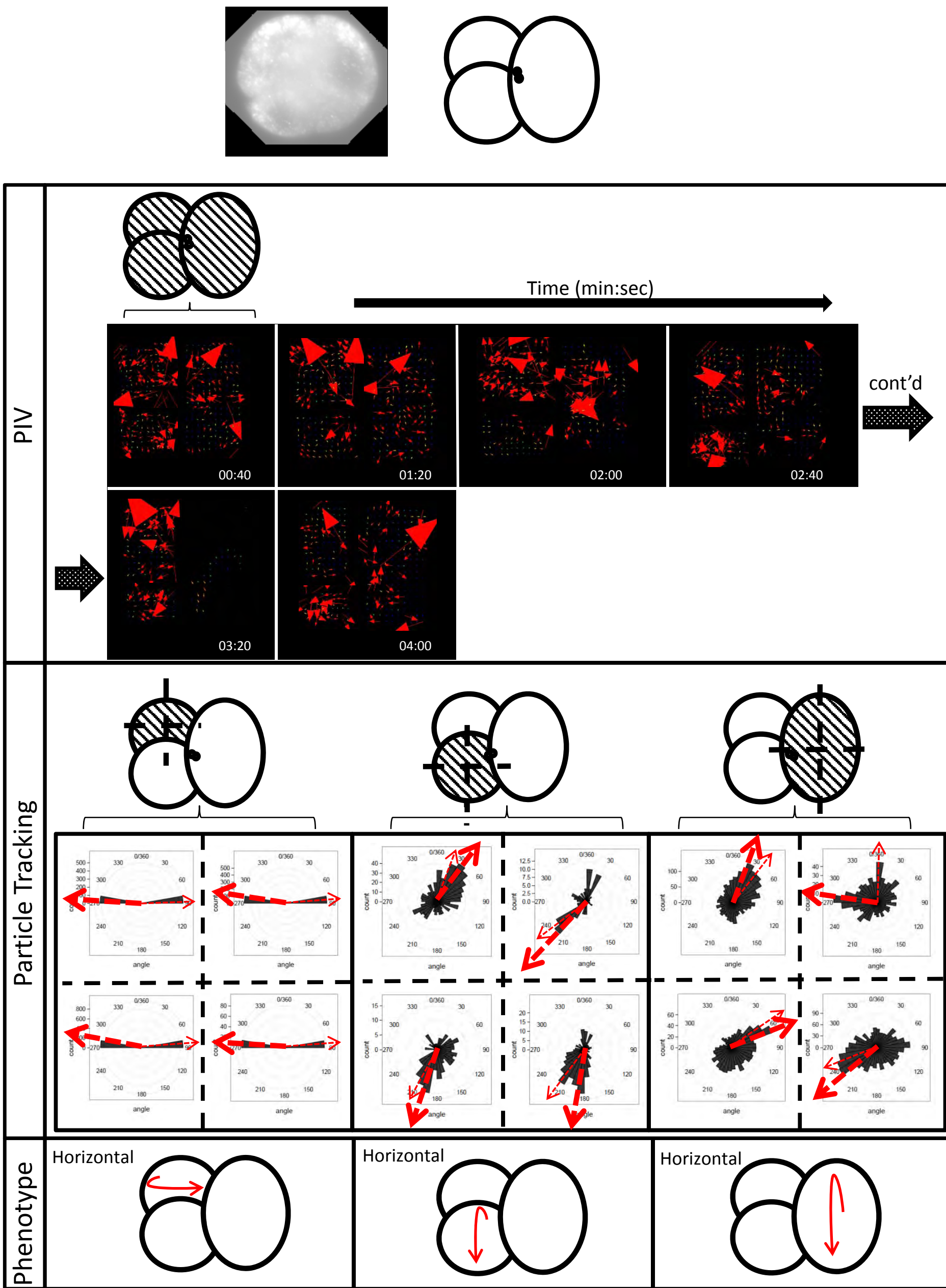

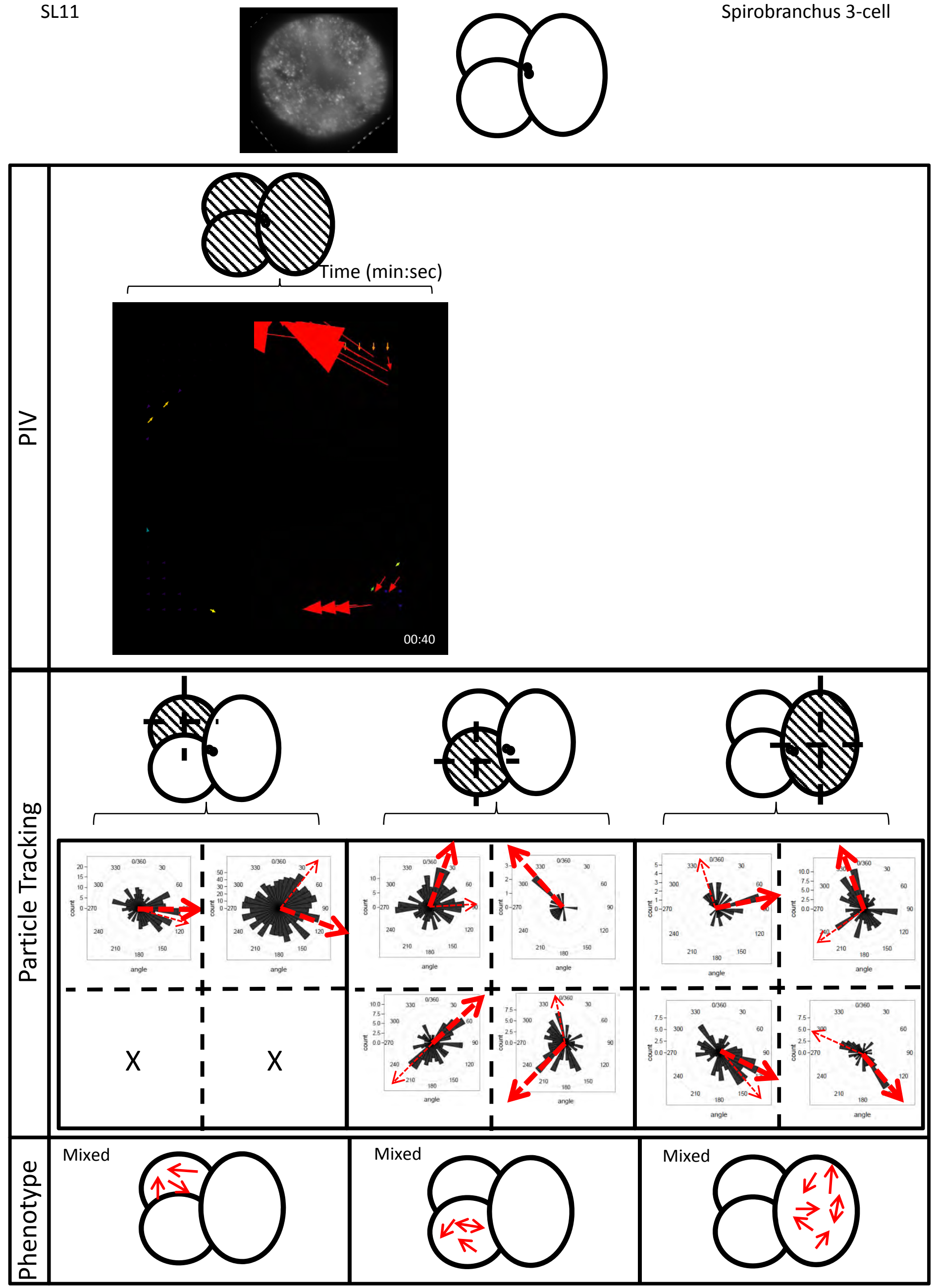

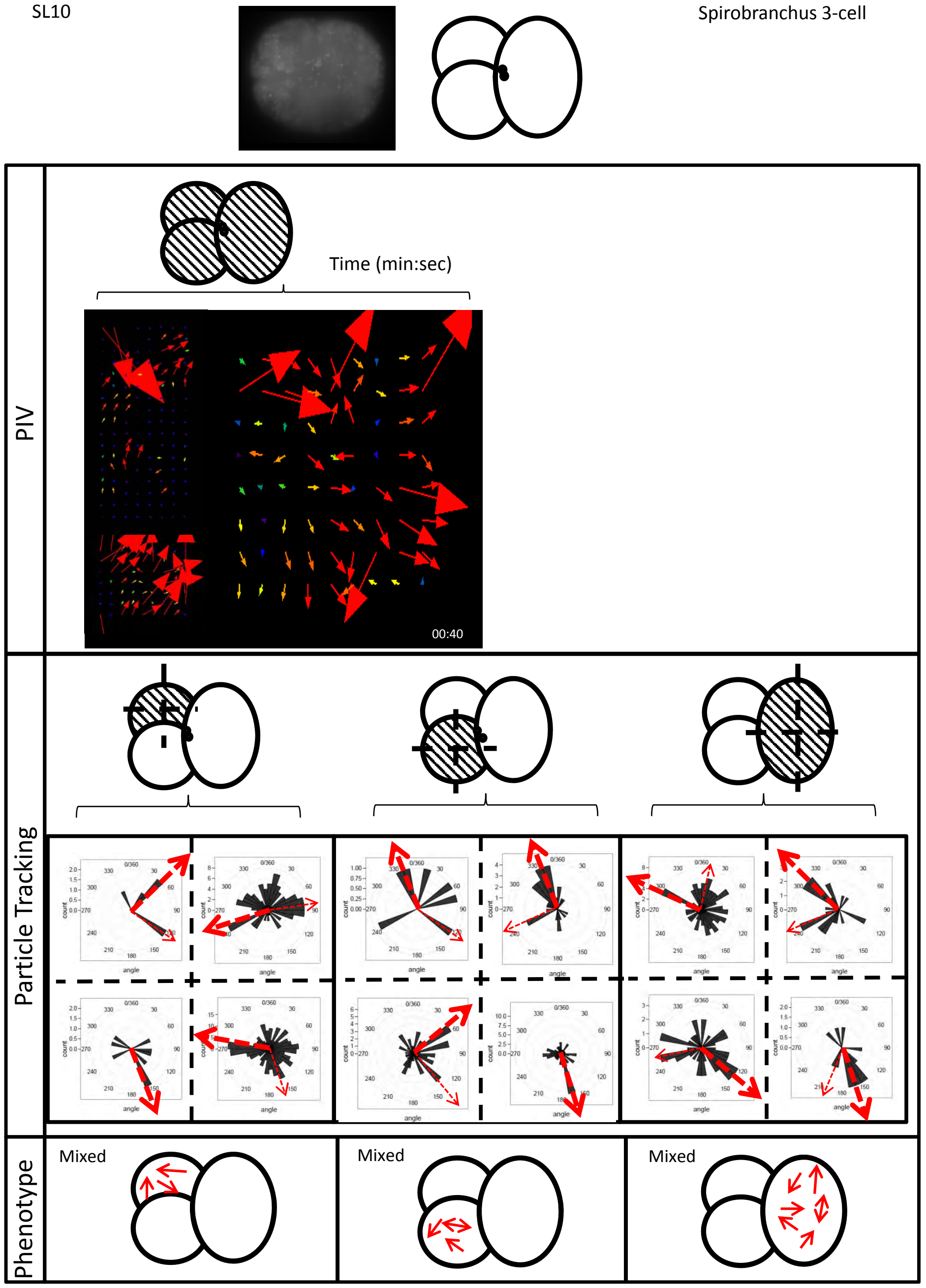

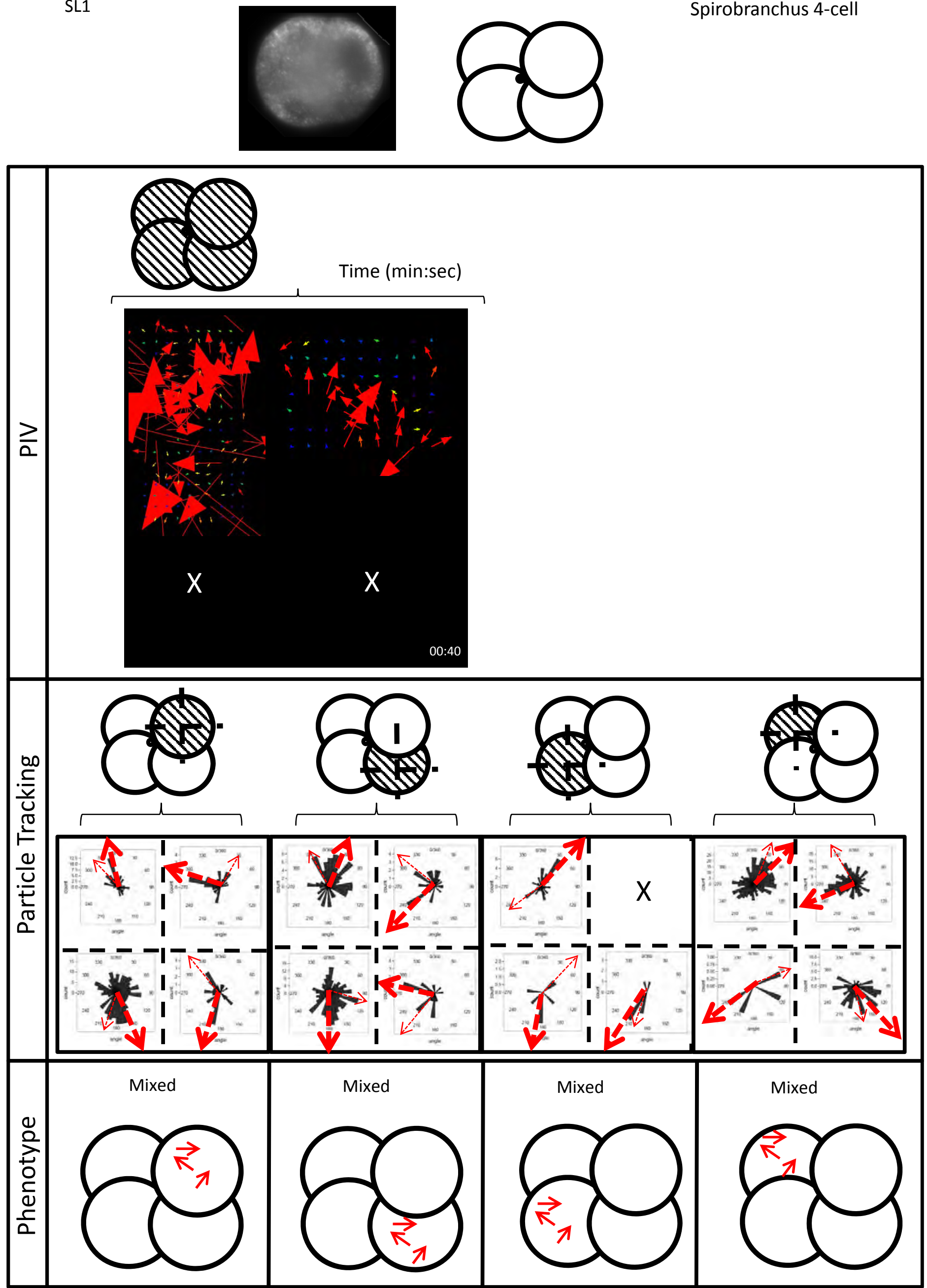

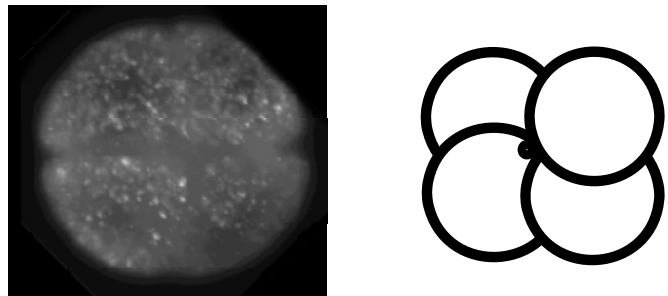

Spirobranchus 4-cell

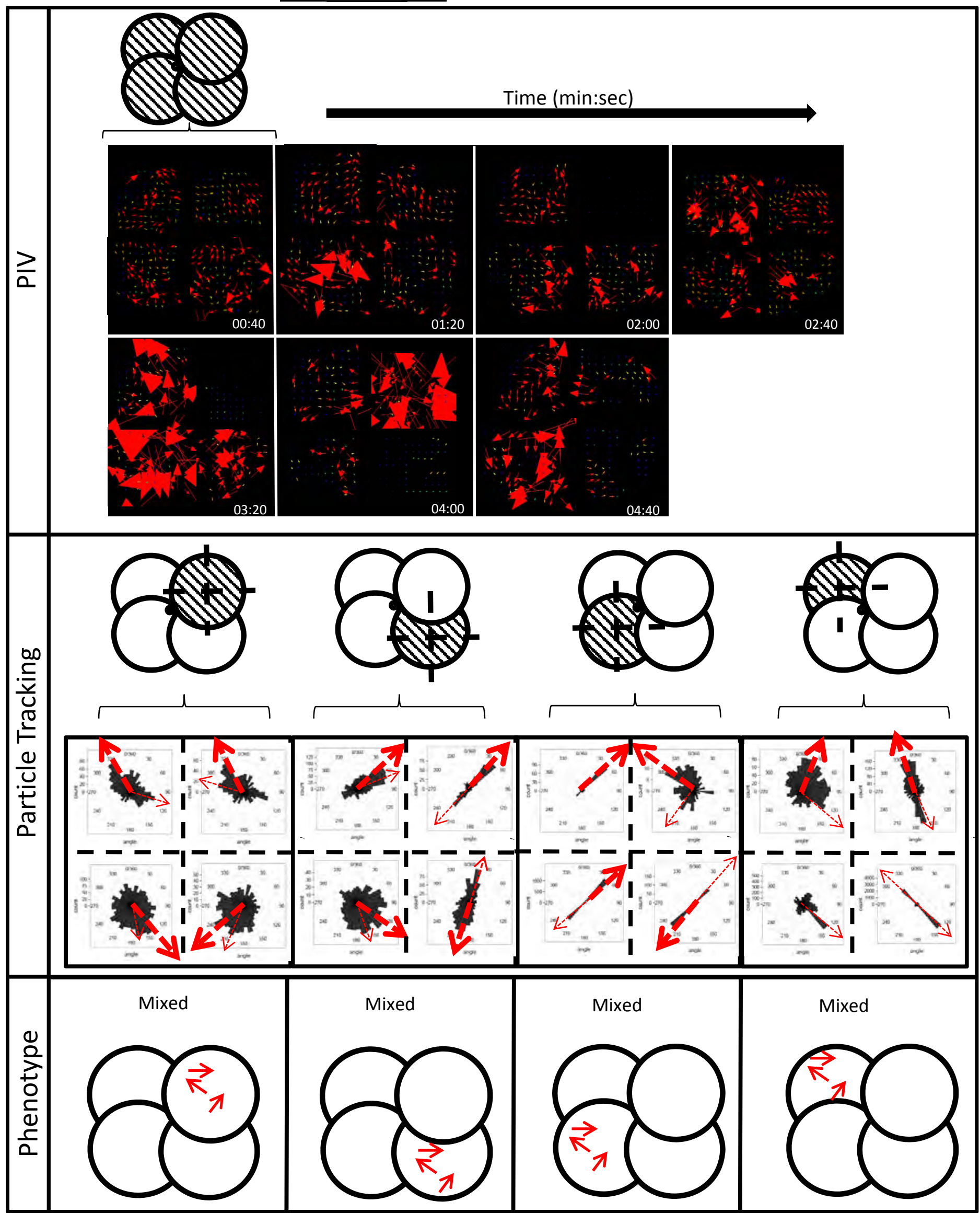




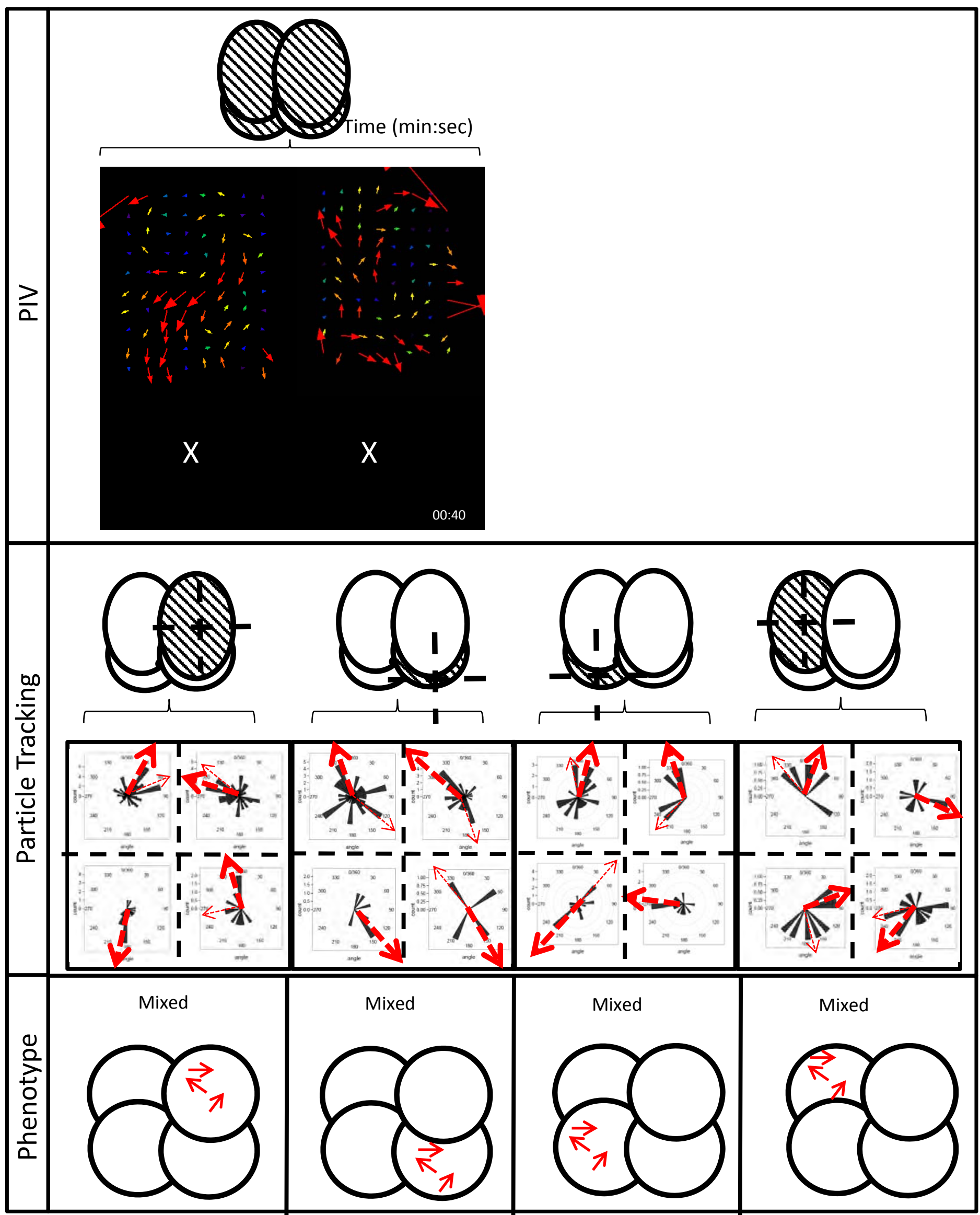



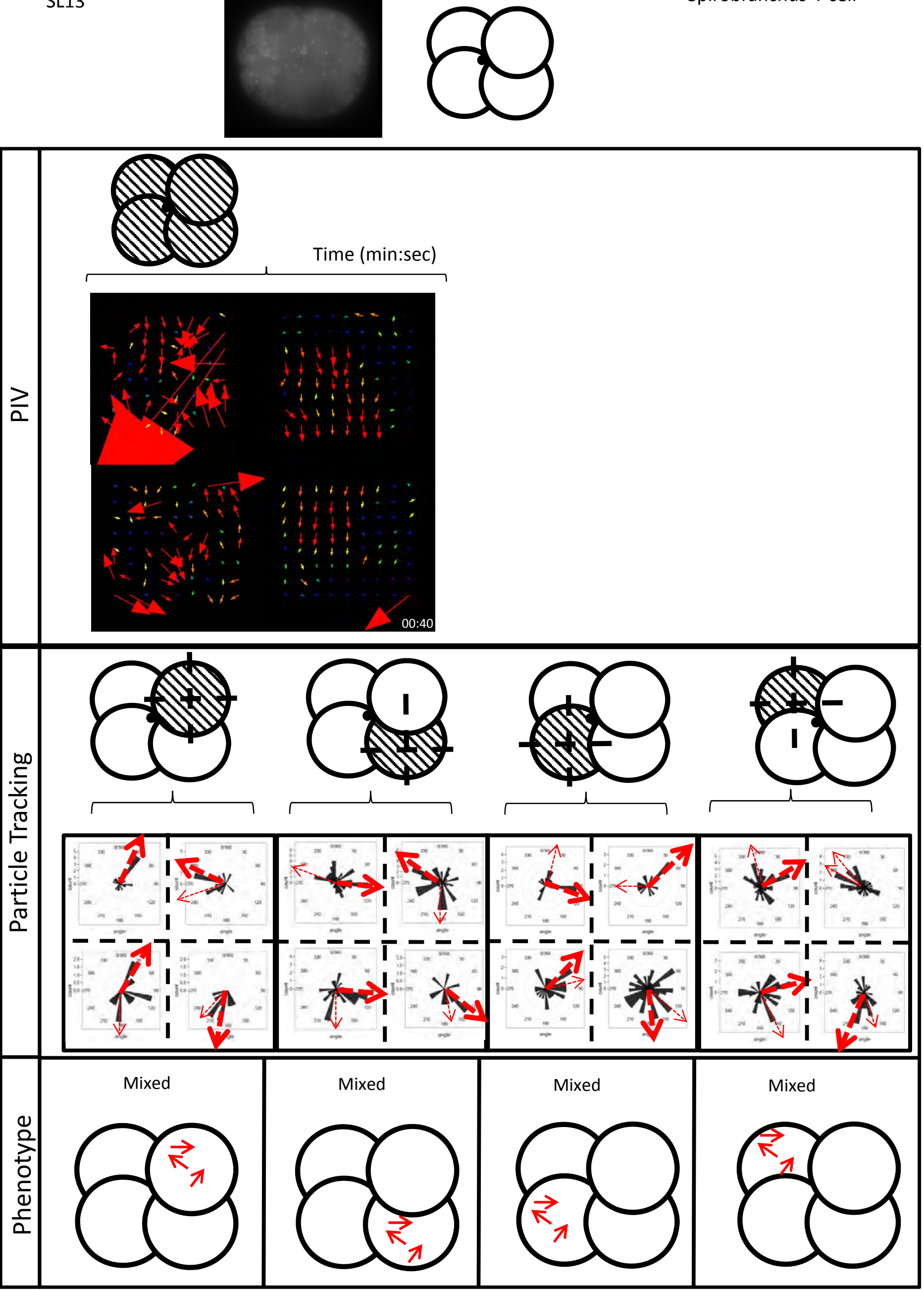
SL6

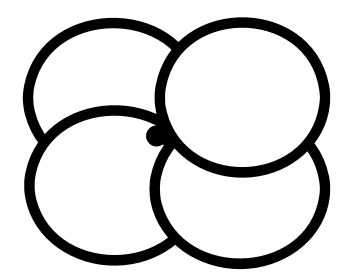

Spirobranchus 4-cell

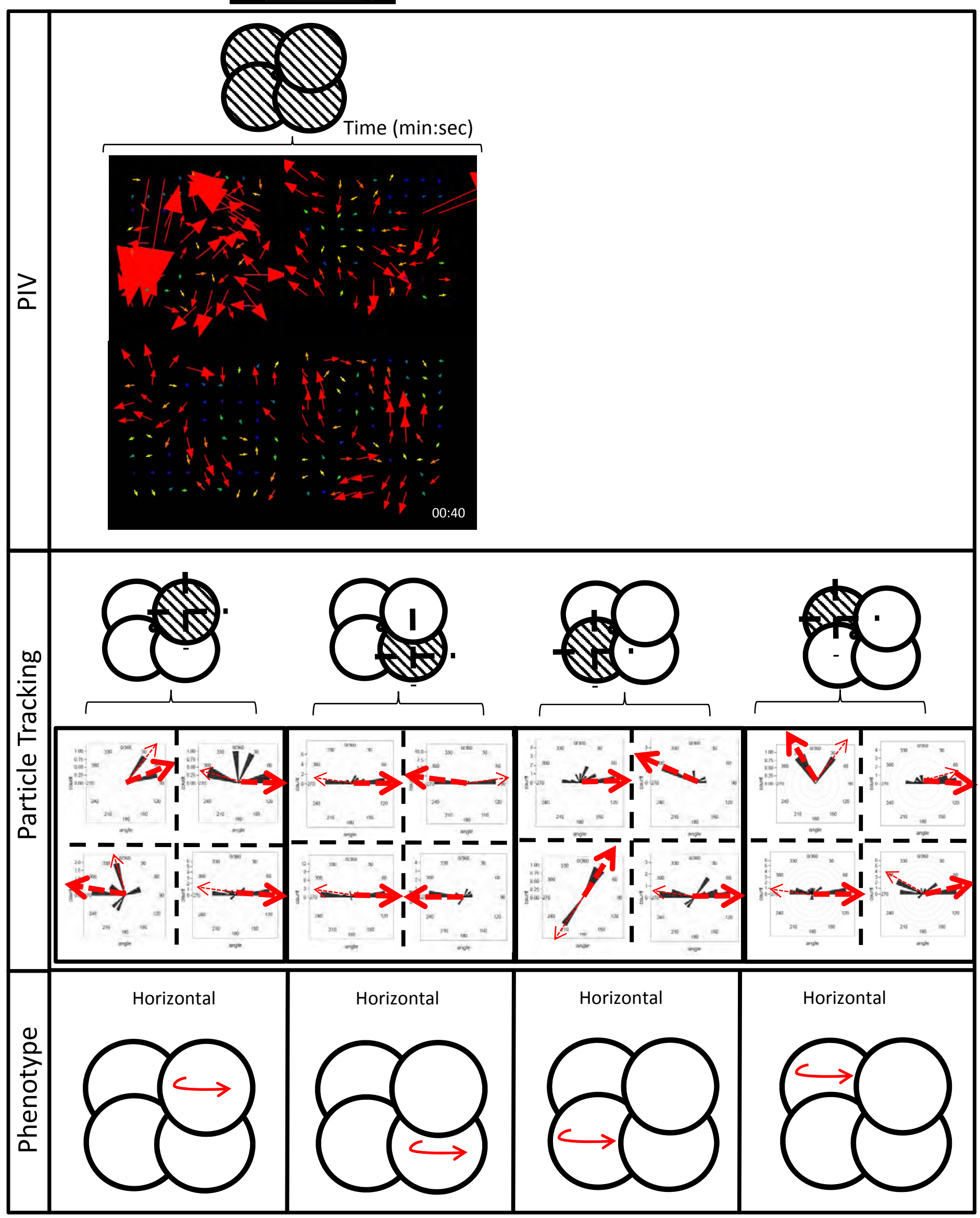

Namigai \& Shimeld 

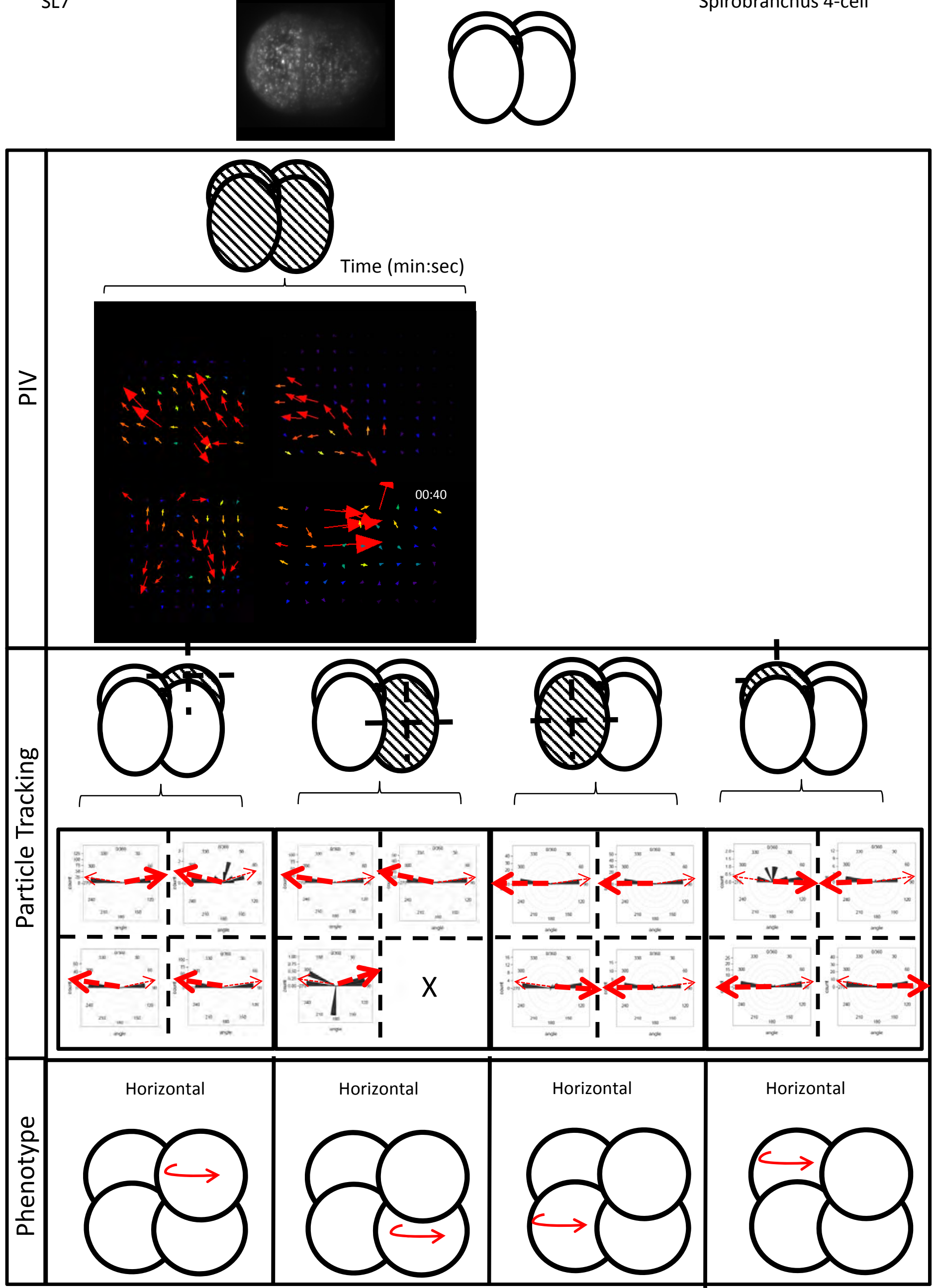

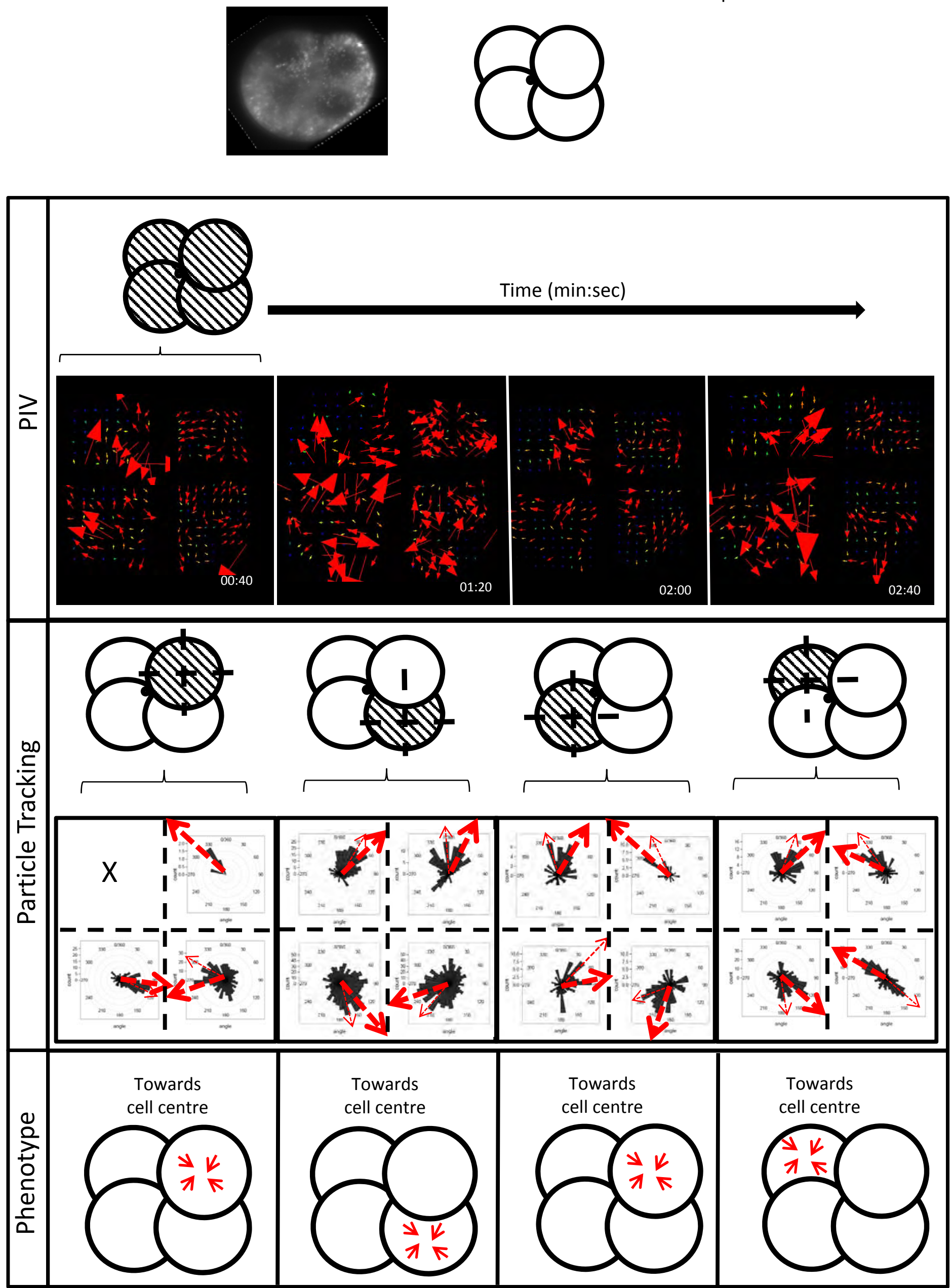


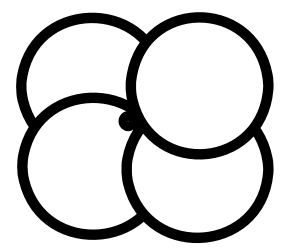

\section{Time (min:sec)}

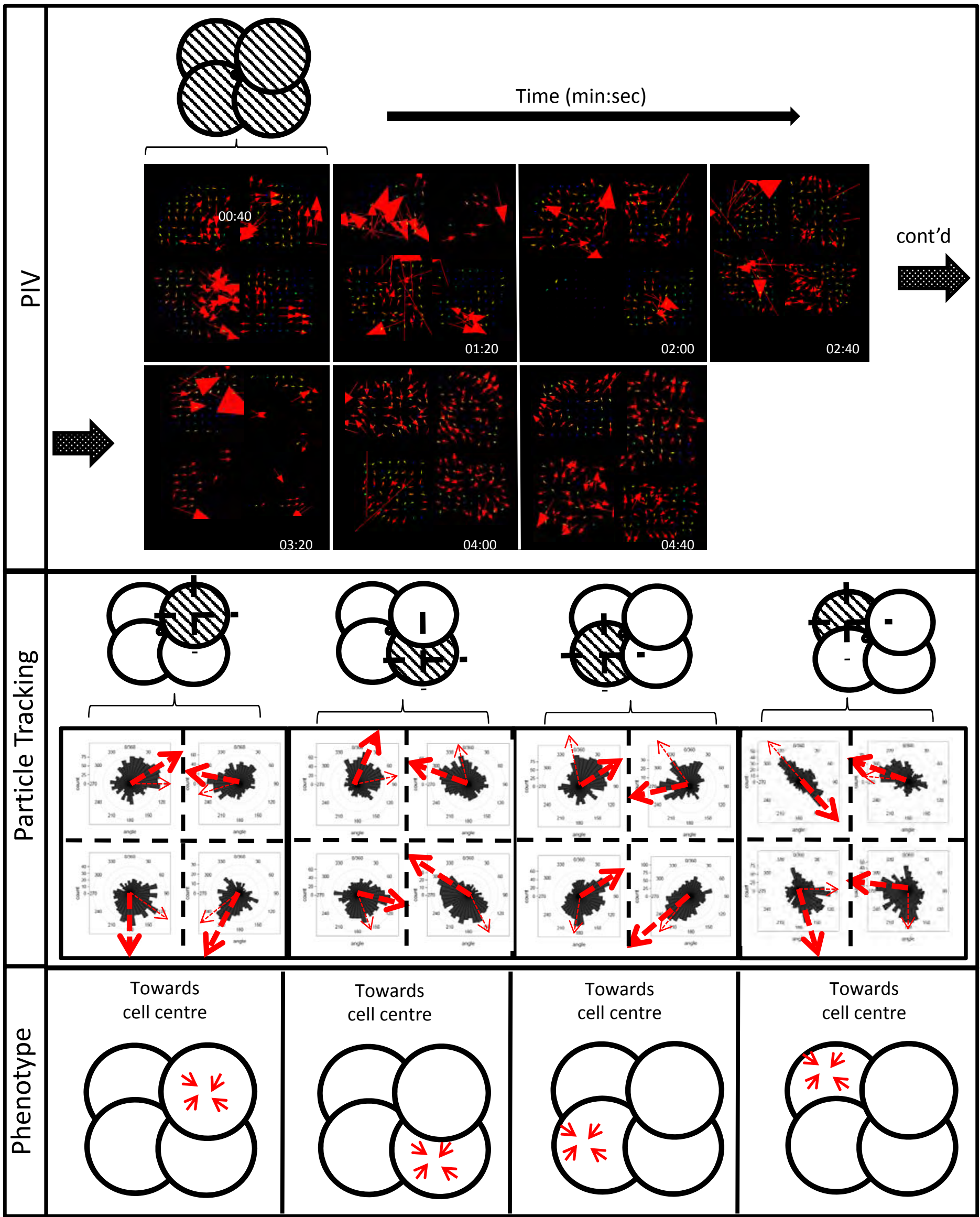



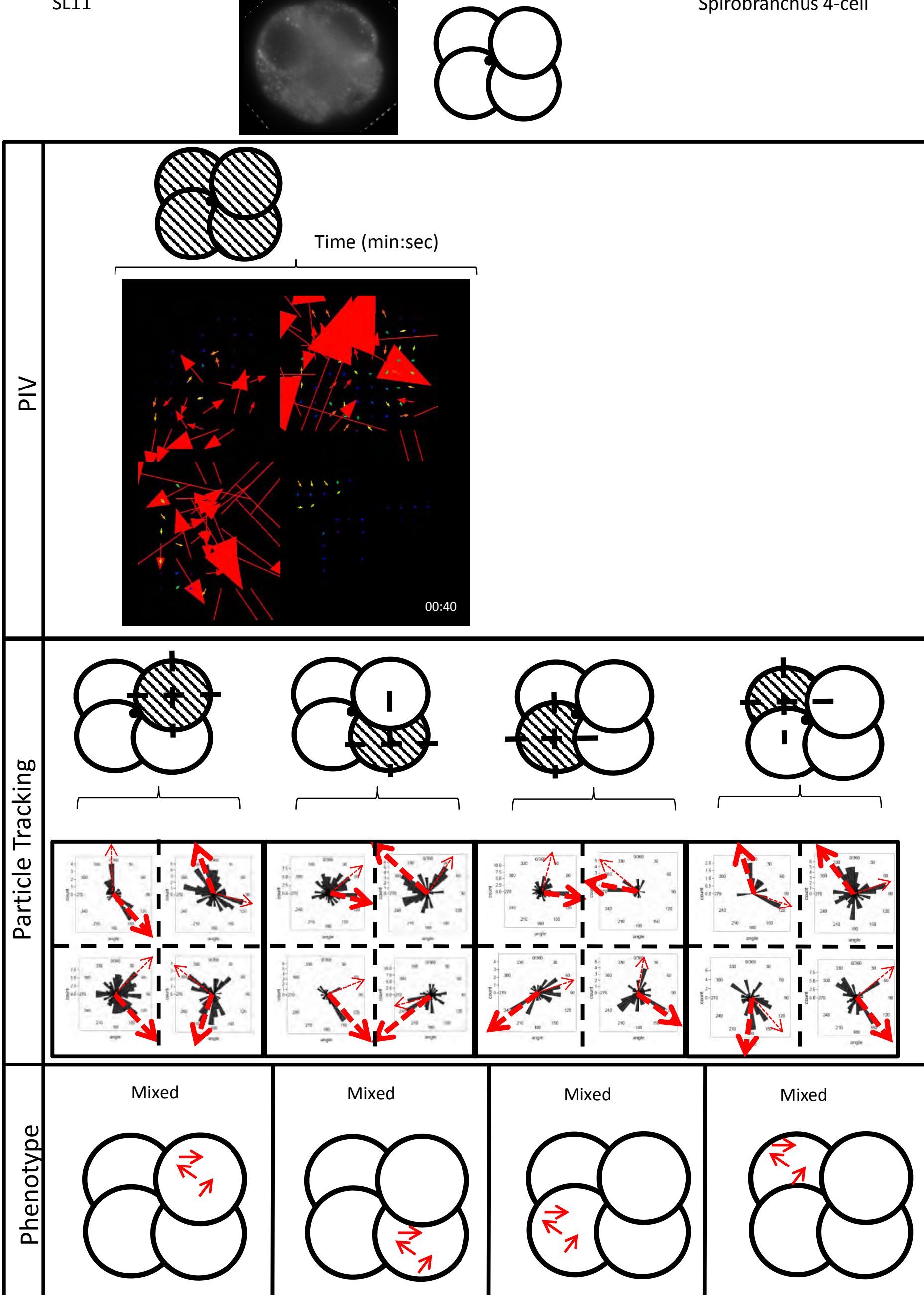

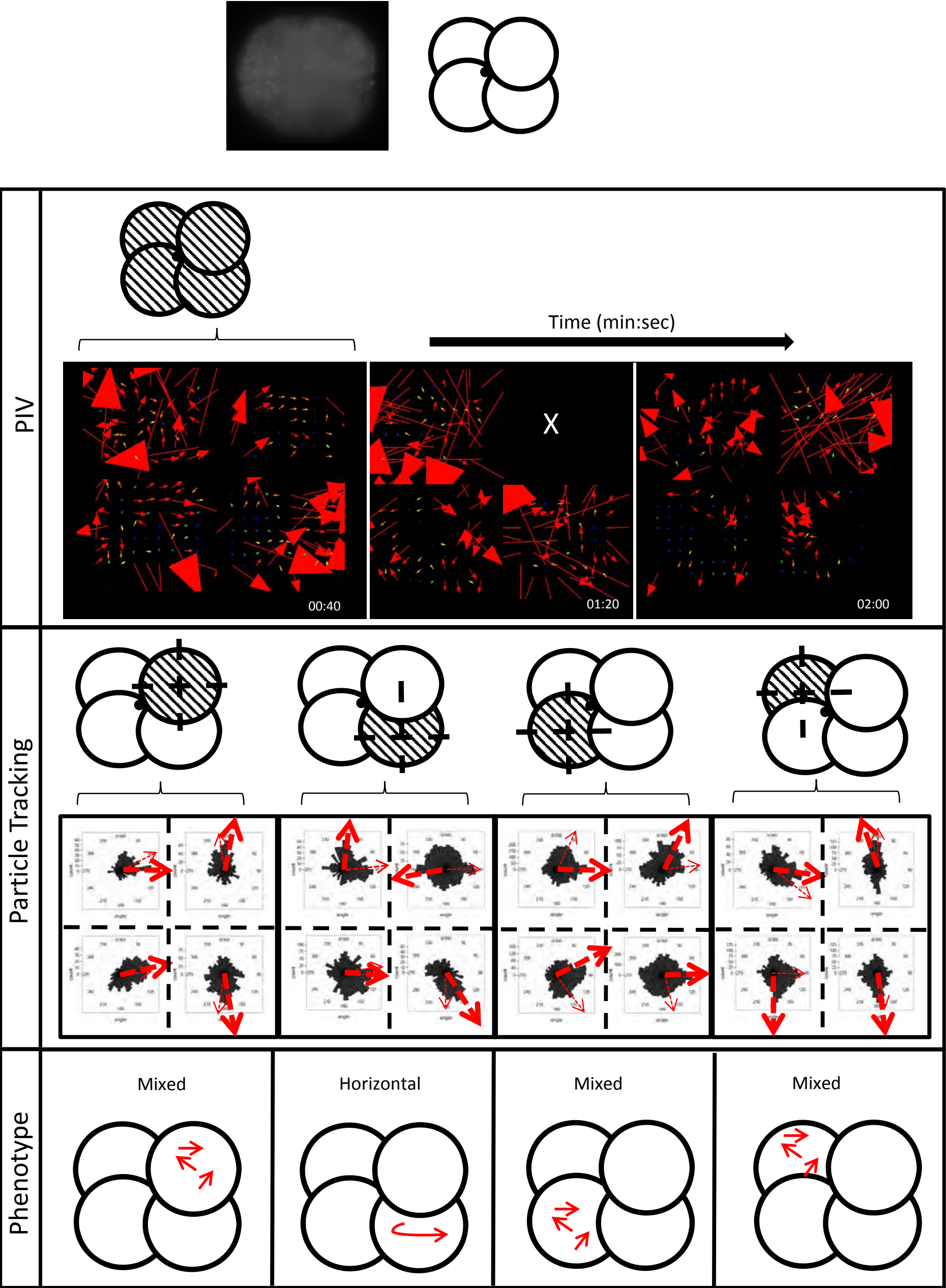

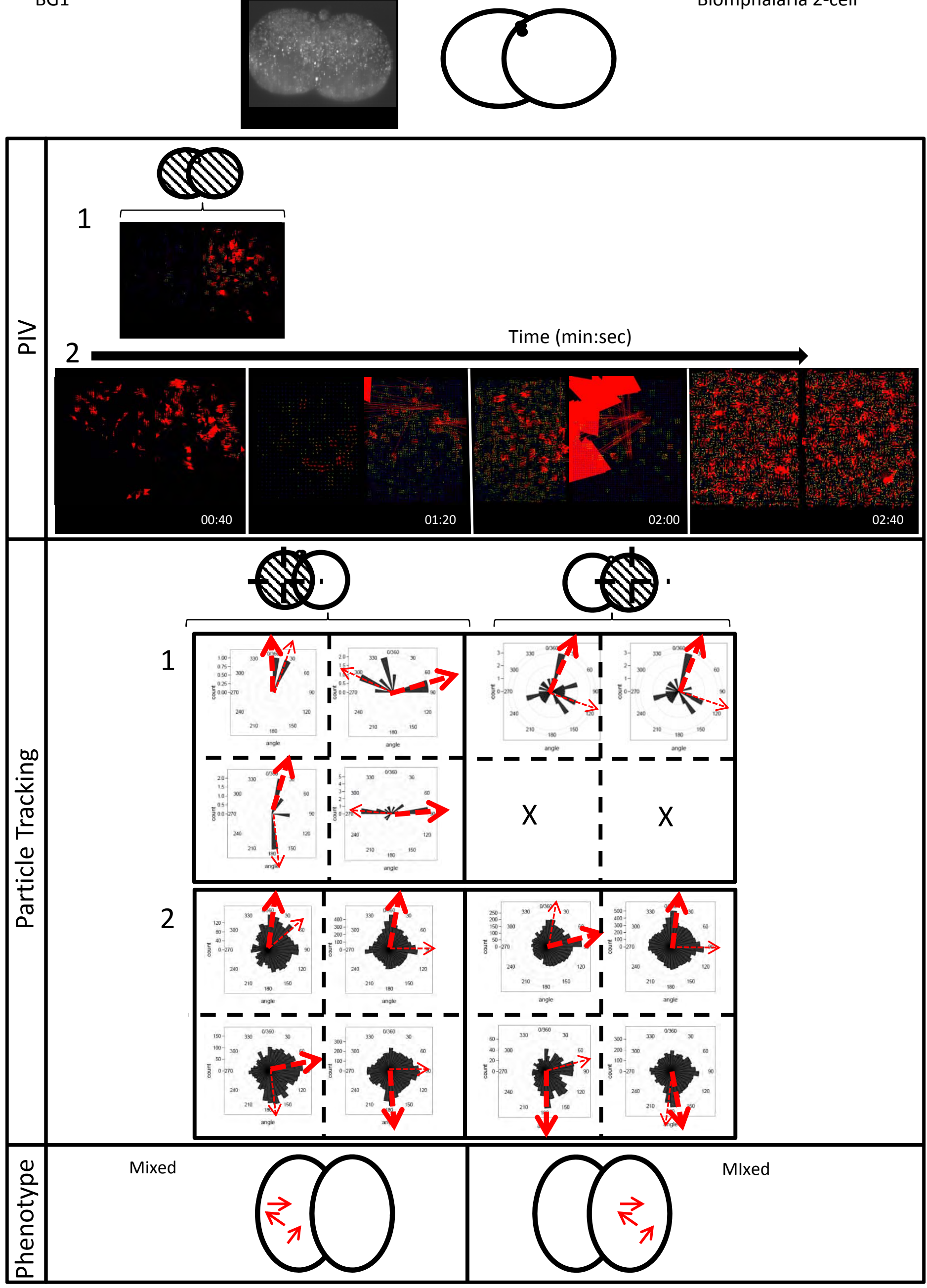

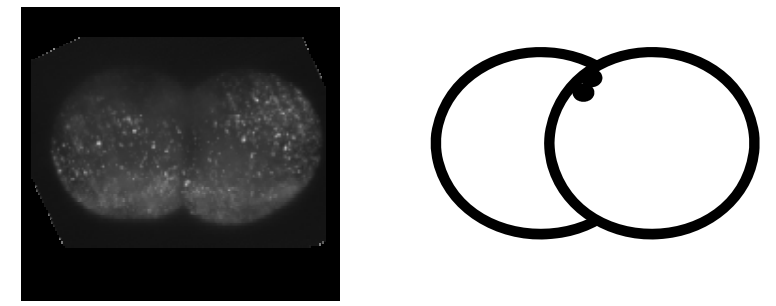

Biomphalaria 2-cell
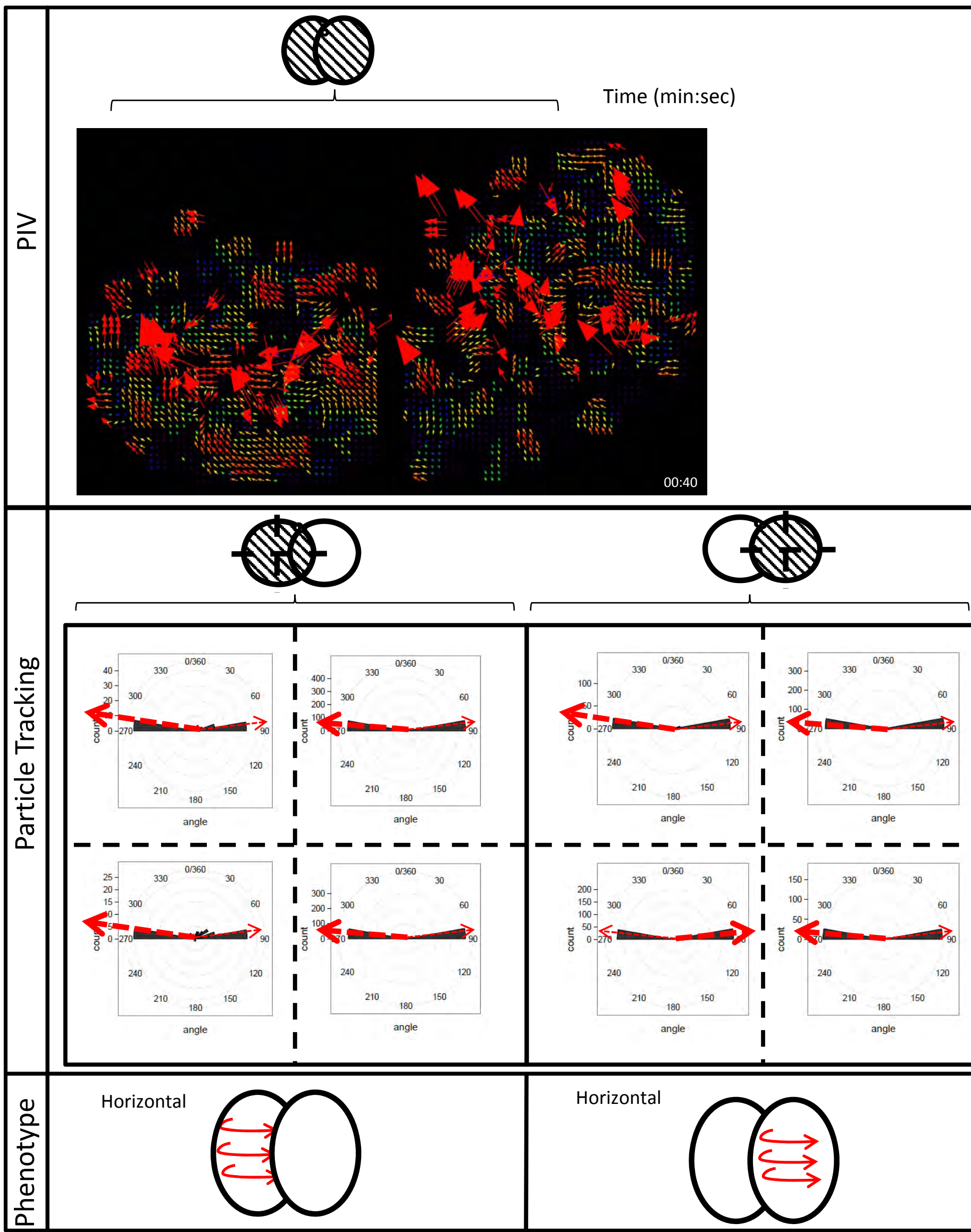

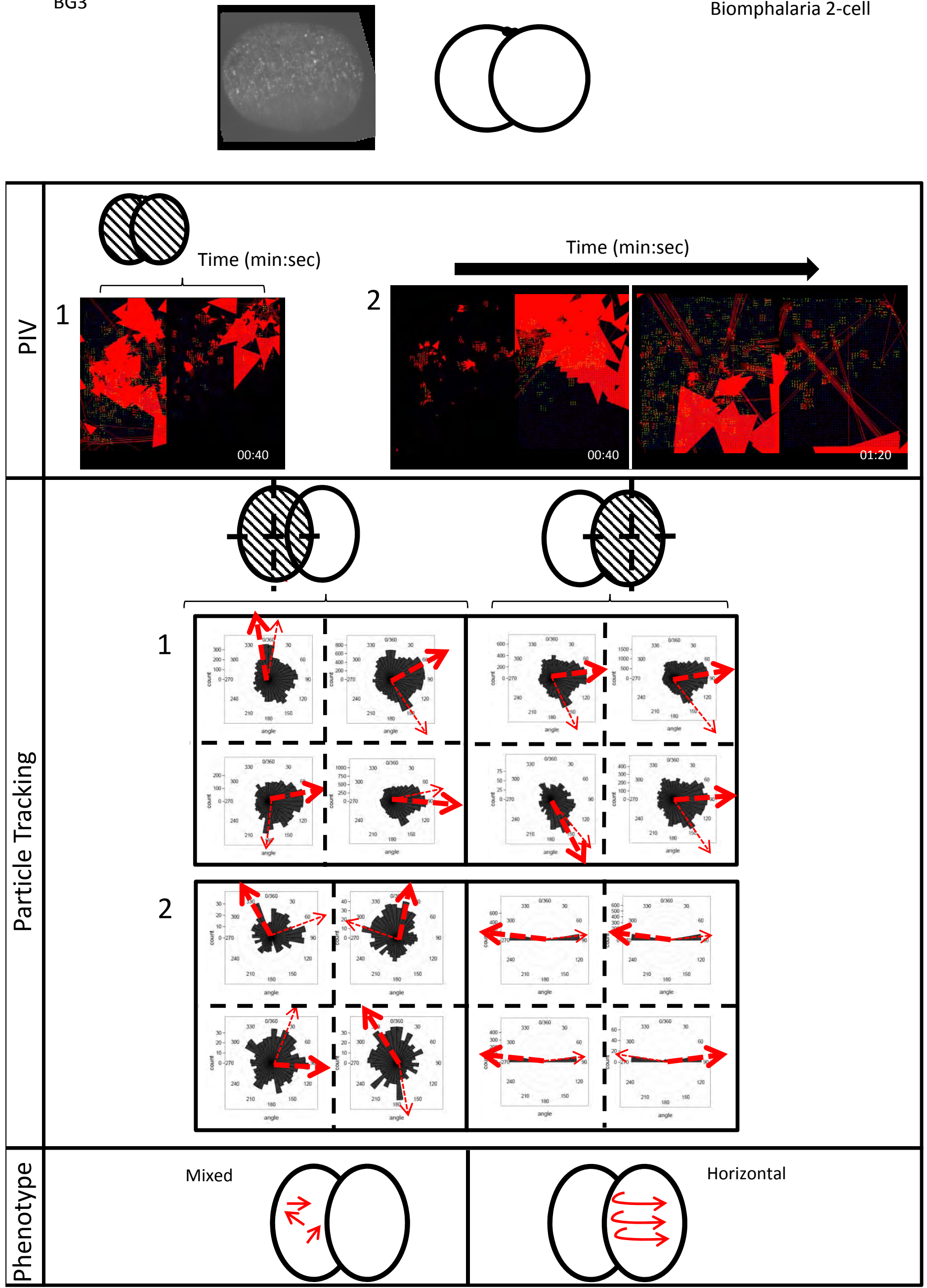

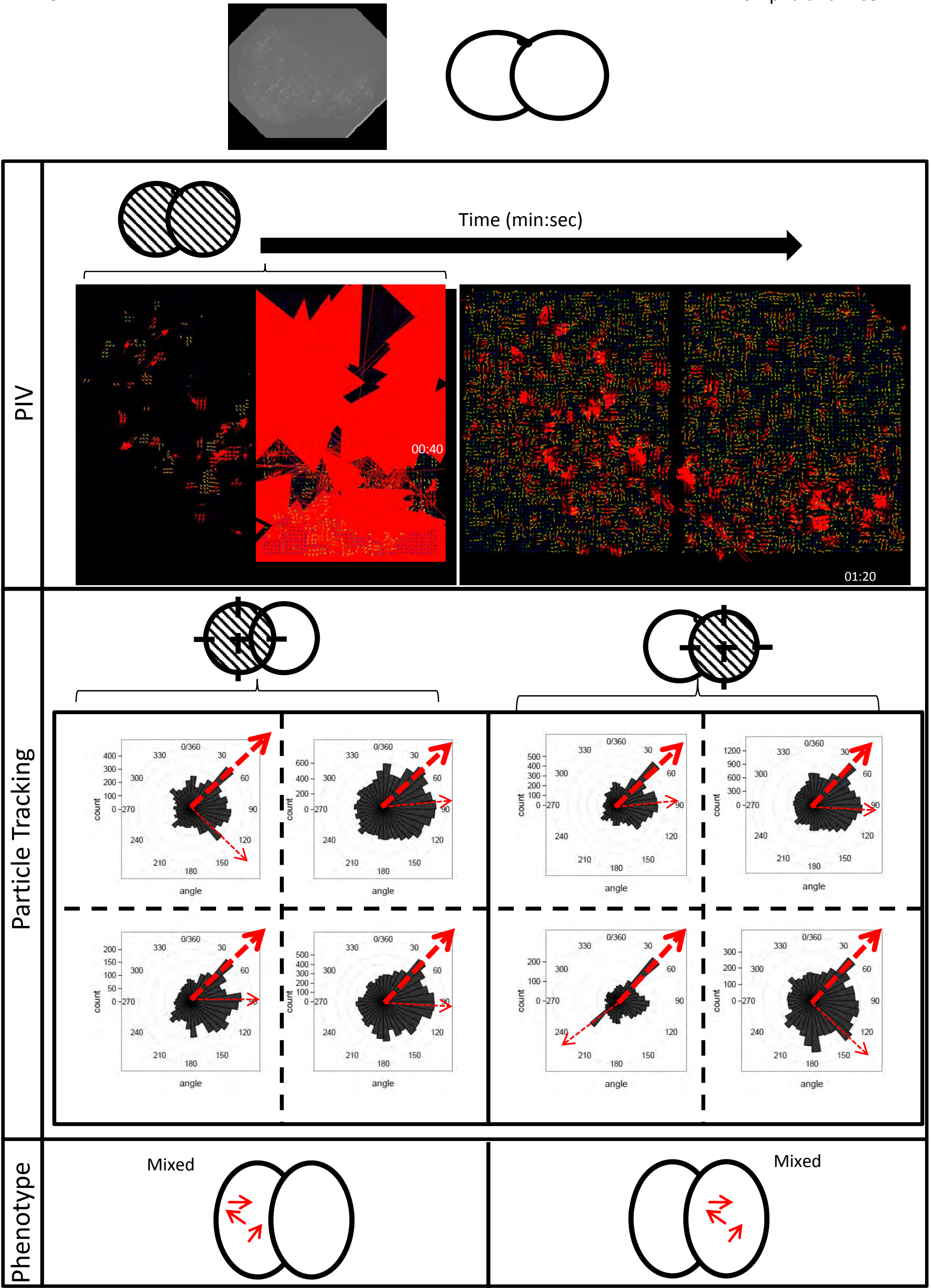

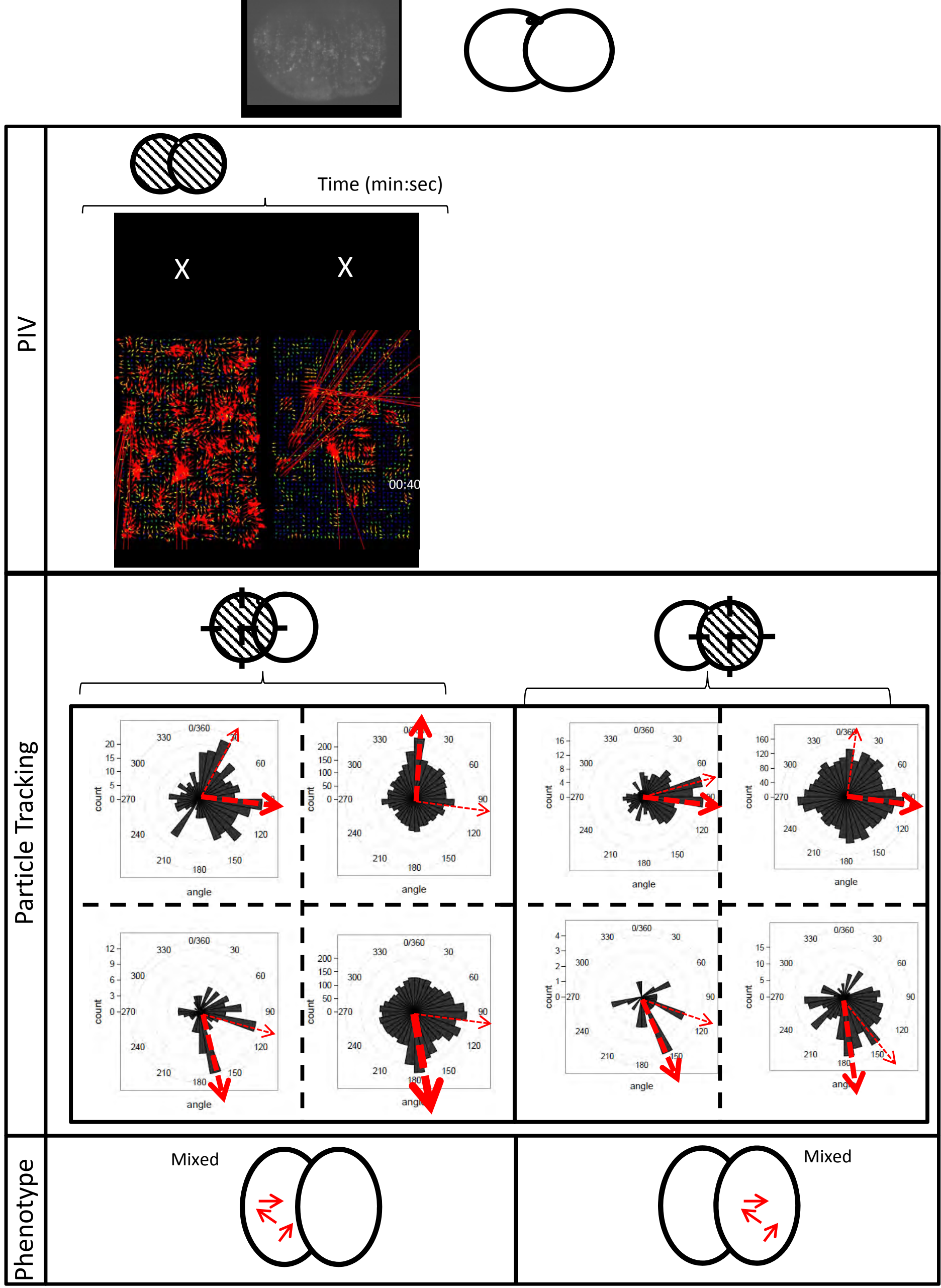

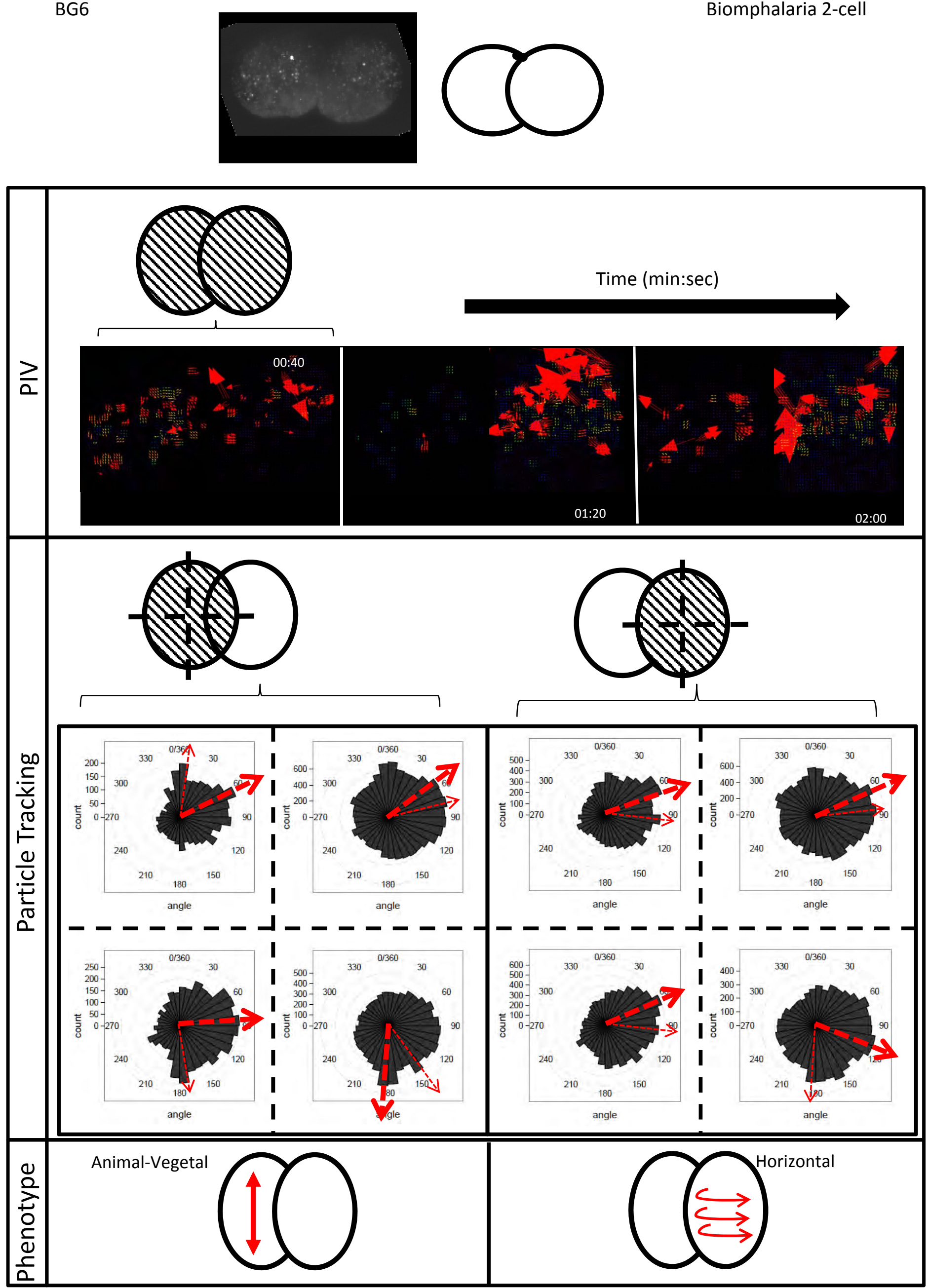

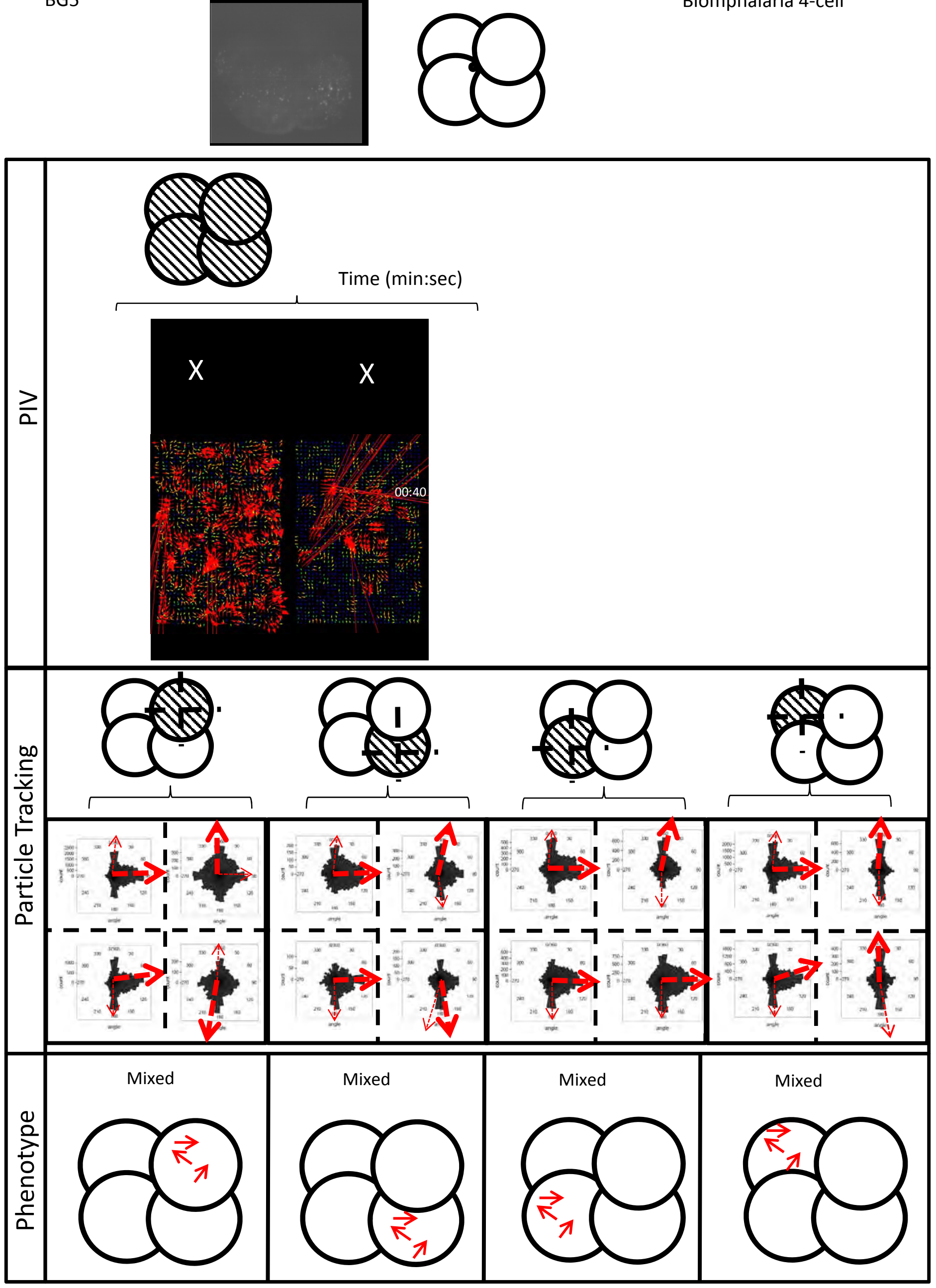


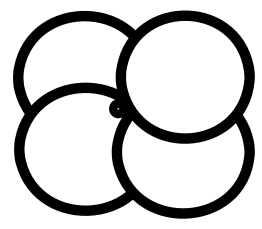

Biomphalaria 4-cell

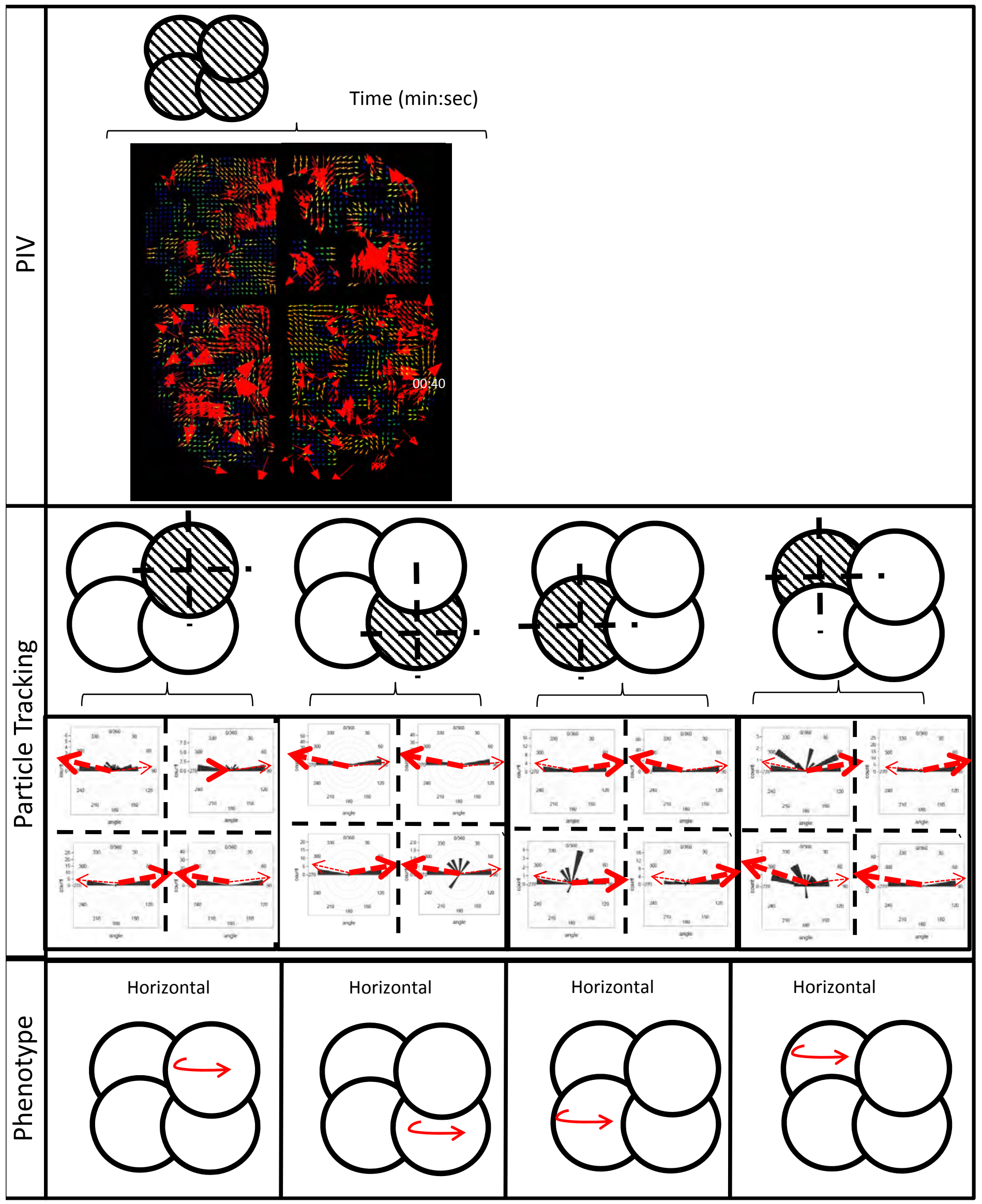




\section{Supplementary File 2}

Please note that due to size limitations this file contains only the first page (of approx 20,000) in PDF format. A full dataset in PDF or Excel format is available from the authors (Size approx. 100mb). 
Spirobranchus lamarcki

$\begin{array}{lll}\text { Identifier } & \text { Blastomere } & \text { Blastomere } \\ 2 \text { number } & \text { subdivision } \\ 2 \text { "SL1" } & \text { A } & \text { one } \\ 2 \text { "SL1" } & \text { A } & \text { one } \\ 2 \text { "SL1" } & \text { A } & \text { one } \\ 2 \text { "SL1" } & \text { A } & \text { one } \\ 2 \text { "SL1" } & \text { A } & \text { one } \\ 2 \text { "SL1" } & \text { A } & \text { one } \\ 2 \text { "SL1" } & \text { A } & \text { one } \\ 2 \text { "SL1" } & \text { A } & \text { one } \\ 2 \text { "SL1" } & \text { A } & \text { one } \\ 2 \text { "SL1" } & \text { A } & \text { one } \\ 2 \text { "SL1" } & \text { A } & \text { one } \\ 2 \text { "SL1" } & \text { A } & \text { one } \\ 2 \text { "SL1" } & \text { A } & \text { one } \\ 2 \text { "SL1" } & \text { A } & \text { one } \\ 2 \text { "SL1" } & \text { A } & \text { one } \\ 2 \text { "SL1" } & \text { A } & \text { one } \\ 2 \text { "SL1" } & \text { A } & \text { one } \\ 2 \text { "SL1" } & \text { A } & \text { one } \\ 2 \text { "SL1" } & \text { A } & \text { one } \\ 2 \text { "SL1" } & \text { A } & \text { one } \\ 2 \text { "SL1" } & \text { A } & \text { one } \\ 2 \text { "SL1" } & \text { A } & \text { one } \\ 2 \text { "SL1" } & \text { A } & \text { one } \\ 2 \text { "SL1" } & \text { A } & \text { one } \\ 2 \text { "SL1" } & \text { A } & \text { one } \\ 2 \text { "SL1" } & \text { A } & \text { one } \\ 2 \text { "SL1" } & \text { A } & \text { one } \\ 2 \text { "SL1" } & \text { A } & \text { one } \\ 2 \text { "SL1" } & \text { A } & \text { one } \\ 2 \text { "SL1" } & \text { A } & \text { one } \\ 2 \text { "SL1" } & \text { A } & \text { one } \\ 2 \text { "SL1" } & \text { A } & \text { one } \\ 2 \text { "SL1" } & \text { A } & \text { one } \\ 2 \text { "SL1" } & \text { A } & \text { one } \\ 2 \text { "SL1" } & \text { A } & \text { one } \\ 2 \text { "SL1" } & \text { A } & \text { one } \\ 2 \text { "SL1" } & \text { A } & \text { one } \\ 2 \text { "SL1" } & \text { A } & \text { one } \\ 2 \text { "SL1" } & \text { A } & \text { one } \\ & & \\ & & \\ & & \end{array}$

Trajectory Frame 12 Frame $x \quad y$ Spirobranchus lamarck Spirobranchus lamarck Spirobranchus lamarcki Spirobranchus lamarcki Spirobranchus lamarcki Spirobranchus lamarcki Spirobranchus lamarcki Spirobranchus lamarcki Spirobranchus lamarck Spirobranchus lamarcki Spirobranchus lamarck Spirobranchus lamarcki Spirobranchus lamarck Spirobranchus lamarcki Spirobranchus lamarcki Spirobranchus lamarck Spirobranchus lamarck Spirobranchus lamarck Spirobranchus lamarcki Spirobranchus lamarcki Spirobranchus lamarck Spirobranchus lamarcki Spirobranchus lamarck Spirobranchus lamarcki Spirobranchus lamarcki Spirobranchus lamarcki Spirobranchus lamarcki Spirobranchus lamarcki Spirobranchus lamarck Spirobranchus lamarck Spirobranchus lamarcki Spirobranchus lamarcki Spirobranchus lamarck Spirobranchus lamarcki Spirobranchus lamarck Spirobranchus lamarcki
476.972 y2-y1 $x 2-x 1$ atan2 degrees bearing degrees radians $\begin{array}{llllllllll}324 & 434.24 & 197.613 & 22.196 & 50.944 & 0.410894 & 23.54247 & 66.45753 & 66.457527 & 1.15990267\end{array}$ $\begin{array}{rrrrrrrrrr}324 & 434.246 & 197.639 & -46.984 & -19.935 & -1.97207 & -112.991 & 202.9912 & 202.99119 & 3.54286463 \\ 42 & 83.918 & 197.673 & -81.117 & 85.687 & -0.75801 & -43.4306 & 133.4306 & 133.43064 & 2.32880392\end{array}$

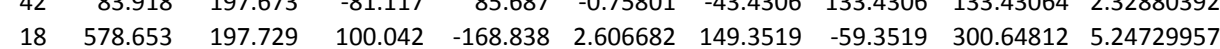
$\begin{array}{rrrrrrrrrr}283 & 139.42 & 197.792 & -0.319 & 0.663 & -0.44845 & -25.6944 & 115.6944 & 115.69436 & 2.01924754\end{array}$ $\begin{array}{rrrrrrrrrr}283 & 139.42 & 197.792 & -0.319 & 0.663 & -0.44845 & -25.6944 & 115.6944 & 115.69436 & 2.01924754 \\ 83 & 88.476 & 197.819 & -18.638 & -21.525 & -2.42795 & -139.111 & 229.1115 & 229.11147 & 3.99874947\end{array}$ $\begin{array}{rrrrrrrrrr}83 & 88.476 & 197.819 & -18.638 & -21.525 & -2.42795 & -139.111 & 229.1115 & 229.11147 & 3.99874947 \\ 281 & 141.256 & 197.904 & -136.455 & 85.943 & -1.00873 & -57.7962 & 147.7962 & 147.79618 & 2.57952999\end{array}$ $\begin{array}{llllllllll}18 & 497.93 & 197.904 & 42.509 & -10.146 & 1.805092 & 103.4241 & -13.4241 & 346.57586 & 6.04888988\end{array}$ $\begin{array}{llllllllll}180 & 89.045 & 198.061 & -10.635 & 64.089 & -0.16444 & -9.42187 & 99.42187 & 99.42187 & 1.73523898\end{array}$ $\begin{array}{lllllllllll}3 & 566.399 & 198.23 & 50.664 & 30.642 & 1.026849 & 58.83411 & 31.16589 & 31.165891 & 0.54394741\end{array}$ $\begin{array}{llllllllll}89 & 253.024 & 198.508 & 30.453 & 14.241 & 1.133371 & 64.93739 & 25.06261 & 25.062608 & 0.43742503\end{array}$ $\begin{array}{rrrrrrrrrr}89 & 253.024 & 198.508 & 30.453 & 14.241 & 1.133371 & 64.93739 & 25.06261 & 25.062608 & 0.43742503 \\ 61 & 275.975 & 198.536 & 85.721 & -97.314 & 2.419448 & 138.6241 & -48.6241 & 311.37586 & 5.43453402\end{array}$ $\begin{array}{rrrrrrrrrr}61 & 275.975 & 198.536 & 85.721 & -97.314 & 2.419448 & 138.6241 & -48.6241 & 311.37586 & 5.43453402 \\ 408 & 51.028 & 198.58 & 44.073 & 57.149 & 0.656928 & 37.63922 & 52.36078 & 52.360785 & 0.91386809\end{array}$ $\begin{array}{llllllllll}386 & 235.338 & 198.677 & -40.093 & -49.024 & -2.45608 & -140.723 & 230.7229 & 230.72288 & 4.02687389\end{array}$ $\begin{array}{llllllllll}44 & 201.969 & 198.699 & 38.211 & -20.049 & 2.054002 & 117.6856 & -27.6856 & 332.31437 & 5.79997991\end{array}$ $\begin{array}{llllllllll}119 & 590.589 & 198.875 & -44.805 & -60.214 & -2.50188 & -143.347 & 233.3472 & 233.34721 & 4.07267712\end{array}$ $\begin{array}{llllllllll}119 & 590.589 & 198.875 & -44.805 & -60.214 & -2.50188 & -143.347 & 233.3472 & 233.34721 & 4.07267712\end{array}$ $\begin{array}{llllllllll}427 & 123.07 & 198.96 & -34.832 & -18.717 & -2.06388 & -118.251 & 208.2514 & 208.25139 & 3.63467248\end{array}$ $\begin{array}{llllllllll}298 & 435.468 & 199.039 & 23.484 & -4.303 & 1.752017 & 100.3832 & -10.3832 & 349.61681 & 6.10196441\end{array}$ $\begin{array}{llllllllll}48 & 256.653 & 199.127 & 155.795 & 41.703 & 1.309249 & 75.01446 & 14.98554 & 14.985538 & 0.26154698\end{array}$ $\begin{array}{lllllllllll}459 & 445.333 & 199.14 & -36.225 & -3.343 & -1.66282 & -95.2726 & 185.2726 & 185.27257 & 3.23361634\end{array}$ $\begin{array}{llllllllll}320 & 435.626 & 199.154 & -25.185 & 15.663 & -1.01442 & -58.1218 & 148.1218 & 148.12178 & 2.58521282\end{array}$ $\begin{array}{llllllllll}46 & 257.275 & 199.169 & -0.042 & -0.622 & -3.07417 & -176.137 & 266.137 & 266.13702 & 4.64496721\end{array}$ $\begin{array}{lllllllllll}62 & 81.224 & 199.304 & 15.691 & 236.001 & 0.066389 & 3.803826 & 86.19617 & 86.196174 & 1.50440703\end{array}$ $\begin{array}{llllllllll}12 & 251.214 & 199.395 & -47.663 & 194.547 & -0.24026 & -13.766 & 103.766 & 103.76602 & 1.81105868\end{array}$ $\begin{array}{llllllllll}320 & 143.116 & 199.489 & -24.938 & 8.555 & -1.24033 & -71.0654 & 161.0654 & 161.06543 & 2.81112205\end{array}$ $\begin{array}{llllllllll}339 & 139.618 & 199.493 & -21.713 & -54.852 & -2.76467 & -158.404 & 248.404 & 248.40401 & 4.33546789\end{array}$ $\begin{array}{llllllllll}80 & 249.053 & 199.655 & -18.89 & 39.482 & -0.44626 & -25.5686 & 115.5686 & 115.56859 & 2.01705243\end{array}$ $\begin{array}{llllllllll}35 & 291.546 & 199.688 & 17.336 & 125.99 & 0.13674 & 7.8346 & 82.1654 & 82.1654 & 1.43405677\end{array}$ $\begin{array}{llllllllll}40 & 104.637 & 199.724 & -2.051 & -20.719 & -3.04292 & -174.347 & 264.3466 & 264.34664 & 4.61371918\end{array}$ $\begin{array}{llllllllll}413 & 392.613 & 199.758 & -38.941 & -38.41 & -2.34933 & -134.607 & 224.6067 & 224.60668 & 3.92012611\end{array}$ $\begin{array}{llllllllll}54 & 253.499 & 199.764 & 74.914 & 79.261 & 0.75721 & 43.38496 & 46.61504 & 46.61504 & 0.81358593\end{array}$ $\begin{array}{llllllllll}451 & 386.086 & 199.924 & -62.443 & 21.339 & -1.2415 & -71.1329 & 161.1329 & 161.13287 & 2.81229916\end{array}$ $\begin{array}{llllllllll}343 & 140.208 & 199.936 & -24.586 & -14.385 & -2.10018 & -120.331 & 210.3314 & 210.33144 & 3.67097608\end{array}$ $\begin{array}{lllllllllll}343 & 140.208 & 199.936 & -24.586 & -14.385 & -2.10018 & -120.331 & 210.3314 & 210.33144 & 3.67097608\end{array}$ $\begin{array}{llllllllll}286 & 139.606 & 200.089 & -18.942 & 53.506 & -0.34025 & -19.4948 & 109.4948 & 109.4948 & 1.91104472\end{array}$ $\begin{array}{lllllllllll}337 & 94.161 & 200.278 & 32.644 & -8.966 & 1.838846 & 105.3581 & -15.3581 & 344.64186 & 6.01513525\end{array}$ $\begin{array}{llllllllll}12 & 279.667 & 200.29 & -38.021 & -7.727 & -1.7713 & -101.488 & 191.4878 & 191.48776 & 3.34209185\end{array}$ $\begin{array}{lllllllllll}77 & 86.421 & 200.396 & 1.219 & -1.538 & 2.471388 & 141.6001 & -51.6001 & 308.39991 & 5.3825939\end{array}$ $\begin{array}{llllllllll}88 & 499.913 & 200.398 & -37.379 & 39.943 & -0.75225 & -43.1008 & 133.1008 & 133.10077 & 2.3230466\end{array}$ $\begin{array}{llllllllll}330 & 98.1 & 200.415 & -38.646 & -33.086 & -2.27884 & -130.568 & 220.5678 & 220.56782 & 3.84963475\end{array}$ $\begin{array}{rrrrrrrrrr}80 & 86.374 & 200.424 & 59.321 & -7.596 & 1.698152 & 97.29696 & -7.29696 & 352.70304 & 6.15582927\end{array}$ 


\section{Supplementary file 3}

Namigai \& Shimeld

This files contains the full tabulated data underlying Figure 4 (Namigai \& Shimeld), including the bearing underlying each quadrant, and its translation into categories. Table $1 \mathrm{~S}$ includes blastomere categorization per quadrant in each blastomere in degrees (bearing), Table $2 \mathrm{~S}$ includes blastomere categories selected based on the bearing and the expected category profile. $\mathrm{SL}=$ Spirobranchus lamarcki, BG = Biomphalaria glabrata. 
Table 1S. Blastomere categorization by quadrant per blastomere in degrees. Quantification of bearing per quadrant per blastomere based on the largest bearing in the Suppl 1 bearing graphs (in degrees, table below).

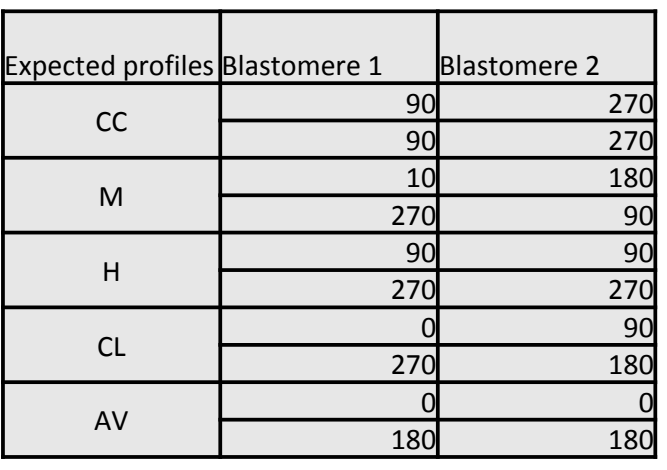

\begin{tabular}{|c|c|c|c|c|c|c|c|c|c|c|c|c|c|c|c|c|c|c|}
\hline \multirow{3}{*}{$\begin{array}{l}\text { Blastomere } \\
\text { SL1 }\end{array}$} & \multicolumn{2}{|c|}{1} & \multicolumn{2}{|c|}{2} & \multicolumn{2}{|c|}{1} & \multicolumn{2}{|c|}{2} & \multicolumn{2}{|c|}{3} & \multicolumn{2}{|c|}{1} & \multicolumn{2}{|c|}{2} & \multicolumn{2}{|c|}{3} & \multicolumn{2}{|c|}{4} \\
\hline & 40 & 120 & 10 & 130 & 270 & 270 & 40 & 240 & 30 & 280 & 350 & 290 & 20 & 240 & 40 & - & 50 & 260 \\
\hline & 40 & 260 & 280 & 230 & 270 & 270 & 200 & 190 & 70 & 250 & 180 & 200 & 180 & 290 & 190 & 220 & 240 & 140 \\
\hline \multirow{2}{*}{ SL2 } & 90 & 280 & 100 & 270 & \multirow{2}{*}{\multicolumn{2}{|c|}{ - }} & & & & & & \multirow{2}{*}{\multicolumn{2}{|c|}{-}} & \multirow{2}{*}{\multicolumn{2}{|c|}{ - }} \\
\hline & 270 & 270 & 230 & 230 & & & & & & & & & & & & & & \\
\hline \multirow{2}{*}{ sL3 } & 90 & 150 & 110 & 110 & \multirow{2}{*}{\multicolumn{6}{|c|}{ No three cell stage }} & 330 & 330 & 60 & 50 & 50 & 310 & 10 & 350 \\
\hline & 180 & 280 & - & 190 & & & & & & & 150 & 240 & 140 & 210 & 50 & 230 & 140 & 140 \\
\hline$k_{14}$ & - & - & 10 & 10 & & & & & & & & & & & & & & \\
\hline $\mathrm{pl}^{24}$ & - & - & 70 & 180 & & & & & & & & & & & & & & \\
\hline$k_{15}$ & 70 & 290 & 100 & 280 & & & & & & & & & & & & & & \\
\hline pls & 130 & 130 & - & 150 & & & & & & & & & & & & & & \\
\hline $\mathrm{s}_{0}$ & 80 & 90 & 90 & 90 & & & Noth & $\| \mathrm{csta}$ & & & 80 & 90 & 90 & 270 & 90 & 300 & 340 & 90 \\
\hline pl6 & 90 & 270 & 270 & 270 & & & No th & II stage & & & 280 & 90 & 90 & 280 & 40 & 90 & 90 & 90 \\
\hline $\mathrm{S}_{17}$ & 10 & 340 & 90 & 90 & & & Noth & Ustare & & & 90 & 280 & 270 & 270 & 270 & 270 & 90 & 270 \\
\hline $\mathrm{pl} /$ & 150 & 220 & 90 & 90 & & & No th & II stage & & & 90 & 90 & 90 & - & 90 & 270 & 270 & 90 \\
\hline $\mathrm{k}_{18}$ & 100 & 70 & 80 & 280 & & & Noth & Uctor & & & - & 330 & 60 & 30 & 30 & 310 & 50 & 310 \\
\hline plo & 110 & 270 & - & - & & & tou & is tage & & & 110 & 270 & 150 & 250 & 90 & 210 & 130 & 310 \\
\hline 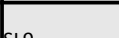 & 130 & 260 & 90 & 360 & & & Noth & II stage & & & 70 & 280 & 20 & 300 & 70 & 270 & 140 & 300 \\
\hline PL9 & 170 & 270 & - & - & & & No th & instage & & & 180 & 220 & 100 & 300 & 70 & 230 & 170 & 280 \\
\hline & 120 & 100 & 100 & 280 & 50 & 250 & 350 & 350 & 300 & 320 & 90 & 10 & 10 & 270 & 90 & 0 & 110 & 0 \\
\hline PLIT & 160 & 190 & 50 & 200 & 160 & 280 & 60 & 170 & 140 & 170 & 80 & 180 & 90 & 160 & 90 & 100 & 180 & 180 \\
\hline$k_{k} 11$ & & & & & 110 & 110 & 30 & 320 & 80 & 350 & 150 & 350 & 100 & 310 & 100 & 280 & 0 & 330 \\
\hline PLII & & & & & - & - & 60 & 230 & 120 & 150 & 140 & 210 & 150 & 240 & 240 & 130 & 180 & 150 \\
\hline$k_{112}$ & & & & & & & & & & & 40 & 290 & 340 & 320 & 30 & 350 & 20 & 110 \\
\hline pL12 & & & & & & & & & & & 190 & 0 & 150 & 150 & 230 & 270 & 90 & 220 \\
\hline$k_{413}$ & & & & & & & & & & & 40 & 290 & 100 & 300 & 100 & 50 & 70 & 300 \\
\hline PLIS & & & & & & & & & & & 30 & 220 & 110 & 140 & 60 & 170 & 160 & 200 \\
\hline $\mathrm{BGG}_{1}$ & 10 & 10 & 90 & 10 & & & & & & & & & & & & & & \\
\hline 1001 & 90 & 180 & 180 & 180 & & & & & & & & & & & & & & \\
\hline hon & 270 & 270 & 270 & 270 & & & & & & & & & & & & & & \\
\hline$B G 2$ & 270 & 270 & 90 & 270 & & & No thr & tll stage & & & & & & & & & & \\
\hline$B G 3$ & 340 & 20 & 270 & 270 & & & & & & & & & & & & & & \\
\hline$B G 3$ & 100 & 100 & 270 & 90 & & & & & & & & & & & & & & \\
\hline BG & 50 & 90 & 50 & 50 & & & & & & & & & & & & & & \\
\hline BG4 & 50 & 50 & 50 & 50 & & & & & & & & & & & & & & \\
\hline $8 G 5$ & 100 & 10 & 100 & 100 & & & & & & & 100 & 0 & 90 & 10 & 90 & 10 & 90 & 0 \\
\hline BGS & 170 & 180 & 160 & 180 & & & & & & & 90 & 190 & 90 & 190 & 90 & 90 & 90 & 0 \\
\hline BGG & 70 & 70 & 70 & 70 & & & & & & & & & & & & & & \\
\hline 1560 & 90 & 190 & 70 & 120 & & & & & & & & & & & & & & \\
\hline BG7 & & & & & & & & & & & 270 & 270 & 270 & 270 & 90 & 270 & 90 & 90 \\
\hline | & & & & & & & & & & & 90 & 270 & 90 & 270 & 90 & 90 & 270 & 270 \\
\hline
\end{tabular}


Table 2S. Blastomere categorization by quadrant per blastomere. Categories selected (below) using the reference table with expected profiles (on the right hand side), within approx. 10 degrees of the expected profile. In cases where the bearings are scattered, the category of the bearing was changed to "Mixed" to indicate that it is not possible to identify one main direction of movement from the data.

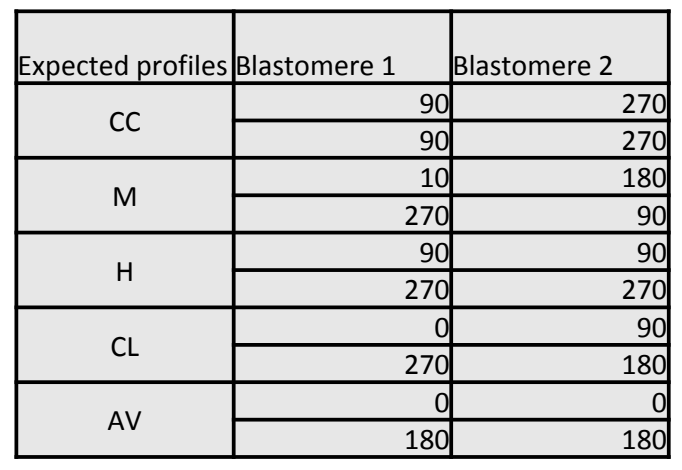

\begin{tabular}{|c|c|c|c|c|c|c|c|c|c|c|c|c|c|c|c|c|c|c|}
\hline \multirow{3}{*}{$\begin{array}{l}\text { Blastomere } \\
\text { SL1 }\end{array}$} & \multicolumn{2}{|c|}{1} & \multicolumn{2}{|c|}{2} & \multicolumn{2}{|c|}{1} & \multicolumn{2}{|c|}{2} & \multicolumn{2}{|c|}{3} & \multicolumn{2}{|c|}{1} & \multicolumn{2}{|c|}{2} & \multicolumn{2}{|c|}{3} & \multicolumn{2}{|c|}{4} \\
\hline & $\mathrm{CL}$ & $\mathrm{CL}$ & $\mathrm{CL}$ & $\mathrm{CL}$ & $\mathrm{H}$ & $\mathrm{H}$ & $\mathrm{H}$ & $\mathrm{H}$ & $\mathrm{H}$ & $M$ & $\mathrm{AV}$ & $M$ & AV & $M$ & $M$ & - & $\mathrm{AV}$ & $M$ \\
\hline & $\mathrm{CL}$ & $\overline{C L}$ & $\mathrm{CL}$ & $\overline{C L}$ & $\mathrm{H}$ & $\mathrm{H}$ & $\mathrm{H}$ & $\mathrm{H}$ & $\mathrm{H}$ & $\mathrm{H}$ & $\overline{A V}$ & $M$ & $M$ & $M$ & $M$ & $A V$ & $M$ & $\mathrm{AV}$ \\
\hline \multirow{2}{*}{ SL2 } & $M$ & $\mathrm{M}$ & M & $\mathrm{M}$ & \multirow{2}{*}{\multicolumn{2}{|c|}{ - }} & & & & & \multirow{2}{*}{\multicolumn{2}{|c|}{ - }} & & & \multirow{2}{*}{\multicolumn{2}{|c|}{-}} & \multirow{2}{*}{\multicolumn{2}{|c|}{ - }} \\
\hline & $\mathrm{H}$ & $\mathrm{H}$ & AV & AV & & & & & & & & & & & & & & \\
\hline \multirow{2}{*}{ sL3 } & $M$ & $M$ & M & $M$ & \multirow{2}{*}{\multicolumn{6}{|c|}{ No three cell stage }} & M & $M$ & $M$ & $M$ & M & $M$ & M & $\mathrm{AV}$ \\
\hline & AV & $\mathrm{H}$ & - & $\mathrm{AV}$ & & & & & & & $A V$ & $\mathrm{AV}$ & AV & AV & $\mathrm{AV}$ & AV & $M$ & $M$ \\
\hline \multirow{2}{*}{ SL4 } & - & - & AV & AV & \multirow{2}{*}{\multicolumn{2}{|c|}{ - }} & & & & & & & & & & 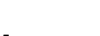 & & \\
\hline & - & - & $M$ & AV & & & & & & & & & & & & & & \\
\hline $\mathrm{k}_{15}$ & $\mathrm{H}$ & $M$ & $M$ & $\mathrm{H}$ & & & & & & & & & & & & - & & \\
\hline plo & $M$ & $M$ & - & $M$ & & & & & & & & & & & & - & & \\
\hline & $\mathrm{H}$ & $\mathrm{H}$ & H & $\mathrm{H}$ & & & & & & & $M$ & $\mathrm{H}$ & H & $\mathrm{H}$ & $\mathrm{H}$ & $\mathrm{H}$ & $M$ & H \\
\hline pL6 & $\mathrm{H}$ & $\mathrm{H}$ & $\mathrm{H}$ & $\mathrm{H}$ & & & & & & & $M$ & $\mathrm{H}$ & $\mathrm{H}$ & $\mathrm{H}$ & $\mathrm{AV}$ & $\mathrm{H}$ & $\mathrm{H}$ & $\mathrm{H}$ \\
\hline & $M$ & $\mathrm{AV}$ & $\mathrm{H}$ & $\mathrm{H}$ & & & & & & & $\mathrm{H}$ & $\mathrm{H}$ & $\mathrm{H}$ & $\mathrm{H}$ & $\mathrm{H}$ & $\mathrm{H}$ & H & $\mathrm{H}$ \\
\hline $\mathrm{pL} /$ & $\mathrm{CC}$ & $\mathrm{CC}$ & $\mathrm{H}$ & $\mathrm{H}$ & & & & & & & $\mathrm{H}$ & $\mathrm{H}$ & $\mathrm{H}$ & - & $\mathrm{H}$ & $\mathrm{H}$ & $\mathrm{H}$ & $\mathrm{H}$ \\
\hline 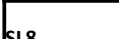 & $M$ & $M$ & CC & $M$ & & & & & & & - & $\mathrm{CC}$ & CC & $\mathrm{CC}$ & $\mathrm{CC}$ & $\mathrm{CC}$ & CC & $\mathrm{CC}$ \\
\hline PLo & $M$ & $\mathrm{H}$ & - & - & & & & & & & CC & $\mathrm{CC}$ & $\mathrm{CC}$ & $\mathrm{CC}$ & CC & $\mathrm{CC}$ & $\mathrm{CC}$ & $\mathrm{CC}$ \\
\hline${ }_{1}$ & $M$ & $M$ & $\mathrm{H}$ & $M$ & & & & & & & CC & $\mathrm{CC}$ & CC & $\mathrm{CC}$ & CC & $\mathrm{CC}$ & $\mathrm{CC}$ & $\mathrm{CC}$ \\
\hline$\$ 59$ & $\mathrm{CC}$ & $\mathrm{H}$ & - & - & & & Not & & & & $\mathrm{CC}$ & $\mathrm{CC}$ & $\mathrm{CC}$ & $\mathrm{CC}$ & $C C$ & $\mathrm{CC}$ & $\mathrm{CC}$ & $\overline{C C}$ \\
\hline$c_{1}$ & $\mathrm{CC}$ & $\overline{C C}$ & $\mathrm{CC}$ & $\mathrm{CC}$ & $M$ & $\mathrm{H}$ & $M$ & $M$ & $M$ & $M$ & $M$ & $\overline{A V}$ & $M$ & $\mathrm{H}$ & $M$ & $M$ & $M$ & $\overline{\mathrm{AV}}$ \\
\hline PLI0 & $\mathrm{CC}$ & $\mathrm{CC}$ & $\mathrm{CC}$ & $\mathrm{CC}$ & $A V$ & $M$ & $M$ & $\mathrm{AV}$ & $M$ & $\mathrm{AV}$ & $\mathrm{H}$ & $\mathrm{AV}$ & $M$ & AV & $M$ & $M$ & $M$ & $\mathrm{AV}$ \\
\hline$L_{1}$ & & & & & $\mathrm{H}$ & $M$ & $M$ & $\mathrm{AV}$ & $M$ & $M$ & M & $M$ & $M$ & $M$ & $M$ & $M$ & $M$ & $M$ \\
\hline PLII & & & & & - & - & $M$ & $\mathrm{AV}$ & $\mathrm{AV}$ & $M$ & $M$ & $M$ & $M$ & $M$ & $M$ & $M$ & $\mathrm{AV}$ & $M$ \\
\hline$k_{s}$ & & & & & & & & & & & M & $M$ & $M$ & $\mathrm{M}$ & $\mathrm{AV}$ & $M$ & AV & $M$ \\
\hline SL12 & & & & & & & & & & & $\mathrm{AV}$ & $M$ & AV & $M$ & $\overline{A V}$ & $M$ & $M$ & $M$ \\
\hline 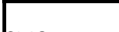 & & & & & & & & & & & $\mathrm{AV}$ & M & $M$ & $M$ & $M$ & $M$ & $M$ & $M$ \\
\hline \$L13 & & & & & & & & & & & $M$ & $\mathrm{AV}$ & $M$ & $M$ & $M$ & $M$ & $M$ & $\overline{A V}$ \\
\hline & $M$ & $M$ & $M$ & $M$ & & & & & & & & & & & & & & \\
\hline BG1 & $M$ & $M$ & $M$ & $M$ & & & & & & & & & & & & & & \\
\hline 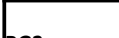 & $\mathrm{H}$ & $\mathrm{H}$ & $\mathrm{H}$ & $\mathrm{H}$ & & & & & & & & & & & & & & \\
\hline BG2 & $\mathrm{H}$ & $\mathrm{H}$ & $\mathrm{H}$ & $\mathrm{H}$ & & & No th & stage & & & & & & & & - & & \\
\hline${ }_{0}$ & $M$ & $M$ & $\mathrm{H}$ & $\mathrm{H}$ & & & & & & & & & & & & & & \\
\hline$B G 3$ & $M$ & $M$ & $\mathrm{H}$ & $\mathrm{H}$ & & & & & & & & & & & & & & \\
\hline 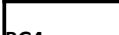 & $M$ & $M$ & $M$ & $M$ & & & & & & & & & & & & & & \\
\hline BSG4 & $M$ & $M$ & $M$ & $M$ & & & & & & & & & & & & & & \\
\hline D & $M$ & $M$ & $\mathrm{H}$ & $M$ & & & & & & & $M$ & $M$ & $M$ & $M$ & $M$ & $\mathrm{AV}$ & $M$ & $\overline{A V}$ \\
\hline BG5 & $M$ & $M$ & $M$ & AV & & & & & & & $M$ & $\mathrm{AV}$ & $M$ & AV & $M$ & $M$ & $M$ & $\overline{A V}$ \\
\hline$D_{0}$ & $M$ & $A V$ & $\mathrm{H}$ & $\mathrm{H}$ & & & & & & & & & & & & & & \\
\hline BGG & $\overline{A V}$ & $\mathrm{AV}$ & $\mathrm{H}$ & $M$ & & & & & & & & & & & & & & \\
\hline 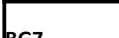 & & & & & & & & & & & $\mathrm{H}$ & $\mathrm{H}$ & $\mathrm{H}$ & $\mathrm{H}$ & $\mathrm{H}$ & $\mathrm{H}$ & $\mathrm{H}$ & $\mathrm{H}$ \\
\hline BG7 & & & & & & & & & & & $\mathrm{H}$ & $\mathrm{H}$ & $\mathrm{H}$ & $\mathrm{H}$ & $\mathrm{H}$ & $\mathrm{H}$ & $\mathrm{H}$ & $\mathrm{H}$ \\
\hline
\end{tabular}

